NBER WORKING PAPER SERIES

\title{
FLOOD RISK BELIEF HETEROGENEITY AND COASTAL HOME PRICE DYNAMICS: GOING UNDER WATER?
}

\author{
Laura A. Bakkensen \\ Lint Barrage \\ Working Paper 23854 \\ http://www.nber.org/papers/w23854 \\ NATIONAL BUREAU OF ECONOMIC RESEARCH \\ 1050 Massachusetts Avenue \\ Cambridge, MA 02138 \\ September 2017, Revised February 2021
}

\begin{abstract}
We thank Stijn Van Nieuwerburgh and two anonymous referees for their excellent comments and helpful suggestions. We also thank Jonathan Colmer, Justin Gallagher, Sol Hsiang, Matt Kahn, Nick Kuminoff, Arik Levinson, John List, Neil Mehrotra, Alvin Murphy, Dov Sax, Jesse Shapiro, Alp Simsek, Matt Turner, Kieran Walsh, and seminar participants at the NBER Summer Institute, IIES Stockholm, ETH CEPE, Mercator MCC, U. Basel, Stanford SEEPAC, UC Boulder, UC Davis, Georgetown, Maryland AREC, UC San Diego, UC Berkeley, U. Arizona, Brown University, UCSB, UVA Darden, USC, U. Maryland AREC, and U Chicago EPIC for their feedback and helpful suggestions, and our excellent research assistants Caroline Blanck, Jane Chen, Yvonne Fong, Jacob Furst, Jamila Gilmore, Rachel Gold, Lydia Gulick, Adam Lipsey, Maria Jesus Perez Ramirez, Zoe Sackman, Lisa Schold, Mohammed-Reda Semlani, Miles Slack, and Asutosh Swain for their great work. Research conducted in this article by Laura Bakkensen was supported by an Early-Career Research Fellowship from the Gulf Research Program of the National Academies of Sciences, Engineering, and Medicine. The content is solely the responsibility of the authors and does not necessarily represent the official views of the Gulf Research Program of the National Academies of Sciences, Engineering, and Medicine nor those of the National Bureau of Economic Research.
\end{abstract}

NBER working papers are circulated for discussion and comment purposes. They have not been peer-reviewed or been subject to the review by the NBER Board of Directors that accompanies official NBER publications.

(C) 2017 by Laura A. Bakkensen and Lint Barrage. All rights reserved. Short sections of text, not to exceed two paragraphs, may be quoted without explicit permission provided that full credit, including $(\odot)$ notice, is given to the source. 
Flood Risk Belief Heterogeneity and Coastal Home Price Dynamics: Going Under Water?

Laura A. Bakkensen and Lint Barrage

NBER Working Paper No. 23854

September 2017, Revised February 2021

JEL No. G12,Q54,R21

\begin{abstract}
$\underline{\text { ABSTRACT }}$
How do climate risk beliefs affect coastal housing markets? This paper provides theoretical and empirical evidence. First, we build a dynamic housing market model and show that belief heterogeneity can reconcile the mixed empirical evidence on flood risk capitalization. Second, we implement a door-to-door survey in Rhode Island. We find significant flood risk underestimation and sorting based on flood risk beliefs and amenity values. Third, we quantify the model and estimate that coastal prices currently exceed fundamentals by around $13 \%$ in our benchmark setting, with the potential for significantly higher overvaluation in other areas. Finally, we quantify both allocative inefficiency and distributional consequences arising from flood risk misperceptions and flood insurance policy reform.
\end{abstract}

Laura A. Bakkensen

School of Government \& Public Policy

University of Arizona

315 Social Science

P.O. Box 210027

Tucson, AZ 85721-0027

laurabakkensen@email.arizona.edu

Lint Barrage

Department of Economics

University of California, Santa Barbara

North Hall

Santa Barbara, CA 93106-9210

and NBER

lint_barrage@ucsb.edu

A data appendix is available at https://data.nber.org/data-appendix/w23854/ 


\section{Introduction}

How do climate risks affect coastal housing markets? In a world with homogeneous rational expectations, vulnerable housing prices should have already adjusted to incorporate the present value of future flood risk increases due to sea level rise. Empirically, however, hedonic analyses have repeatedly found that flood and climate risks are not (yet) fully reflected in housing markets. 1 This paper presents novel evidence for the role of belief heterogeneity and the implications of flood risk misperceptions in coastal U.S. housing markets. From an asset pricing perspective, it is well known that heterogeneity in beliefs about the future value of fundamentals can lead to inflated prices and a host of associated risks including bubbles, excess volatility, overinvestment, and credit crises (e.g., Harrison and Kreps, 1978; Abreu and Brunnermeier, 2003; Scheinkman and Xiong, 2003; Geanakoplos, 2010; Simsek, 2013; Xiong, 2013). This paper investigates whether flood risk misperceptions pose similar risks to coastal housing markets. While skepticism of climatic risks appears intuitively relevant in the United States, standard approaches to modeling the economic impacts of sea level rise have assumed homogeneous rational beliefs, thus potentially underestimating its broader economic ramifications.

First, we develop a dynamic housing market model and use it to review prior empirical evidence. The model builds on recent literature advancements on heterogeneous beliefs and housing prices (e.g., Piazzesi and Schneider, 2009; Favara and Song, 2014; Burnside, Eichenbaum, and Rebelo, 2016). Our theoretical innovation is the introduction of three novel dimensions of heterogeneity, specifically (i) in the housing stock, differentiating coastal from non-coastal homes, (ii) in households' amenity valuations of waterfront living, and (iii) in households' current and future flood risk perceptions. A rich empirical literature (described below) has generally found mixed results on the capitalization of climatic risks,

1 Examples span both new studies focusing on future sea level rise capitalization (e.g., Bernstein, Gustafson, and Lewis, 2019; Murfin and Spiegel, 2020; Baldauf, Garlappi, and Yannelis, 2020) and a larger literature on present day flood zone status (see, e.g., reviews by Daniel, Florax, and Rietveld, 2009; Beltrán, Maddison, and Elliott, 2018). 
but that flood events typically result in sharp declines in the prices of vulnerable homes. We show that these findings can be matched by a model where some agents underestimate flood and climate risks but update their beliefs based on flood realizations, resulting in sorting and different equilibria depending on the distribution of beliefs and other housing market characteristics. At the same time, the model also demonstrates some limitations of reducedform hedonic approaches in isolating flood risk beliefs due to confounders such as sorting dynamics and the role of higher order beliefs.

Second, this paper provides novel direct evidence on the role of flood risk beliefs in coastal housing markets by implementing a door-to-door survey campaign in Rhode Island. We elicit the joint distribution of current and future flood risk perceptions, coastal amenity values, and potential confounders such as flood damage expectations at the household level. Importantly, we elicit coastal risk perceptions and valuations both among households that did and did not purchase properties on the coast in a given community, thus directly informing the relevant counterfactuals. These critical elements are not available in other belief survey products such as from the Yale Program on Climate Change Communication (Howe et al., 2015). ${ }^{2}$ We find evidence of significant flood risk underestimation, and that selection into at-risk homes is driven by both lower risk perceptions and higher amenity values for waterfront living. Among residents of official high risk flood zones, a full $40 \%$ say they are "not at all" worried about flooding over the next ten years. In contrast, a plurality of respondents living inland in the same communities indicate that they would be "very worried" about flooding if they lived on the coast. We also find that the majority of coastal residents underestimate their homes'

2 The Yale data provide estimates of the fraction of the population in a county or city adopting a general climate change belief (e.g,. "global warming is happening"). While these estimates have been used to derive important insights on climate beliefs and risk capitalization (e.g., Bernstein et al., 2019; Baldauf et al., 2020), they could not be used as a substitute for our survey. First, they only measure climate beliefs, whereas our analysis requires a joint assessment of households' amenity valuations, risk beliefs, and confounders such as flood damage and government assistance expectations. Second, the smallest geographic unit in the Yale data is the county or city. Consequently, one cannot compare risk perceptions inside and outside high risk flood zones, or among coastal vs. non-coastal households. Third, the Yale survey does not elicit flood risk beliefs, but rather general climate change concern or beliefs. Lastly, we require information on counterfactual beliefs of households about homes they did not purchase. No such data is available in the Yale study or other surveys products we are aware of. 
flood risks relative to inundation models. Importantly, we confirm that these differences are not driven by confounders such as differential expectations of damages, government assistance, or insurance reimbursements in case of flood event $3^{3}$ Those who have experienced a flood in the past are significantly more concerned about flooding going forward, and coastal residents who are very worried about flooding are significantly more likely to plan on selling their homes in the next five years.

Third, we present a quantitative version of the model in order to simulate future coastal housing market outcomes under different belief, flood risk, and policy scenarios. Our quantification utilizes probabilistic projections of location-specific future flood risk increases due to sea level rise based on Buchanan et al. (2017) and from Kopp et al. (2014). The results imply that coastal housing prices currently exceed fundamentals by $13 \%$ in our benchmark setting in Rhode Island under a business-as-usual climate change scenario. This overvaluation is economically highly significant as it corresponds to around $40 \%$ of our benchmark households' average annual income. ${ }^{4}$ If future sea level rise turns out to be worse (better) than expected, this overvaluation may become significantly larger (smaller) in the absence of policy intervention. These estimates are robust to a range of sensitivity checks and extensions, such as alternative belief updating rules. The results do, however, vary under alternate future sea level rise scenarios. For example, global climate policy reduces overvaluations to $6 \%$. The simulations also reveal that households' beliefs about long-run flood insurance policy can significantly affect coastal housing prices in the present, highlighting the potential power of policy expectations to mitigate - or exacerbate - current mispricing.

In order to gauge the broader relevance of these effects, we extend our analysis to several cities across the United States. We extrapolate from our survey results in Rhode Island to other cities by creating a mapping between our flood risk belief measures and countylevel general climate change belief estimates from the Yale Program on Climate Change Communication (Howe et al., 2015). The results reveal the potential for significantly higher

3 They also do not appear to be due to differential expectations of future coastal protection measures. 4 Housing wealth also plays a prominent role in households' retirement savings (Campbell, 2006). 
overvaluation in other locations. For example, in Charleston, South Carolina, we estimate an initial overvaluation of over $50 \%$ due to both higher projected flood risk optimism and higher expected future flood risk increases due to sea level rise. Indeed, our benchmark Rhode Island location faces lower expected flood risk increases than the median across tidal gauges in the continental United States (Buchanan et al., 2017), and may thus ultimately be a conservative benchmark.

These findings have important policy and welfare implications. We quantify the allocative inefficiency of agents with high amenity values for waterfront living being priced out of coastal areas by agents with lower amenity values but optimistic flood risk beliefs, and consider distributional consequences of flood insurance policy reform 5 The dominant insurer for flooding in the United States is the National Flood Insurance Program (NFIP). The need for NFIP reform is well established. For example, the program has been fiscally insolvent, owing $\$ 30.4$ billion to the U.S. Treasury as of the end of the 2017 fiscal year (GAO, 2018a). Despite offering many policies at subsidized rates and despite flood insurance being technically required for homes with federally insured or regulated mortgages in high risk areas, NFIP take-up is low. By some estimates, only 30 to 50 percent of structures in high flood risk areas are insured (Harrison, Smersh, Schwartz, 2001; Kousky et al., 2018). We model an enforced insurance mandate at actuarially fair rates which would force the internalization of real risk rates and re-align coastal housing prices with fundamentals. Though efficient, this policy has significant distributional impacts. Within our framework, the main winners from immediate reform include excessively optimistic agents who currently live inland but would have purchased an overvalued coastal home in the future in the absence of policy reform. The losers include coastal agents who are concerned about flooding and would have sold their homes to optimists at higher prices absent policy reform. Our analysis thus adds to a

$5 \quad$ While we do not model the mortgage origination process and the use of coastal properties as collateral, we note the potential for significant additional welfare costs through this channel. For example, the devaluation of coastal properties could lead to defaults and adverse credit market impacts (see, e.g., Geanakoplos, 2010), thereby exacerbating market incompleteness. Indeed, new research indicates that lenders are not (yet) adjusting mortgages appropriately to increasing climatic risks (Ouazad and Kahn, 2020; Garbarino and Guin, 2020). 
growing literature studying the impacts of flood insurance reform across different types of households (e.g., Bakkensen and Ma, 2020; Wagner, 2019). Most fundamentally, our results highlight the value of better flood risk information. While the Federal Emergency Management Agency (FEMA) publishes official flood maps, these are backwards-looking and often out of date, with 1 in 6 maps being over 20 years old ${ }^{6}$ Our framework demonstrates how poor flood risk information can threaten the efficiency of coastal housing markets.

The broader literature context and our contributions thereto are as follows. First, our paper builds on the general literature on housing price dynamics (see, e.g., recent reviews by Davis and Van Nieuwerburgh, 2015, and Glaeser and Nathanson, 2014). Most closely related are recent papers that incorporate heterogeneous beliefs into housing market models. Both Piazzesi and Schneider (2009) and Burnside, Eichenbaum, and Rebelo (2016, "BER") present (quasi)-linear utility search models of housing markets coupled with Michigan Consumer and American Housing Survey data on households' expectations. Piazzesi and Schneider consider a one-time unanticipated shock that makes all renters optimistic about future prices to study the effects of momentum traders. BER study social dynamics in housing markets. With a known probability, each period the fundamental value of homes may change permanently to a new level. 'Optimists' expect this new value to be higher than 'skeptical' or 'vulnerable' agents. However, agents can 'infect' each other with their opinions, generating housing booms and busts. Our approach builds on, but differentiates itself from, BER in several ways. On the one hand, we do not employ a search model and do not focus on infectious social dynamics. On the other hand, we extend BER's model by adding several dimensions of heterogeneity relevant for flood risks and by allowing beliefs to evolve in response to external shocks (flood events) in a flexible Bayesian learning framework..$^{7}$

6 Authors' calculations based on FEMA National Flood Insurance Program Community Status Book, accessed 02/2017: https://www.fema.gov/national-flood-insurance-program-community-status-book

7 Another related branch of the housing literature studies residential sorting and its implications for hedonic valuations of amenity values (e.g,. Kuminoff, Smith, and Timmins, 2013; Bayer, McMillan, Murphy, and Timmins, 2016). While our framework takes a different approach, some results relate closely. For example, our finding of the importance of future expectations as a driver of current sorting and thus home prices echoes Bayer et al.'s (2016) finding that static estimates of amenity values may over- or under-estimate true values if those amenities are expected to change in the future. 
Second, we relate to a rich and growing empirical literature on environmental risk capitalization into housing prices. A first generation strand in this literature investigates the effects of current flood risk and official flood zone status. That is, FEMA produces flood risk maps for most coastal communities across the United States, and designates places with an annual inundation risk exceeding 1 in 100 as "Special Flood Hazard Areas." Empirical studies generally find weak capitalization of this flood zone status into coastal housing prices (see, e.g., meta analyses by Daniel, Florax, and Rietveld, 2009; Beltrán, Maddison, and Elliott, 2018). Studies often fail to detect significant negative effects, or may even find positive premiums (e.g., Bin and Kruse, 2006; Atreya and Czajkowski, 2016). Others find flood risk discounts that are significant but less than the present value of insurance premiums, suggesting only partial capitalization (Harrison, Smersh, Schwartz, 2001). Some studies also find significant flood risk penalties (e.g., Bin, Crawford, Kruse, and Landry, 2008), particularly for inland flood zones. A new nation-wide analysis by Hino and Burke (2020) identified off of flood zone changes also finds very modest overall effects. We contribute to this literature in two ways. One, our model can potentially account for this range of results as flood risk penalties are predicted to depend on market-specific variables, such as the distribution of risk beliefs and amenity valuations relative to the size of the coastal housing segment. In addition, our survey provides direct evidence for present-day flood risk misperceptions as a potential driver of incomplete capitalization.

Another strand analyzes the impacts of flood events. These studies have repeatedly found that prices of properties that are at high risk of, but were not damaged by, a flood typically drop sharply in the aftermath of an event, with estimates ranging from around 5-20 percent (e.g., Hallstrom and Smith, 2005; Kousky, 2010; Bin and Landry, 2013; Gibson and Mullins, 2017; Ortega and Taspinar, 2018). These price fluctuations are difficult to rationalize as based on changes in fundamentals, but are consistent with flood risk learning. Gibson and Mullins (2017) similarly find that FEMA flood map updates - another flood risk signal - decreased the prices of non-flooded homes in New York City after Hurricane Sandy 
by $18 \%$. Interestingly, studies that track longer run impacts typically find that prices return to baseline within 4-10 years (e.g., Bin and Landry, 2013; Atreya, Ferreira, Kiresel, 2013). Gallagher (2014) documents an analogous pattern in national flood insurance markets, where take-up rises sharply after floods but declines back to baseline within a decade. Gallagher (2014) demonstrates that this pattern is most consistent with a modified Bayesian updating model. We incorporate these findings by allowing for Bayesian learning about flood risks. Though not a targeted moment in our calibration, our model quantitatively predicts coastal home price declines of around $-10 \%$ in the aftermath of a future flood event, in line with empirical studies.

A newer strand studies the capitalization of future sea level rise risks. While their methods and results vary, these studies all indicate that sea level rise (SLR) risks are not fully reflected in home prices. Bernstein, Gustafson, and Lewis (2019, "BGL") present evidence from coastal housing markets across the United States. They combine national Zillow ZTRAX data on housing prices and characteristics with National Oceanic and Atmospheric Administration (NOAA) elevation and SLR exposure measures, such as whether a home will be inundated at a certain SLR level. For regular owner-occupied homes, BGL fail to detect a significant SLR vulnerability discount, even when controlling for waterfront proximity amenity values in detailed distance bins. In the non-owner occupied segment, however, they find a significant and large (7\%) discount associated with SLR exposure. Murfin and Spiegel (2020) similarly combine detailed national housing market data from CoreLogic with NOAA forecasts. In order to isolate the effects of sea level rise from those of elevation, they further use differential regional patterns of land rebound and subsidence to generate identifying variation. They fail to detect a significant effect of SLR on property prices. Next, Giglio et al. (2018) combine housing transactions with home listings information across four coastal states. They use the latter to create a "climate attention index" based on the frequency with which terms such as hurricanes or flood zones are mentioned in listings. Their results indicate that flood risk capitalization depends on this climate attention index. 
Most closely related to our work, Baldauf, Garlappi, and Yannelis (2020) investigate the role of general climate change beliefs in SLR risk capitalization. They present a housing price model with heterogeneity in SLR expectations also building on BER. In their framework, homophily - that is, agents with similar beliefs deriving utility from being near each other - generates stationary sorting of belief types into different areas. Baldauf et al. (2020) show that this sorting should generate attenuated SLR capitalization in areas with more skeptics, and show this to be empirically the case. They combine housing transactions data with sea level rise forecasts and county-level estimates of the population share believing that "global warming is happening" from the Yale data (Howe et al., 2015). They identify a significant negative SLR effect but only in areas with sufficiently high climate change belief, echoing similar results in BGL. On the one hand, these empirical results are in support of our model and main mechanism. On the other hand, we note important differences between our models. Baldauf et al. (2020) focus on cross-sectional properties of housing prices in stationary equilibrium with sorting based on fixed beliefs and across homogeneous homes. In contrast, our analysis distinguishes coastal from non-coastal homes, models flood events, flood risk changes, and learning dynamics, and features heterogeneity in coastal amenity values as well as higher order beliefs. Importantly, while Baldauf et al. (2020) focus on theoretical insights from their model, we develop a quantitative framework to project future price dynamics, welfare, and policy counterfactuals. Lastly, while Baldauf et al. (2020) rely on county-level estimates of general climate change beliefs, our original survey can more precisely inform questions about flood risk beliefs versus house-specific flood risk, potential confounders, and their roles in driving sorting behavior.

Our study also adds to new work on the asset market impacts of climate skepticism. In an empirical analysis of agricultural land markets, Severen, Costello, and Deschenes (2018) find that counties with more climate skepticism incorporate future expectations to a lesser degree. Kahn and Zhao (2018) theoretically analyze the impacts of skeptics in a spatial equilibrium between two cities, finding that skeptics lower the price of land in the cooler 
city less impacted by climate change. Barrage and Furst (2019) empirically show that new housing investment is negatively associated with sea level rise exposure but only in areas with sufficiently high levels of climate change belief.

Finally, we also relate to a broader finance literature that has documented significant effects of personal experiences on beliefs and investment behavior. For example, Malmendier and Nagel (2011) show that agents who experienced the Great Depression are more pessimistic about and less likely to participate in the stock market. Kuchler and Zafar (2019) show that individuals' experiences of local home price movements inform their beliefs about aggregate prices. Our survey results similarly show that agents that have experienced floods are more concerned about flooding, in line with prior empirical studies, and our model highlights the potential effects of such belief changes on coastal home price dynamics.

The remainder of this paper proceeds as follows. Section 2 presents a simplified version of our model for intuition. Section 3 describes our field survey and results. Section 4 contains the full structural model and calibration details. The main quantitative results and robustness checks are described in Section 5. We present an extension to other cities in Section 6. Section 7 concludes.

\section{Model Intuition}

This section presents a simplified version of our model and illustrates how empirically observed flood risk premiums would be expected to differ under alternative belief distributions. As the purpose of this section is to provide basic intuition, several model elements are left implicit until Section 4, which presents a full specification with proper formality.

Our setup follows Burnside, Eichenbaum, and Rebelo (2016, "BER") in studying an economy populated by a continuum of agents with linear utility and utility discount rate $\beta$. As in BER, agents can own one home or rent, houses cannot be sold short, and there is a fixed stock of houses available for sale $k<18$ We first introduce heterogeneity in the housing

\footnotetext{
$8 \quad$ We thus abstract from housing construction. Empirical estimates find supply in coastal areas to be
} 
stock: fraction $k_{1}<k$ of homes are "coastal" properties (empirically later defined as within 400 feet of the waterfront). Coastal properties differ from inland homes in two dimensions. One, they provide an additional flow utility value of $\xi^{i}$, which is indexed by $i$ to indicate that it may vary across households. Two, each period, coastal homes incur net flood damages $\delta$ with probability $\pi_{t}^{*}$. In principle, one could model households as expecting gross damages $\widetilde{\delta}^{i}$ net of government transfers $G^{i}$ in case of a flood, and allow these expectations to vary across households. However, we focus on net damages $\delta$ as FEMA disaster aid is, in reality, very small (typically a few thousand dollars, Kousky, 2013), and as our survey results suggest that heterogeneity in flood risk concern is not driven by optimism about public assistance. By the same token, we also leave insurance premiums and payouts implicit in the model, but note that they would be straightforward to add, especially given the linear utility framework. Importantly, however, we allow households to disagree with scientifically forecast flood risks, which we informally denote $E_{t}^{*}\left\{\pi_{s}^{*}\right\}_{s=t}^{\infty}$, and to hold their own first-order beliefs denoted $E_{t}^{i}\left\{\pi_{s}^{i}\right\}_{s=t}^{\infty}$. Both the full information dynamics of future flood risk changes and higher-order beliefs are left implicit in the expectations operator here, but made explicit in Section 4 .

The rental market, also as in BER, consists of $1-k$ homes which are produced by competitive firms charging a rental rate of $w$ per period. The flow utilities of owning versus renting a home are given by $\varepsilon^{h}$ and $\varepsilon^{r}$, respectively. Each period, households thus face the decision of whether to (i) buy a non-coastal home at price $P_{t}^{N C}$, (ii) buy a coastal home at price $P_{t}$, or (iii) rent (inland). We focus on a frictionless housing market where prices are determined by the valuation of the marginal buyer 9 Letting $m_{t}$ index his identity at time $t$, in equilibrium, the marginal buyer must be just indifferent between his options:

$$
-P_{t}+\beta\left(\varepsilon^{h}+\xi^{m_{t}}-\pi_{t}^{m_{t}} \delta+E_{t}^{m_{t}}\left[P_{t+1}\right]\right)=\beta\left(\varepsilon^{r}-w\right)=-P_{t}^{N C}+\beta\left(\varepsilon^{h}+E_{t}\left[P_{t+1}^{N C}\right]\right)
$$

highly inelastic, driven by topographic constraints (Glaeser, Gyourko, and Saks, 2005; Green, Malpezzi, and Mayo, 2005). Saiz (2010) estimates MSA-level elasticities, finding Miami, Los Angeles, Fort Lauderdale, and San Francisco to have the lowest supply elasticities. For a theoretical analysis of how developers may respond to climate risks, see Bunten and Kahn (2017).

9 The Online Appendix considers transaction costs in a stylized version of the model. We show that the level of overvaluation due to flood risk misperceptions is unaffected by transaction costs. 
where $E_{t}^{m_{t}}\left[P_{t+1}\right]$ is $m_{t}$ 's expectation of the re-sale value of a coastal home in period $t+1$. Further defining $e^{h} \equiv \varepsilon^{h}-\left(\varepsilon^{r}-w\right)$ as the net flow utility of being a homeowner rather than a renter, (1) thus yields the following pricing condition for coastal homes:

$$
P_{t}=\beta\left(e^{h}+\xi^{m_{t}}-\pi_{t}^{m_{t}} \delta+E_{t}^{m_{t}}\left[P_{t+1}\right]\right)
$$

Intuitively, (2) indicates that coastal home prices depend on the marginal buyer's amenity values, current flood risk beliefs, and re-sale value expectations, which, in turn, depend on the agent's (first- and higher-order) beliefs about future flood risks.

For the remainder of this illustration, we will assume that scientists can predict sea level rise perfectly. The full model in Section 4 accounts for uncertainty over sea level rise. We also assume - broadly in line with the survey results - that coastal amenity values are independently and uniformly distributed with $f_{\xi}\left(\xi^{i}\right) \sim U[0, \Xi]$. The parameter $\Xi$ thus denotes the maximum per-period willingness to pay for waterfront living among the population.

\subsection{Homogeneous Rational Beliefs}

We first consider the implications of the benchmark assumption of homogeneous rational flood risk beliefs, implying that $E_{t}^{i}\left\{\pi_{s}^{i}\right\}_{s=t}^{\infty}=E_{t}^{*}\left\{\pi_{s}^{*}\right\}_{s=t}^{\infty} \forall i$ and thus that $E_{t}^{i}\left[P_{t+1}\right]=E_{t}\left[P_{t+1}\right]$ $\forall i, t$. For completeness, consider a housing market which starts in a 'pre-climate change predictions' equilibrium where sea-level rise and its implications for flood risks were not yet a part of official or widely disseminated scientific predictions. If everyone believes that flood risks will remain constant at a low level $\pi_{t}^{*}=\pi^{L} \forall t$, the initial $(t=-1)$ equilibrium coastal home price would be given by the stationary solution to (2):

$$
P_{-1}=\frac{\beta\left(e^{h}+\Xi\left(1-k_{1}\right)-\pi^{L} \delta\right)}{(1-\beta)}
$$

The term $\Xi\left(1-k_{1}\right)$ captures the $k_{1}^{\text {st }}$ and thus market-clearing amenity value. Through the

lens of the model, the empirically estimated hedonic coastal housing premium $P R E M_{t}^{\text {Coast }}$ 
$\equiv\left(P_{t}-P_{t}^{N C}\right)$ and the flood risk premium $P R E M_{t}^{\text {Flood }} \equiv \frac{\partial P_{t}}{\partial \pi_{t}^{*}}$ should thus correspond to:

$$
\begin{aligned}
P R E M_{-1}^{\text {Coast }} & =\left[\Xi\left(1-k_{1}\right)-\pi^{L} \delta\right]\left(\frac{\beta}{1-\beta}\right) \lesseqgtr 0 \\
P R E M_{-1}^{\text {Flood }} & =-\delta\left(\frac{\beta}{1-\beta}\right)<0
\end{aligned}
$$

The overall coastal premium (4) thus depends on both the amenity value $\Xi$ and expected damages $\pi^{L} \delta$, and could be positive or negative. The ceteris paribus effect of flood risk (5), however, should be unambiguously negative in the homogeneous rational beliefs model.

Next, consider a stylized representation of climate change expectations where, at $t=0$, it is announced that flood risk will permanently increase to $\pi^{H}>\pi^{L}$ at some future time $T_{1}$. That is, $\pi_{t}^{*}=\pi^{L}$ for $t<T_{1}$ and $\pi_{t}^{*}=\pi^{H}$ for $t \geq T_{1}$. In order to derive predictions for the resulting flood risk premium, the correlation between current and future flood risks must be specified. Since waterfront flood risk is mainly a function of elevation, we first consider a simple relationship with proportional flood risk increase $\gamma^{S L R}$ :

$$
\pi^{H}=\gamma^{S L R} \cdot \pi^{L}
$$

It is easy to show (through backwards iteration) that the flood risk premium should immediately fall to reflect the new forecast, and continue to grow more negative until converging to its new long-term value. That is, the flood risk premium should immediately incorporate the present value of future flood risk increases:

$$
\begin{aligned}
P R E M_{t}^{\text {Flood }} & =\underbrace{-\delta\left(\frac{\beta}{1-\beta}\right)}_{\text {Current Risk Effect }}-\underbrace{\left\{\gamma^{S L R}-1\right\} \frac{\beta^{T_{1}+1-t}}{(1-\beta)} \delta}_{\text {Present Value of Future Risk Effect }} \text { for } t \in\left\{0,1, \ldots T_{1}\right\} \\
& =-\left\{\gamma^{S L R}\right\} \delta\left(\frac{\beta}{1-\beta}\right) \text { for } t>T_{1}
\end{aligned}
$$

With homogeneous rational beliefs, observed flood risk penalties should thus be unambiguously negative and growing in full anticipation of climate change-induced future risk in- 
creases. This prediction is clearly counterfactual for many segments of the U.S. housing market, as described in Section 1. The Online Appendix further presents hedonic estimates of the flood risk premium over a longer time horizon (1970-2017) in our empirical setting, which also fails to match this predicted pattern. The next sub-section consequently proposes a generalization of the standard model to accommodate disagreement with official forecasts as potential explanation of these empirically observed risk capitalization patterns.

\subsection{Skepticism}

We now consider the possibility that at least some agents' beliefs diverge from the scientific forecast. Specifically, we generalize the homogeneous rational beliefs model to allow for a second belief type $\left[{ }^{10}\right.$ Fraction $\left(1-\theta^{\circ}\right)$ of the population remain "realists" who believe in the scientific forecast $\left(\left\{\pi_{s}^{r}\right\}_{s=t}^{\infty}=\left\{\pi_{s}^{*}\right\}_{s=t}^{\infty}\right)$, whereas fraction $\theta^{o}$ holds more optimistic beliefs with $\pi_{t}^{o} \leq \pi_{t}^{*} \forall t$. In Section 4, optimists' beliefs are micro-founded via skepticism of the scientific forecast, which they believe to be true only with some prior probability. Here, for ease of illustration, we present a simpler specification where optimists' flood risk perceptions lie fraction $\lambda_{t}^{O p t} \in[0,1]$ below official estimates $\pi_{t}^{*}$ :

$$
\pi_{t}^{o}=\left(1-\lambda_{t}^{O p t}\right) \cdot \pi_{t}^{*}
$$

As before, the market-clearing marginal buyer will be the agent with the $k_{1}^{\text {st }}$ valuation for coastal properties. There are now three general cases to consider.

\subsubsection{Case 1}

First, if there are more optimists than coastal homes $\left(\theta^{o}>k_{1}\right)$, it is possible that only optimists will live on the coast if even the realist with the highest amenity value $\left(\xi^{r}=\Xi\right)$

$\overline{10}$ Our model alo allows for the possibility of homogeneously misinformed agents if $\theta^{\circ}=1$. 
assigns a lower value to buying a coastal home than the (then marginal) optimist:

$$
\underbrace{\beta\left(e^{h}+\Xi-\pi_{t}^{r} \delta+E_{t}^{r}\left[P_{t+1}\right]\right)}_{\text {Maximum WTP for coastal home among realists }}<\underbrace{\beta\left(e^{h}+\widehat{\xi^{o}}-\pi_{t}^{o} \delta+E_{t}^{o}\left[P_{t+1}\right]\right)}_{\text {WTP for coastal home of (marginal) optimist }}
$$

In this case, the marginal optimist's amenity value $\widehat{\bar{\xi}^{o}}$ must clear the market:

$$
\frac{\theta^{o}}{\Xi}\left(\Xi-\widehat{\overline{\xi^{o}}}\right)=k_{1}
$$

Rearranging (11) reveals that (10) will hold if risk perceptions are sufficiently different:

$$
\Xi \frac{k_{1}}{\theta^{o}}+\left\{E_{t}^{r}\left[P_{t+1}\right]-E_{t}^{o}\left[P_{t+1}\right]\right\}<\delta\left(\pi_{t}^{r}-\pi_{t}^{o}\right)
$$

The equilibrium coastal home price in this setting is then defined by:

$$
P_{t}=\beta\left(e^{h}+\Xi\left(1-\frac{k_{1}}{\theta^{o}}\right)-\pi_{t}^{o} \delta+E_{t}^{o}\left[P_{t+1}\right]\right)
$$

The cross-sectional flood risk premium - estimated as home price change with respect to official risk $\pi_{t}^{*}$ - now differs from the homogeneous model's prediction (7):

$$
P R E M_{t}^{\text {Flood }}=\underbrace{-\left(1-\lambda_{t}^{O p t}\right) \delta}_{\text {Current Risk Effect }} \beta+\underbrace{\Delta E_{t}^{o}\left[P_{t+1}\right] \beta}_{\text {Future Risk Effect }} \text { for } t \geq 0
$$

Here, $\Delta E_{t}^{o}\left[P_{t+1}\right]$ denotes the change in optimists' expectations of the re-sale value of coastal homes across areas with higher official flood risk.

On the one hand, the current risk capitalization is now attenuated by optimists' discounting of flood risk $\left(1-\lambda_{t}^{O p t}\right)$. The survey results suggest that $50 \%$ of coastal homeowners in our sample underestimate their homes' flood risk by $50 \%$ or more, implying a potentially substantive value for $\lambda_{t}^{O p t}$. In addition, the future risk internalization is generally also at- 
tenuated compared to the rational beliefs case ${ }^{11}$ We formalize this statement in Section 4. The central point here, however, that a model with belief heterogeneity can account for the empirically observed under-capitalization of current and future flood risks in markets with a sufficient density of excessively optimistic (or climate skeptical) households ${ }^{12}$

\subsubsection{Case 2}

Next, Case 2 occurs when both optimists and realists buy coastal homes. The marginal buyers' valuations are then equated:

$$
\beta\left(e^{h}+\overline{\xi_{t}^{r}}-\pi_{t}^{r} \delta+E_{t}^{r}\left[P_{t+1}\right]\right)=\beta\left(e^{h}+\overline{\xi_{t}^{o}}-\pi_{t}^{o} \delta+E_{t}^{o}\left[P_{t+1}\right]\right)=P_{t}
$$

Intuitively, the marginal realist has a sufficiently high amenity value $\overline{\xi_{t}^{r}}$ so as to equate their coastal home valuation to that of the marginal optimist. The marginal amenity values and equilibrium prices are then pinned down jointly by (14) and market clearing:

$$
\frac{\theta^{o}}{\Xi}\left(\Xi-\bar{\xi}_{t}^{o}\right)+\frac{\left(1-\theta^{o}\right)}{\Xi}\left(\Xi-\bar{\xi}_{t}^{r}\right)=k_{1}
$$

A ceteris paribus increase in official flood risk $\pi_{t}^{*}$ now has the interesting effect that it will alter the identity and thus amenity values of the marginal buyers, in addition to changing the valuation of flood risks. That is, the cross-sectional flood risk premium (across two otherwise identical housing markets in equilibrium Case 2) would contain impacts of both sorting and potentially underestimated current and future risks:

$$
P R E M_{t}^{\text {Flood }}=\left(\Delta \overline{\xi_{t}^{r}}-\delta+\Delta E_{t}^{r}\left[P_{t+1}\right]\right) \beta=\left(\Delta \overline{\xi_{t}^{o}}-\left(1-\lambda_{t}^{O p t}\right) \delta+\Delta E_{t}^{o}\left[P_{t+1}\right]\right) \beta
$$

$\overline{11}$ Optimists may underestimate future flood risk levels $\pi^{H}$ in $(6)$ either by directly discounting the sealevel rise projection $\left(\gamma^{S L R}\right)$, or indirectly even if they believe that sea-level rise will increase flood risks by factor $\gamma^{S L R}$ if they apply this factor to an under-estimated baseline flood risk level as in $(9)$.

12 Case 1 also covers the setting with homogeneous misperception $\left(\theta^{\circ}=1\right)$ as optimists would trivially be pricing coastal homes, thus leading to an attenuation of the flood risk premium as in 13 . 
Since the direct effect of higher flood risk on optimists' valuations is weakly less negative than the realists' $\left(-\left(1-\lambda_{t}^{O p t}\right) \delta \geq-\delta \beta\right)$, and assuming that the same will be true of the impact on future price expectations $\left(\Delta E_{t}^{o}\left[P_{t+1}\right] \geq \Delta E_{t}^{r}\left[P_{t+1}\right]\right)$, the marginal realist in the higher risk setting must have higher amenity values for waterfront living $\left(\Delta \overline{\xi_{t}^{r}}>0\right)$, whereas the marginal optimists moving must have lower amenity values $\left(\Delta \overline{\xi_{t}^{o}}<0\right)$. This comparative static also illustrates the allocative inefficiency resulting from flood risk misperceptions. Importantly for our purposes, however, (16) highlights why the presence of some market participants with realistic flood risk beliefs is not necessarily sufficient to ensure that those risks are fully capitalized into coastal housing prices, in line with the empirical evidence.

\subsubsection{Case 3}

Finally, if there are fewer optimists than coastal homes $\left(\theta^{\circ}<k_{1}\right)$, the marginal buyer is trivially a realist. In this case, the marginal realist's amenity value $\widehat{\bar{\xi}^{r}}$ must clear the market for coastal homes net of the space already occupied by the optimists:

$$
\frac{\left(1-\theta^{o}\right)}{\Xi}\left(\Xi-\widehat{\bar{\xi}^{r}}\right)=k_{1}-\theta^{o}
$$

The equilibrium price in this setting will then satisfy:

$$
P_{t}=\beta\left(e^{h}+\Xi\left(1-\frac{\left(k_{1}-\theta^{o}\right)}{\left(1-\theta^{o}\right)}\right)-\pi_{t}^{r} \delta+E_{t}^{r}\left[P_{t+1}\right]\right)
$$

The flood risk premium in this type of market would then be:

$$
\operatorname{PREM} M_{t}^{\text {Flood }}=\underbrace{-\delta \beta}_{\text {Current Effect }}+\underbrace{\Delta E_{t}^{r}\left[P_{t+1}\right] \beta}_{\text {Future Risk Effect }} \text { for } t \geq 0
$$

The current flood risk capitalization in this market thus matches that of the homogeneous rational expectations setting. Since realists will remain marginal buyers, their future risk internalization should moreover capture the full climate change forecast. It should be noted 
that coastal home price levels (17) are still distorted in this setting as some optimists with lower amenity values take up coastal real estate that should, from an efficiency perspective, go to realists with higher amenity values. If realists expect that these optimists will one day change their beliefs to match the official forecast, thus exiting the coastal property market, realists would anticipate an additional future devaluation due to this correction to optimists' beliefs. Overall, however, the heterogeneous beliefs model can thus also accommodate the finding that markets dominated by agents with realistic flood risk beliefs are likely to internalize these and future climate risks, again in line with the empirical evidence.

\section{Direct Evidence: Field Survey}

The analysis thus far indicates that a housing market model with flood risk misperceptions fits the empirical evidence better than a benchmark homogeneous rational beliefs model. At the same time, the model also illustrates the structural challenges inherent in seeking to isolate risk beliefs from hedonically estimated flood risk premiums. We therefore turn to surveys as a methodology that can elicit flood risk and confounding beliefs directly and provide direct evidence on heterogeneity and sorting. In light of well-known potential concerns about stated preference elicitation, we complement the survey with a hedonic analysis of housing prices, and use its results to inform the robustness analysis in Section 5.3 .

\subsection{Design}

We conduct in-person surveys through a door-to-door campaign in Rhode Island, targeting communities with both coastal (defined as within 400 feet of the waterfront) and non-coastal homes ${ }^{13}$ The surveys were conducted in two waves across February and July 2017. The

13 Two key model features motivate the need for an original door-to-door survey campaign rather than leveraging existing survey products. First, while prominent publicly-available surveys exist assessing flood risk perception across the United States (e.g., FEMA, 2013), our model requires the joint distribution of both waterfront living valuation and flood risk perception at the household level. Second, to assess the existence and frequency of optimists in the market, we need to compare homeowner flood risk perception with hydrological flood risk at the property level, the latter of which is often not collected 
survey instruments are provided in the Appendix. The key components of the survey are as follows. First, we elicit households' ceteris paribus willingness to pay (WTP) for living within 400 feet of the water using a double-bounded dichotomous choice (DBDC) choice contingent valuation mechanism (Hanemann, Loomis, and Kanninen, 1991).14 We use contingent valuation $(\mathrm{CV})$ instead of the often utilized hedonic model for several reasons. First, the hedonic model has difficulty in estimating the coastal amenity value given the strong correlation between coastal amenities and flood risk that can potentially bias results in a revealed preference setting (Bin et al., 2008). Second, as our model indicates, hedonic estimates confound amenity values with sorting and future price expectations. Third, our model needs information on amenity values for both residents who chose to live on the coast and those who did not, whereas the hedonic model only estimates a value for the marginal buyer. Lastly, the CV technique, while not without criticism including for its elicitation of non-use values (Diamond and Hausman, 1994), has been shown for decades to be a useful and accurate estimate of environmental values when following best practices (Kling at al., 2012), including those laid out by, e.g., Kenneth Arrow, Robert Solow, and others who participated in National Oceanic and Atmospheric Administration's Blue Ribbon Panel on the contingent valuation method (Arrow et al., 1993).

Both our use of face-to-face interviews and the DBDC mechanism are motivated by best practices recommendations in CV survey design and implementation (Arrow et al., 1993; Mitchell and Carson, 2013). Guided by the literature on efficient starting bid design (Kanninen, 1993; Alberini, 1995), the three starting bids of $\$ 150, \$ 250$, and $\$ 350$ were chosen based on a hedonic estimation of the annualized waterfront living premium using U.S. Census American Housing Survey data for 2013 performed by the authors. The DBDC question was asked early in the survey to avoid bias due to priming with flood risk information (Cameron and James, 1987; Arrow et al., 1993; Hanemann, 1994; Carson and Mitchell, 1995).

or collected at a coarser level (see review by Kellens et al., 2013).

14 DBDC has been shown to be a more efficient WTP estimate relative to a single-bounded approach (Hanemann et al., 1991). For sensitivity, we also estimate WTP using a single-bounded dichotomous choice with the first bid and find the mean WTP to be similar (11\% lower). 
Second, we elicit coastal flood risk perceptions. In line with best practices in the risk elicitation literature (Manski, 2004), we consider both quantitative and qualitative subjective risk measures. The quantitative elicitation asks subjects about their perception of the probability of experiencing at least one flood over the course of the next 10 years ${ }^{15}$ Coastal residents are asked about their homes specifically, whereas non-coastal residents are asked to consider a home like theirs located within 400 feet of the waterfront in their community. As a visual aid, subjects are shown a table of both natural frequencies and probabilities. Next, as a qualitative measure we ask subjects to indicate how worried they are on a 10-point scale about the risk of a flood affecting their or a coastal home over the next 10 years. This question format is motivated by the findings of Schade, Kunreuther, and Koellinger (2012) that such a worry scale performs significantly better as a predictor of demand for insurance against low probability disasters than quantitative subjective probability measures.

Third, the survey asks subjects about potential confounders that could affect concern about flooding, including expectations over flood damages, insurance reimbursements, and government assistance, as well as flood risk mitigation. We also ask about flood experiences and intentions to sell or buy a home in the next five years. Finally, the survey asks subjects about their beliefs about changes in future flood risk and the climate. We supplement demographic information elicited in the survey with publicly available information on home characteristics from tax assessor records.

This section reports results from $n=187$ interviews ( $52 \%$ coastal,) conducted in several Rhode Island communities ${ }^{16}$ This sample size is in line with prior survey studies of flood

15 We deliberately do not attempt to financially incentivize subjects' subjective flood risk responses. This is because any scoring rule would have to pit subjects' answers against official inundation-model based flood risk projections as the true benchmark. However, it is precisely subjects' deviations in their subjective beliefs from official FEMA announcements of flood risk that we are seeking to understand. In contrast to economic experiments which can often benchmark subjective probabilities against events occurring in the laboratory in real time, we also could not wait for flood risk realizations over the next year(s) to financially reward respondents' answers. Indeed, for these and similar reasons, field surveys eliciting expectations commonly do not incentivize these responses (Manski, 2004).

16 The study design and implementation was approved by Brown University and the University of Arizona's Institutional Review Boards and all surveyors completed the Collaborative Institutional Training Initiative training. Informed consent was obtained from all respondents. Respondents were also compensated $\$ 5$ for agreeing to take the survey although some respondents declined compensation. 
risk perceptions, particularly ones using face-to-face interviewing techniques ${ }^{17}$ Close to $40 \%$ of people who answered their doors agreed to take the survey. The overall estimated response rate (including unanswered doors) of approximately $12.5 \%$ is similar to DellaVigna, List, and Malmendier's (2012) response rates of 10-15\% in their unannounced door-to-door survey treatment groups. Though not designed to be statistically representative, our sample of survey respondents also appear demographically comparable to county-level populations, although they skew slightly older and more educated (see Online Appendix).

Before proceeding, we highlight several reassuring survey quality checks, which are described in further detail in the Online Appendix. First, we compare homeowners' stated guesses of their homes' current market values against Zillow Zestimates. ${ }^{18}$ We find a correlation of 0.89 , indicating a high level of agreement. This result is the more reassuring as the home market values question was placed at the end of the survey, making it relatively more vulnerable to survey fatigue. Second, we compare homeowners' stated purchase year with tax assessor data. In the cases where we can establish the purchase date of a home with reasonable confidence (e.g., where the most recent deed on record is a sale to new owners at a positive price), there is a very high level of agreement between the survey and the deed records. With the exception of one outlier, the correlation is 0.996 .19 Third, respondents' stated expectations of key outcomes such as damages in case of a flood event compare favorably with data-based estimates. In particular, our survey-based median gross damage estimate of $20 \%$ of property values compares well with Kousky and Michel-Kerjan's (2016) estimate of $24.8 \%$ average flood losses as a fraction of home values based on micro-data on NFIP flood damage claims. Finally, our survey's predicted values of the percentage of flood risk optimists in each of the three counties we visit correlates very highly (up to 0.99) with

$\overline{17}$ For example, Pagneux et al. (2011) present face-to-face interviews on flood risk perceptions with $n=112$ subjects in Iceland. Lindell and Hwang (2008) present a mail survey with $n=321$ responses. Kellens, Zaalberg, and De Maeyr (2012) utilize $n=266$ complete online surveys (based on 313 responses). See also meta analysis by Kellens, Terpstra, and De Maeyer (2013).

18 We thank an anonymous referee for suggesting this comparison.

19 As discussed in the Online Appendix, the outlier household is a flood zone resident stating high levels of worry, so excluding them from our sample would only strengthen our main results. 
county-level estimates of general climate change concern from the Yale Program on Climate Change communication, as described in Section 6 .

\subsection{Main Survey Results}

First, we find strong evidence of heterogeneity in flood risk perceptions. In line with the sorting mechanism implied by the model, we find that coastal residents living in official FEMA high-risk flood zones are significantly less worried about flooding than those whose homes are outside the flood zone, as shown in Figure 1.

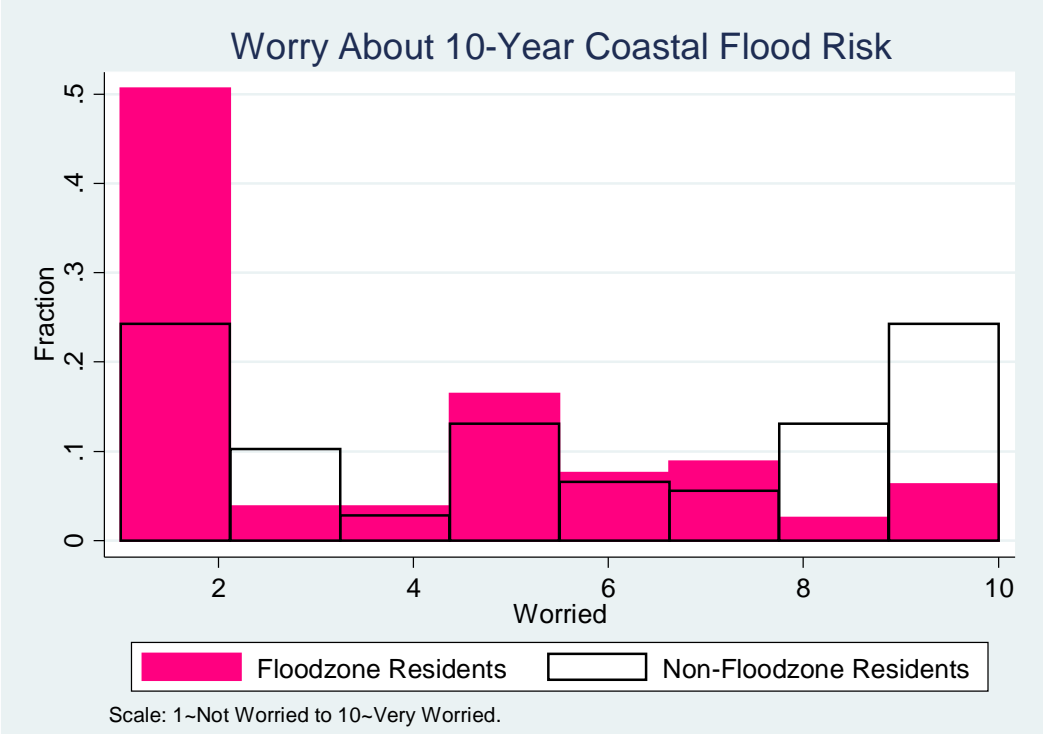

Figure 1: Flood Worry Distribution

Of course one may be concerned that a low degree of worry could be driven by differences in expectations over losses conditional on a flood, rather than flood risk itself. Figure 2 showcases the distribution of expected flood damages (as percentage of home value) net of expected insurance reimbursements and government assistance ${ }^{20}$ While flood zone residents generally expect slightly lower damages, they also expect less insurance and government assistance (see Table 1). The net damage expectations are thus very similar across the two

20 Households whose (net) estimates imply flood damages in excess of $100 \%$ (below $0 \%$ ) of home values are re-coded as $100 \%$ damage $(0 \%)$ estimates. 
groups, and the means are statistically indistinguishable, suggesting that differences in flood worries are not driven by differential expectations of damages or ex-post flood assistance.

Other potential confounders include the following. First, flood zone residents could be secondary homeowners who are disproportionately less concerned about flooding. However, using property tax records, we construct a measure of secondary homeownership and verify that the results are virtually unchanged if secondary homeowners are excluded (see Online Appendix for details). Second, another potential explanation for low worry among some coastal residents is that they may have taken flood risk mitigation measures, such as installing a water pump. We ask about such mitigation measures in the second wave of the survey. While the sample size is correspondingly limited, the results indicate that flood zone residents who report low worry actually also report fewer mitigation measures, although not significantly so (see Online Appendix). Focusing on the most important mitigation measures - sea walls or home elevation ${ }^{21}$ - we further find that respondents listing these protection efforts appear, if anything, more worried about flooding on average, although again not significantly so ${ }^{22}$ Our results are thus consistent with the notion that worry drives risk reducing behaviors, including residential location choice.

Table 1 presents differences in means and t-tests for their significance across the two groups. Both demographics and home characteristics appear similar across flood zone and non-flood zone residents. Beyond exhibiting highly significantly lower flood risk concerns, flood zone residents differ from non-flood zone residents mainly in having smaller households and homes.23 The central take-home point is thus that we find evidence of significant het-

21 Homes that have been elevated sufficiently to reduce their annual flood risk below $1 \%$ can be removed from FEMA's high risk flood zone through a so-called "Letter of Map Revision." Our analysis would then not count those homes as being in the high risk flood zone.

22 One may also be concerned about households' beliefs about future public protective infrastructure projects. Our survey asks respondents who express a belief in future flood risk increases or decreases for the reasons for their belief. Only four mention sea walls or construction. Excluding them does not change the result of significantly lower flood risk worry among flood zone residents. Further excluding those expressing a belief that future flood risk will remain unchanged - who were not asked about reasons for their beliefs - also leaves our main result intact. See Online Appendix for details.

23 For the living area variable, we use finished area information from Barrington, Bristol, and Warren, and effective area for Portsmouth and Warwick. We set one home with a recorded finished area of zero to missing. Treating the zero as data instead would render the difference in sizes in Table 1 slightly 


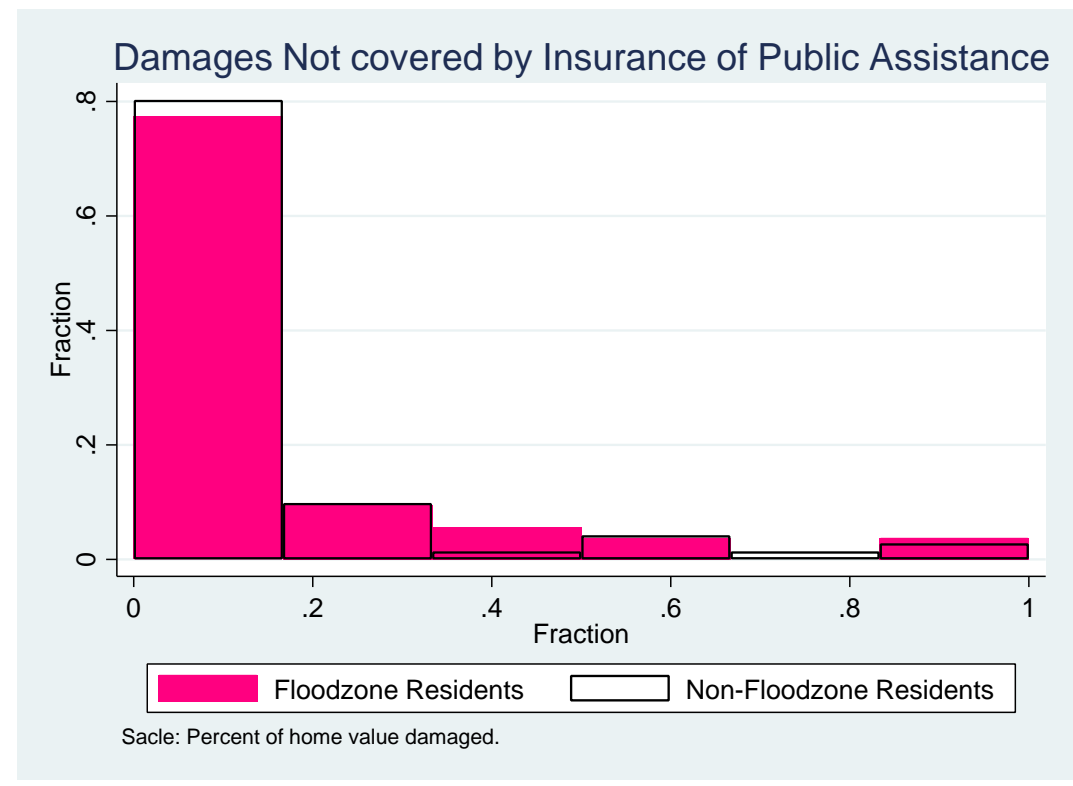

Figure 2: Net Damage Expectations

erogeneity in concerns about flooding that does not appear to be driven by differences in confounders such as government or insurance assistance expectations.

The results presented thus far focus on flood risk perceptions measured by a worry index. However, we also elicit numerical flood risk beliefs. Figure 3 compares these perceptions with respondents' homes' 10-year flood risk, which we estimate based on property-specific elevation data from 1-meter resolution digital elevation model LiDAR data from the University of Rhode Island Environmental Data Center, and STORMTOOLS, a set of Rhode Island inundation maps and flood return rates developed by partners including the University of Rhode Island and NOAA (SAMP, 2017). The sample is restricted to coastal homes so that responses reflect flood risk estimates specific to respondents' homes. On the one hand, we find that actual flood risk is a highly significant predictor of perceived flood risk (see Online Appendix for regression results). On the other hand, however, coastal residents appear to systematically under-estimate their flood risk relative to inundation models. Assessments that agree with the storm surge model should be near the $45^{\circ}$ line. However, around $60-70 \%$ of coastal residents under-estimate their homes' flood risk relative to the inundation model, smaller and no longer marginally significant. 
Table 1: Differences in Sample Means: Flood Zone Residents

\begin{tabular}{|c|c|c|c|}
\hline Variable & Non-Flood Zone & Flood Zone & Difference (SE) \\
\hline Flood Worry Index (1-10) & 5.62 & 3.65 & $\begin{array}{l}1.97^{* * *} \\
(0.46)\end{array}$ \\
\hline Flood Probability (midpoints) & 0.27 & 0.24 & $\begin{array}{l}0.02 \\
(0.05)\end{array}$ \\
\hline Age & 53.09 & 52.74 & $\begin{array}{l}0.34 \\
(2.25)\end{array}$ \\
\hline Household Income & 118.72 & 130.39 & $\begin{array}{l}-11.67 \\
(9.37) \\
\end{array}$ \\
\hline Education Index (1-9) & 6.92 & 7.00 & $\begin{array}{l}-0.08 \\
(0.31)\end{array}$ \\
\hline Household Size & 3.10 & 2.55 & $\begin{array}{l}0.55^{* * *} \\
(0.20)\end{array}$ \\
\hline Parcel Area (square feet) & 10,884 & 8,049 & $\begin{array}{l}2,835^{* * *} \\
(932)\end{array}$ \\
\hline Living Area (square feet) & 1,758 & 1,597 & $\begin{array}{l}161.1^{*} \\
(93.0)\end{array}$ \\
\hline $\begin{array}{l}\text { Flood Damages } \\
\% \text { of Perceived Home Value }\end{array}$ & $41.7 \%$ & $33.5 \%$ & $\begin{array}{l}8.2 \% \\
(6.3 \%)\end{array}$ \\
\hline $\begin{array}{l}\text { Flood Damages: } \\
\$ \text { '000's }\end{array}$ & 194.1 & 117.9 & $\begin{array}{l}76.2 \\
(51.0)\end{array}$ \\
\hline $\begin{array}{l}\text { Expectation of Gov't Assistance: } \\
\% \text { of Flood Damages }\end{array}$ & $15.1 \%$ & $10.6 \%$ & $\begin{array}{l}4.5 \% \\
(3.5 \%)\end{array}$ \\
\hline $\begin{array}{l}\text { Expectation of Insurance: } \\
\% \text { of Flood Damages }\end{array}$ & $63.1 \%$ & $50.3 \%$ & $\begin{array}{l}12.9 \% * * \\
(5.1 \%)\end{array}$ \\
\hline
\end{tabular}

and the average perceived flood risk is significantly lower than model-based estimates. ${ }^{24}$

With regards to flood risk perceptions, the survey provides evidence on two additional elements of the model. First, households that have experienced a naturally caused flood at their homes are significantly more likely to be concerned about flooding (see Online Appendix Figure A5). Second, coastal residents who are very worried about flooding are significantly more likely to plan on selling their homes within the next five years, as shown in Figure 4. ${ }^{25}$

24 A two-sided t-test for the mean perceived risk (0.21) and mean actual estimated risk (0.37) rejects the null of equal means with a p-value $<0.0001$. See Online Appendix for details.

25 Defining "very worried" as flood worry levels of 9 or 10 out of 10, the difference is significant with a p-value of 0.0375 for one-sided and 0.075 for two-sided t-test, respectively. 


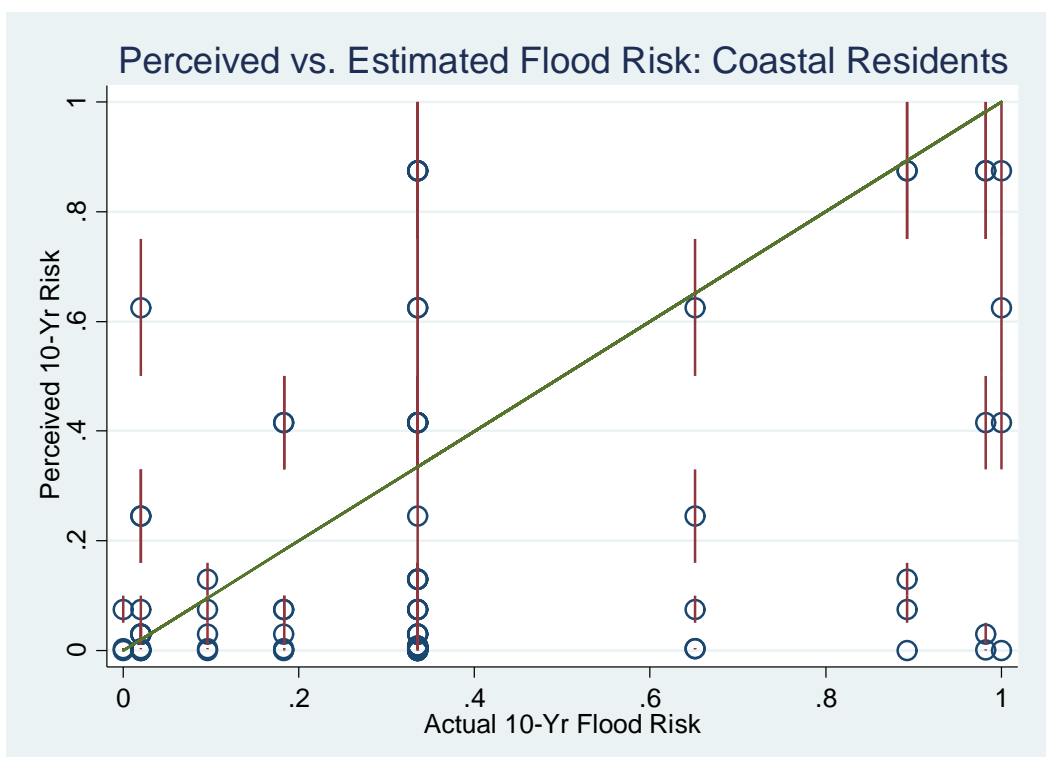

Figure 3: Perceived vs. Estimated Flood Risk. Note: Red lines span range of perceived 10-year flood risk probability (e.g., 5-10\%) on the y-axis, with blue circles marking the mid-points.

Both results are in line with the model's central mechanisms that households learn about flooding from past events, and are more likely to select out of coastal property markets as their flood risk perceptions increase.

The second main goal of the survey is to assess household-specific willingness-to-pay (WTP) for living within 400 feet of the waterfront. The survey question asks households about their WTP assuming that all other home attributes - including environmental risks - remain unchanged compared to their current homes. If households ask for clarification, surveyors were instructed to explain that this includes flood risks, and that the question asks strictly about the amenity value of living by the water without changes in flood risks or insurance requirements. Estimation details are presented in the Online Appendix.

Figure 5 plots the joint distribution of coastal amenity values and flood risk perceptions among coastal (circles) and non-coastal (x's) residents. The results indicate that selection into coastal homes is driven by a combination of higher amenity values and lower flood risk concerns, in line with the core mechanisms of the model. Figure 5 also provides a visual gauge on allocative inefficiency, which appears modest at present. 


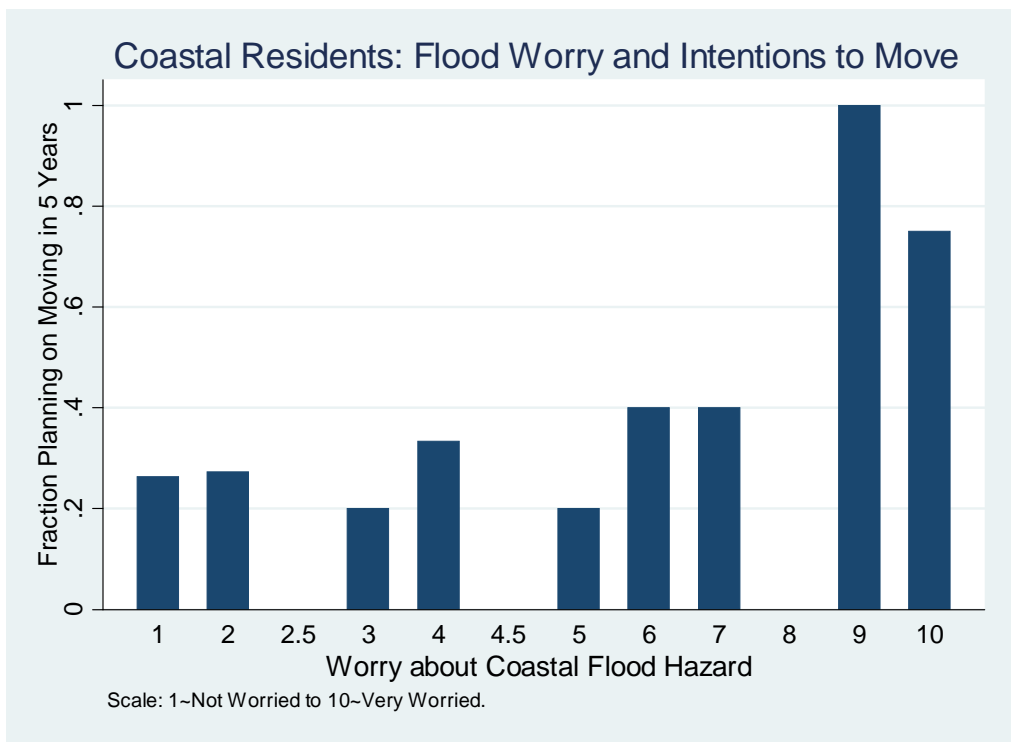

Figure 4: Flood Worry and Intentions to Move

With regards to risk belief types, we classify respondents as 'optimists' if they underestimate coastal 10-year flood risk by at least $\sim 50 \%$. Specifically, respondents are 'optimists' if their subjective coastal 10-year flood risk assessment is between $0-5 \%$. In fact, FEMA high flood risk zone residents' annual flooding probability is at least 1\%, implying a 10-year probability of at least one flood around $9.6 \% \cdot{ }^{26}$ While the mean of amenity values is slightly higher for optimists than for realists, the distributions appear sufficiently similar in the two populations that we maintain the assumption of equal $\xi$ distributions as a benchmark in the calibration below. The Online Appendix presents a further comparison of demographic and other variables between optimists and realists. They appear statistically indistinguishable on most dimensions. Prior literature has likewise found that demographics have little explanatory power over general housing market optimism (Pizzesi and Schneider, 2009). We return to this issue in the discussion of welfare effects in Section 5.2.

The final survey result is that the majority of respondents expect future flood risks to be at least "somewhat greater" than current risks. Figure 6 plots the distribution of these

$26 \quad$ While not all coastal homes in our sample are in a FEMA flood zone due to their elevation, other homes' risks exceed $1 \%$ per year. As we estimate the average annual flood risk for coastal homes in our sample to exceed $1 \%$ per year, using a $1 \%$ figure is thus conservative. 


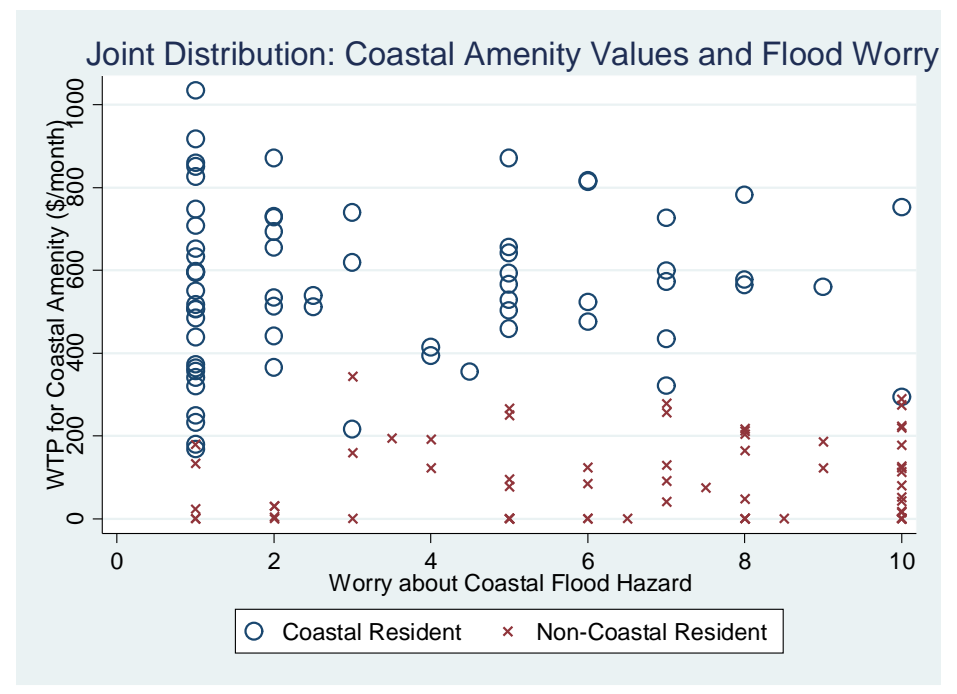

Figure 5: Joint Amenity Value and Flood Worry Distribution

beliefs across types. As expected, realists are more likely to assume higher future flood risk increases than optimists ${ }^{27}$ However, even the majority of optimists anticipates some increase in flood risks. Informed by these results, our model assumes that optimistic agents anticipate the possibility of a future flood risk increases and that they become Bayesian learners with some positive prior on the probability that sea level rise has occurred.

\section{$4 \quad$ Full Structural Model}

This section presents the remaining assumptions and the solution method employed to simulate future coastal home price trajectories across different scenarios.

\section{Flood Risk and Beliefs}

First, we assume that current flood risk is known to scientists. Realists adopt this official announcement as their belief. Optimists, in line with the survey, under-estimate current flood

$27 \quad$ One may be concerned about expectations of future public flood risk mitigation measures, such as sea walls. Our survey asked subjects expecting a change in future risk "Why do you think flood risk will change this way?" Only four respondents mention sea walls or construction as a reason why they expect flood risk to decrease in the future. Indeed, Rhode Island has state-wide regulations that prohibit or highly restrict the construction of new structural shoreline protection measures across many of the state's coastal areas (Rhode Island Coastal Resources Management Council, 2013; 2020). 


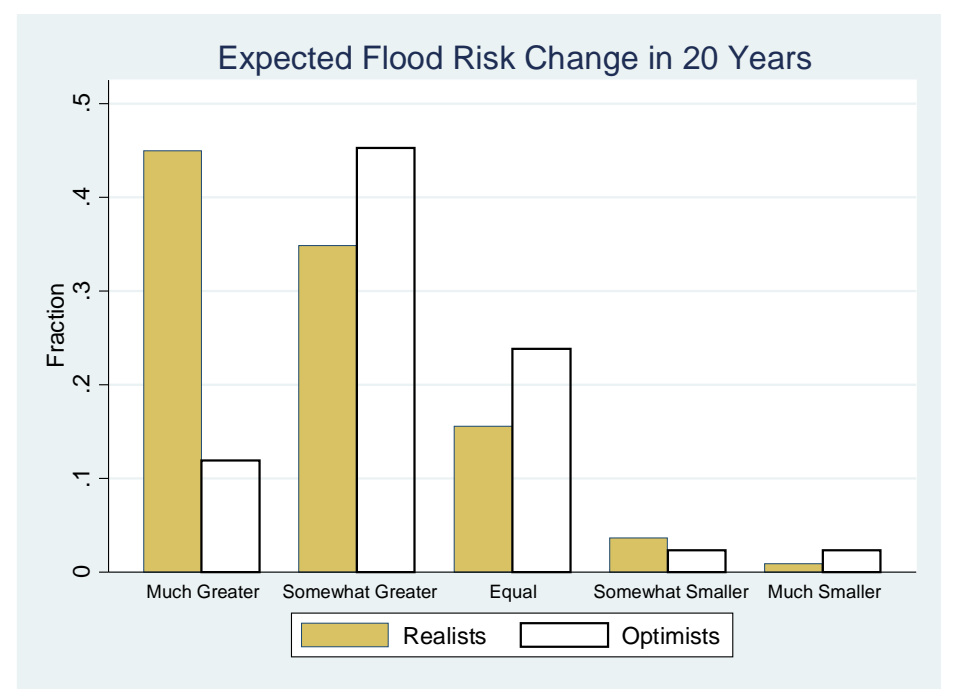

Figure 6: Future Flood Risk Expectations

risk. In the future, flood risk will change due to sea level rise. The level of future sea level rise is uncertain. The official scientific announcement is thus a probability distribution over future flood risk levels. This specification abstracts from deep uncertainty, which is discussed in Section 5.3. Realists form their expectations based on this official forecast. Optimists are aware but skeptical of the forecast. They hold a prior belief about the probability that flood risk will or has truly change(d) to the official distribution (level), and update their beliefs in the future as they observe whether flood events occur.

More formally, we assume that flood risk is initially at a low level $\pi_{0}^{*}=\pi^{L}$. We generally use an asterisk to denote the official or scientifically announced value. We discretize sea level rise as flood risk changing to random variable $\Pi_{1}$ at time $t=T_{1}$ and again to $\Pi_{2}$ at time $t=T_{2}>T_{1}$. The scientific forecast takes the form of a probability distribution $f(\boldsymbol{\pi})$ with $\boldsymbol{\pi}=\left\{\pi_{1}, \pi_{2}\right\}$. Due to the limited availability of estimates of conditional future flood risk increase distributions, we assume that, at time $T_{1}$, both $\pi_{1}$ and $\pi_{2}$ are learned ${ }^{28}$ Realists immediately update their beliefs in line with the scientific announcement ${ }^{29}$ Opti-

28 We were unable to find projections of the probability distribution of, e.g,. year 2050 flood risk increases conditional on year 2030 realizations. We thus assume that the percentile of the realization in 2030 also reveals the percentile of the 2050 realization.

29 Realists' beliefs are thus $E_{t}^{r}\left[\left\{\pi_{s}\right\}_{s=0}^{\infty}\right] \sim\left\{\pi^{L}\right.$ for $t<T_{1}, E_{0}^{*}\left[\Pi_{1}\right]$ for $T_{1} \leq t<T_{2}, E_{0}^{*}\left[\Pi_{2}\right]$ for $\left.t \geq T_{2}\right\}$ for $0 \leq t<T_{1}$, and update for $t \geq T_{1}$ to $E_{t}^{r}\left[\left\{\pi_{s}\right\}_{s=T_{1}}^{\infty}\right] \sim\left\{\pi_{1}\right.$ for $T_{1} \leq t<T_{2}, \pi_{2}$ for $\left.t \geq T_{2}\right\}$. 
mists assign a prior probability $0<q_{T_{1}}^{o}<1$ to the possibility that sea level rise is real and will begin happening at time $T_{1}$, but maintain that flood risk will remain at their initial belief level $\pi_{0}^{o}<\pi^{L}$ with positive probability $\left(1-q_{T_{1}}^{o}\right)$. Before sea level rise is realized, that is, at times $0 \leq t<T_{1}$, optimists expect that their future flood risk beliefs will update to $\left(q_{T_{1}}^{o}\right) E_{t}^{*}\left[\Pi_{1}\right]+\left(1-q_{T_{1}}^{o}\right)\left(\pi_{0}^{o}\right)$ at time $T_{1}$ and to $q_{T_{2}}^{o}\left(E_{t}^{*}\left[\Pi_{2}\right]\right)+\left(1-q_{T_{2}}^{o}\right)\left(\pi_{0}^{o}\right)$ at time $T_{2}$ (where they further initially expect that $q_{T_{1}}^{o}=q_{T_{2}}^{o}$ as discussed below). Our belief updating framework is an adaptation from Dieckmann (2011) for the present setting. As of time $T_{1} \leq t<T_{2}$, optimists' contemporaneous flood risk beliefs are given by $\pi_{t}^{o}=q_{t}^{o}\left(\pi_{1}\right)+\left(1-q_{t}^{o}\right)\left(\pi_{0}^{o}\right)$, and their expectations of future flood risk after time $T_{2}$ is given by $E_{t}^{o}\left[\pi_{T_{2}}\right]=q_{t}^{o}\left(\pi_{2}\right)+\left(1-q_{t}^{o}\right)\left(\pi_{0}^{o}\right)$, again reflecting the notion that $q_{t}^{o}$ captures their belief that sea level rise is real and that flood risk is changing as per the scientific announcement. Note that we use lower case letters for flood risks after sea level rise has been observed (after $T_{1}$ ), but that flood risk beliefs remain uncertain. In line with the empirical literature, the optimists' beliefs are updated each period based on whether or not flood events occur:

$$
\begin{aligned}
& \left.q_{t+1}^{o}\right|_{\text {Flood }=1}=\operatorname{Pr}\left(\pi_{1} \mid \text { Flood }=1\right)=\frac{\pi_{1} \cdot q_{t}^{o}}{\pi_{1} q_{t}^{o}+\left(1-q_{t}^{o}\right) \pi_{0}^{o}} \\
& \left.q_{t+1}^{o}\right|_{\text {Flood }=0}=\operatorname{Pr}\left(\pi_{1} \mid \text { Flood }=0\right)=\frac{\left(1-\pi_{1}\right) \cdot q_{t}^{o}}{\left(1-\pi_{1}\right) q_{t}^{o}+\left(1-q_{t}^{o}\right)\left(1-\pi_{0}^{o}\right)}
\end{aligned}
$$

While the benchmark specification assumes rational Bayesian updating, the Online Appendix shows that the results are robust to a behavioral extension introducing an overreaction parameter to better match the empirical literature's evidence on the speed at which, e.g., insurance demand responds to flood events (Gallagher, 2014).

With regards to higher order beliefs, our benchmark assumption is that realists have rational higher order expectations of optimists' belief changes, meaning they take into account that, in each future period $t+j$ a flood will occur with probability $E_{t}^{r}\left[\Pi_{t+j}\right]$ and change optimists' beliefs according to (19). We stress two aspects of this assumption. First, it is conservative in that more rationality should generally lead us to predict less mispricing of 
coastal homes. Second, this assumption does not imply that realists know optimists' future beliefs - only that they understand optimists' updating rules. In contrast, optimists expect that they will update their beliefs at time $T_{1}$ but do not anticipate subsequent belief changes correctly, including with regards to their expectations of realists' future beliefs about their (optimists') flood risk perceptions. Together, the benchmark case thus implies that, for example, at $T_{1} \leq t<T_{2}$ (after new sea levels are observed):

$$
\begin{aligned}
E_{t}^{o}\left[\pi_{t+1}^{o}\right]= & \pi_{t}^{o} \\
E_{t}^{r}\left[\pi_{t+1}^{o}\right]= & \pi_{t}^{r}\left[\left(\left.q_{t+1}^{o}\right|_{\text {Flood }=1}\right)\left(\pi_{1}\right)+\left(1-\left.q_{t+1}^{o}\right|_{\text {Flood }=1}\right)\left(\pi_{0}^{o}\right)\right] \\
& +\left(1-\pi_{t}^{r}\right)\left[\left(\left.q_{t+1}^{o}\right|_{\text {Flood }=0}\right)\left(\pi_{1}\right)+\left(1-\left.q_{t+1}^{o}\right|_{\text {Flood }=0}\right)\left(\pi_{0}^{o}\right)\right]
\end{aligned}
$$

While contemporaneous flood risk beliefs are common knowledge, agents may thus have different expectations of how optimists' beliefs will evolve in the future. We again stress that these are likely conservative assumptions. If, instead, we assumed that realists failed to anticipate optimists' potential future learning about higher flood risks, they may overestimate optimists' future willingness-to-pay for vulnerable properties, and thus the re-sale price of coastal homes, further contributing to contemporaneous overvaluations.

\section{Solving the Model}

We solve for pricing dynamics through backwards iteration. We assume that effective flood risk beliefs will not diverge indefinitely. Over our model horizon of interest, arguably the most likely and interesting scenario forcing effective belief convergence is reform of the National Flood Insurance Program (NFIP). Congress enacted NFIP in 1968 due to rising damages from flooding and limited private market insurance penetration. To this day, NFIP remains the dominant insurer for flooding in the United States, with more than five million policies in force as of January 2017 covering more than $\$ 1.2$ trillion of property and contents (FEMA, 2017; Moore, 2017). NFIP is, however, considered fiscally unsustainable and has been labeled 
as a "high risk" program due its failure to charge actuarially fair rates for many policies (GAO, 2017). One in five policies has traditionally been subsidized, charging less than half of full risk levels on average (CBO, 2014). The extent to which even full risk rates are actuarially fair is moreover an open question (CBO, 2014). The Biggert-Waters Flood Insurance Reform Act of 2012 sought to bring the program closer into fiscal balance through insurance subsidy phase-outs and immediate price increases (FEMA, 2013). However, due to concerns over homeowner impacts, the Homeowner Flood Insurance Affordability Act of 2014 partially repealed and modified Biggert-Waters. Looking toward the future, however, a move towards real risk rates and more strictly enforced insurance mandates is highly likely.

In theory, a fully enforced flood insurance requirement would force all agents - regardless of their actual beliefs - to internalize flood risks at the probability implied by the insurance rate. In the context of our linear utility model, policy reform mandating actuarially fair insurance is thus equivalent to a convergence of effective flood risk beliefs towards their true values 30 We formally assume that, at some future time $T$, effective flood risk beliefs will converge to true risk values ${ }^{31}$ We stress again that we do not assume that actual beliefs converge, but only that flood insurance mandates will be enforced. Our approach also does not need to assume that insurance rates will be actuarially fair or reflect true probabilities. Even if continued climate change after the policy reform period were to remain uncertain, our approach would be valid as long as agents' expectations of insurance rates align after the policy reform. Indeed, we set up the model to permit continued sea level rise after insurance reform, so that we assume $T_{1}<T<T_{2}$, meaning that some sea level rise occurs before and some after insurance reform. At time $T-1$ the realists and optimists each hold expectations over the announced schedule of current and future flood risks or insurance rates, $E_{T-1}^{r}\left[\boldsymbol{\pi}^{*}\right]$

30 Alternatively, one might also argue that, in the very long run, flood risk beliefs must converge as sea levels continue to rise to the point of making annual flood risks undeniable (approaching unity as sea levels rise to reach current coastal properties).

31 Implicit in this setup is the assumption that the timing of policy reform is known, which is obviously an abstraction. Section 5.3 shows that the main quantitative results are not sensitive to changing the assumed date $T$. Eliciting beliefs and extending the model to formally consider uncertainty and disagreement about policy reform would be an interesting area for future work. 
and $E_{T-1}^{o}\left[\boldsymbol{\pi}^{*}\right]$, respectively, where $\boldsymbol{\pi}^{*}=\left\{\pi_{T}^{*}, \pi_{T_{2}}^{*}\right\}$. Note that this formulation assumes that period $T-1$ is after period $T_{1}$ when sea level rise is first observed.

Given assumptions about beliefs, it is straightforward to solve for time $T-1$ prices. Once $\boldsymbol{\pi}^{*}$ becomes common knowledge, both optimists and realists will be in the market for coastal property and the marginal buyer will consequently be the one with the $k_{1}^{\text {st }}$ amenity value $\bar{\xi}=\Xi\left(1-k_{1}\right)$. Consequently, at time $T-1$, realists expect the price of coastal homes at time $T$ and thereafter to be given by the stationary solution to (2) adjusted for changes in flood risk between times $T$ and $T_{2}$. If there are $n=T-T_{2}$ periods after insurance reform and before continued sea level rise, this expectation will be:

$$
E_{T-1}^{r}\left[P_{T}\right]=\sum_{j=0}^{n-1} \beta^{j+1}\left[e^{h}+\Xi\left(1-k_{1}\right)-E_{T-1}^{r}\left[\pi_{T}^{*}\right] \delta\right]+\frac{\beta^{n+1}\left[e^{h}+\Xi\left(1-k_{1}\right)-E_{T-1}^{r}\left[\pi_{T_{2}}^{*}\right] \delta\right]}{(1-\beta)}
$$

Optimists reason analogously, but with a potentially different expectation over the flood risk announcement $E_{T-1}^{o}\left[\boldsymbol{\pi}^{*}\right]$ defining $E_{T-1}^{o}\left[P_{T}\right]$. Given both groups' price expectations, condition (12) determines the identity of the marginal buyer at $T-1$. In particular, if:

$$
\Xi \frac{k_{1}}{\theta^{o}}+\left\{E_{T-1}^{r}\left[P_{T}\right]-E_{T-1}^{o}\left[P_{T}\right]\right\}<\delta\left(\pi_{T-1}^{r}-\pi_{T-1}^{o}\right)
$$

only optimists are in coastal real estate (Case 1 ) at $T-1$ and the market-clearing price is:

$$
P_{T-1}=\beta\left(e^{h}+\Xi\left(1-\frac{k_{1}}{\theta^{o}}\right)-\pi_{T-1}^{o} \delta+E_{T-1}^{o}\left[P_{T}\right]\right)
$$

If (22) does not hold, both types are in the market (Case 2) and the $T-1$ price solves:

$$
\begin{aligned}
P_{T-1} & =\beta\left(e^{h}+\bar{\xi}_{T-1}^{o}-\pi_{T-1}^{o} \delta+E_{T-1}^{o}\left[P_{T}\right]\right) \\
\bar{\xi}_{T-1}^{o} & =\Xi\left(1-k_{1}\right)-\delta\left(1-\theta^{o}\right)\left(\pi_{T-1}^{r}-\pi_{T-1}^{o}\right)+\left(1-\theta^{o}\right)\left\{E_{T-1}^{r}\left[P_{T}\right]-E_{T-1}^{o}\left[P_{T}\right]\right\}
\end{aligned}
$$

Next, consider $P_{T-2}$ to illustrate the process of finding prices further back in time. For 
illustration assume that $T-2 \geq T_{1}$ so that the true extent of sea level rise is known at time $T-2$. The identity of the marginal buyer then again depends on whether:

$$
\Xi \frac{k_{1}}{\theta^{o}}+\left\{E_{T-2}^{r}\left[P_{T-1}\right]-E_{T-2}^{o}\left[P_{T-1}\right]\right\}<\delta\left(\pi_{T-2}^{r}-\pi_{T-2}^{o}\right)
$$

Importantly, however, each type's expectation of next period prices now depends on his expectation of his own and others' expectations about flood risk beliefs in subsequent periods. For example, the realists' prediction at time $T-2$ of the coastal price at time $T-1$ depends on their expectation over who the marginal buyer will be at $T-1$, which, in turn, depends on their time $T-2$ expectation of the marginal buyer condition (22). That is, if:

$$
\left[\Xi \frac{k_{1}}{\theta^{o}}+\left\{E_{T-2}^{r}\left[E_{T-1}^{r}\left[P_{T}\right]\right]-E_{T-2}^{r}\left[E_{T-1}^{o}\left[P_{T}\right]\right\}<\delta\left(E_{T-2}^{r}\left[\pi_{T-1}^{r}\right]-E_{T-2}^{r}\left[\pi_{T-1}^{o}\right]\right)\right]\right.
$$

then the realists at time $T-2$ expect that optimists will dominate the coastal housing market at time $T-1$, and will expect prices to be determined by their $T-2$ expectation of $(23)$ :

$$
E_{T-2}^{r}\left[P_{T-1}\right]=\beta\left(e^{h}+\Xi\left(1-\frac{k_{1}}{\theta^{o}}\right)-E_{T-2}^{r}\left[\pi_{T}^{o}\right] \delta+E_{T-2}^{r}\left[E_{T-1}^{o}\left[P_{T}\right]\right]\right)
$$

If inequality (26) does not hold, realists expect that both types will be in the coastal housing market in the next period, and $E_{T-2}^{r}\left[P_{T-1}\right]$ is given by the realists' time $T-2$ expectations of (24) and (21). Analogous calculations for optimists yield their time $T-2$ expectations of re-sale prices at time $T-1, E_{T-2}^{o}\left[P_{T-1}\right]$. Given each type's respective price expectations, we can then use (25) to identify the marginal buyer at time $T-2$, and solve for the marketclearing $P_{T-2}$ accordingly. We solve for prices at earlier times $T-n$ analogously through backwards iteration through the relevant expectation matrices. On the one hand, accounting for dynamic belief heterogeneity in a non-stationary setting thus clearly introduces a curse of dimensionality which limits our ability to consider a richer set of belief types ${ }^{32}$ On the

32 Calculating the $P_{T-n}$ price requires iteratively imputating $2 \times\left(\sum_{k=0}^{n-1} 2\left(2^{k}\right)\right)-2$ expectations. 
other hand, however, our setup enables us to compute equilibrium price dynamics while flexibly accounting for different belief and policy reform structures, in a setting that strictly generalizes the benchmark homogeneous beliefs framework.

\section{Policy Reform Beliefs}

The last element is to specify agents' beliefs about enforced policy rates after time $T$. Realists are assumed to adopt the scientifically forecast probability distribution of sea level rise and then update to the relevant flood risk realizations:

$$
E_{t}^{r}\left[\pi_{T}^{*}\right]=\left\{\begin{array}{cl}
E_{t}^{*}\left[\Pi_{1}\right] & \text { if } t<T_{1} \\
\pi_{1} & \text { if } t \geq T_{1}
\end{array}, E_{t}^{r}\left[\pi_{T_{2}}^{*}\right]=\left\{\begin{array}{cc}
E_{t}^{*}\left[\Pi_{2}\right] & \text { if } t<T_{1} \\
\pi_{2} & \text { if } t \geq T_{1}
\end{array}\right.\right.
$$

For optimists, our benchmark assumption is that they believe that enforced rates after time $T$ will correspond to a weighted average of beliefs at the time:

$$
\begin{aligned}
E_{t}^{o}\left[\pi_{T}^{*}\right]= & \left(\omega^{o}\right) E_{t}^{o}\left[\pi_{T}^{o}\right]+\left(1-\omega^{o}\right) E_{t}^{r}\left[\pi_{T}^{r}\right] \\
& =\left\{\begin{array}{cc}
\left(\omega^{o}\right)\left[q_{T_{1}}^{o}\left(E_{t}^{*}\left[\Pi_{1}\right]\right)+\left(1-q_{T_{1}}^{o}\right)\left(\pi_{0}^{o}\right)\right]+\left(1-\omega^{o}\right) E_{t}^{*}\left[\Pi_{1}\right] & \text { if } t<T_{1} \\
\left(\omega^{o}\right)\left[q_{t}^{o}\left(\pi_{1}\right)+\left(1-q_{t}^{o}\right)\left(\pi_{0}^{o}\right)\right]+\left(1-\omega^{o}\right) \pi_{1} & \text { if } t \geq T_{1}
\end{array}\right.
\end{aligned}
$$

The optimists' expectation of $E_{t}^{o}\left[\pi_{T_{2}}^{*}\right]$ is analogous to (27). Our benchmark assumption is that optimists consider the population-weighted average $\left(\omega^{o}=\theta^{o}\right)$, but our quantitative analysis considers two polar alternatives as well $\left(\omega^{o}=0, \omega^{o}=1\right)$.

\subsection{Model Calibration}

\section{Flood Risk Changes}

We quantify future flood risk changes based on probabilistic sea level rise projections by Kopp et al. $(2014,2017)$ and of corresponding flood risk amplification factors (AF) estimated by Buchanan et al. (2017). These studies are widely used in both policy and academic analy- 
ses ${ }^{33}$ For Newport, RI, Kopp et al. (2014) project median sea level rise of $20 \mathrm{~cm}$ by 2030 and $38 \mathrm{~cm}$ by 2050 (with a 5-95\% range of $19-56 \mathrm{~cm}$, values relative to 2000). Buchanan et al. (2017) estimate joint probability distributions over sea level rise and flood frequencies to generate probabilistic estimates of the corresponding 100-year flood risk amplification factors. Importantly, in contrast with scenario-based approaches focusing on median outcomes, their estimates of expected values for each location account for positive skew in the underlying distributions, such as in sea level rise distributions arising due to uncertainty over Antarctic ice sheet contributions (Buchanan et al., 2017). By 2050, in a business-as-usual or high greenhouse gas emissions scenario (the Representative Concentration Pathway (RCP) 8.5, Van Vuuren et al., 2011), the expected frequency increase of what used to be 100-year floods is projected to increase 11.5 -fold (with a 5-95\% range of 1.5-22.2). Consideration of other locations reveals that this increase is comparatively modest: Buchanan et al. (2017) estimate a median 2050 expected 100-year flood risk amplification factor of around 40 across tidal gauge locations in the contiguous United States. We extend our model to other locations in Section 6. Our sensitivity analysis also showcases results under a global climate policy scenario with moderate emissions (RCP 4.5). In Newport, RI, the expected flood risk amplification factor by 2050 in this scenario falls to 7.4 (5-95\% range $1.3-15.0)$.

In our model, we discretize sea level rise as increasing flood risk in 2030 and 2050. We interpolate flood risk amplification by 2030 exponentially based on the decadal sea level rise projections from Kopp et al. (2017) and both 2050 and subsequent flood risk AF projections of Buchanan et al. (2017) ${ }^{34}$ For Newport, RI, this yields a 2030 mean amplification factor of 4.79 (RCP 8.5). Given that the sea level rise projections are relative to the year 2000, we use the same procedure to correct for flood risk increases that have already occurred by

33 For example, the estimates of Kopp et al. (2014) are routinely used in government analyses of sea level rise (e.g., NOAA, 2017a; EPA, 2017) and also in economic studies (e.g., Desmet et al., 2020).

34 Separately for each city, we first use SLR and mean flood risk AF projections for times 2050 and 2100 for scenarios RCP 8.5 and 4.5, respectively, from Buchanan et al. (2017) as "data" to estimate $\ln \left(A F_{t}-1\right)=\beta_{0}+\beta_{1} \ln S L R_{t}$. We then use 2030 sea level rise projections for each location and scenario (from Kopp et al., 2017) to infer $\widehat{A F_{2030}}=e^{\widehat{\beta_{0}}} S L R^{\widehat{\beta_{1}}}+1$. 
Table 2: Benchmark Model Calibration

\begin{tabular}{|c|c|c|c|}
\hline \multicolumn{2}{|c|}{ Parameter } & Value & Source \\
\hline$k_{1}$ & Share of coastal homes & 0.145 & $\begin{array}{l}\text { Authors' calculation from RIGIS properties } \\
\text { and coastline (Bristol, Kent, Newport counties) }\end{array}$ \\
\hline$\theta^{\circ}$ & Share of optimists & 0.35 & Survey: Share estimating $\pi_{10 y r}^{\text {Flood }}<5 \%$ \\
\hline$\Xi$ & Max. coastal amenity $\xi(\$ /$ yr $)$ & $\$ 7.7 \mathrm{k}$ & $\begin{array}{l}\text { Survey: Max WTP within } 10 \% \text { of } \\
\text { median coastal home price }\end{array}$ \\
\hline$\delta$ & Flood damages $(\$)$ & $\$ 82 \mathrm{k}$ & Survey: Med. damage/price $\times$ Med. price \\
\hline$e^{h}$ & Net value of own home living & Variable & Match initial med. coastal home price $\$ 410 \mathrm{k}$ \\
\hline$\beta$ & Annual discount factor & 0.96 & \\
\hline$\pi_{L}$ & Initial annual flood risk & $1.21 \%$ & FEMA benchmark adjusted to 2017 SLR \\
\hline$E_{0}^{*}\left[\Pi_{1}\right]$ & $\begin{array}{l}\text { Expected annual flood risk } \\
\text { as of } 2030\end{array}$ & $4.79 \%$ & $\begin{array}{l}\text { Interpolated from Buchanan et al. (2017), } \\
\text { Kopp et al. (2014) }\end{array}$ \\
\hline$E_{0}^{*}\left[\Pi_{2}\right]$ & $\begin{array}{l}\text { Expected annual flood risk } \\
\text { as of } 2050\end{array}$ & $11.5 \%$ & Buchanan et al. (2017) \\
\hline$T$ & Policy reform period & 2041 & \\
\hline$\overline{q_{T_{1}}^{o}}$ & Optimists' prior on sea level rise & 0.1 & \\
\hline$\pi_{0}^{o}$ & Optimists' initial flood risk belief & $0.5 \cdot \pi^{L}$ & $\begin{array}{l}50 \% \text { below official value in line with } \\
\text { with optimist definition from survey }\end{array}$ \\
\hline
\end{tabular}

our model base year ${ }^{35}$ Finally, while we treat the probability distribution of sea level rise outcomes as known, we discuss concerns over deep uncertainty in Section 5.3 .

\section{Calibration Summary}

This section presents our calibration. Table 2 summarizes the benchmark parameters.

Some points should be noted. First, we select the net value of living in an owner-occupied home $e^{h}$ to match the initial median coastal home price $(\$ 410 \mathrm{k})$ at our benchmark parameters. Second, we set the utility discount rate to $4 \%$ per year, matching recent literature (e.g., Favilukis and Van Nieuwerburgh, 2018; Glaeser and Nathanson, 2017; Head et al., 2014; Glaeser et al., 2014). Third, while the calibration makes arbitrary assumptions about the number and timing of future flood events, these do not affect the main results as current prices

35 This adjustment is for $10 \mathrm{~cm}$ SLR as per NOAA data for Newport, RI (2017 mean), yielding a flood amplification factor of 1.21. We apply this factor to our base 100 -year flood risk level of $1 \%$ as per standard FEMA designation to compute the initial flood risk. Importantly, however, we maintain $1 \%$ as reference number when computing the share of optimists in the population. 
and fundamental values depend only on expectations of storm events (see Table 5). For computational reasons, we run the model with one period corresponding to two calendar years, and adjust the relevant calibration parameters accordingly. Finally, the benchmark share of optimists represents a re-weighted average of the survey population to correct for over-sampling of coastal homes.

\section{$5 \quad$ Quantitative Results}

\subsection{Main Results}

Figure 7 presents the main results for the benchmark calibration with sea level rise realizations matching their expected values in a business as usual or high emissions climate scenario (RCP 8.5). We run the model varying the percentage of optimists from $0 \%$ to $45 \%$, including our benchmark estimate of $\theta^{\circ}=35 \%$. The first central finding is that flood risk underestimation leads to a significant overvaluation of coastal homes compared to their fundamental value (black line with stars) implied by the homogeneous rational beliefs model. Our benchmark estimates imply that current prices exceed fundamentals by $13 \%$. Economically, an overvaluation of this magnitude would be highly significant.

Before proceeding, we note two 'tests' of the model. First, the model's projected initial non-coastal housing price of $\$ 319 \mathrm{k}$ matches our sample average of $\$ 324 \mathrm{k}$ very closely, despite being a non-targeted moment. Second, the model's predicted relative change in coastal versus inland housing prices after the future storm event of -9.6 percent aligns very well with the empirical literature's difference-in-differences estimates of storm impacts on relative prices ranging from -5 to -20 percent (e.g., Hallstrom and Smith, 2005; Kousky, 2010; Bin and Landry, 2013; Ortega and Taspinar, 2018) ${ }^{36}$

$36 \quad$ Conceptually, the model only pins down the difference between coastal and non-coastal housing prices. This is because the price of houses - which are in fixed supply - is determined by their differential value 


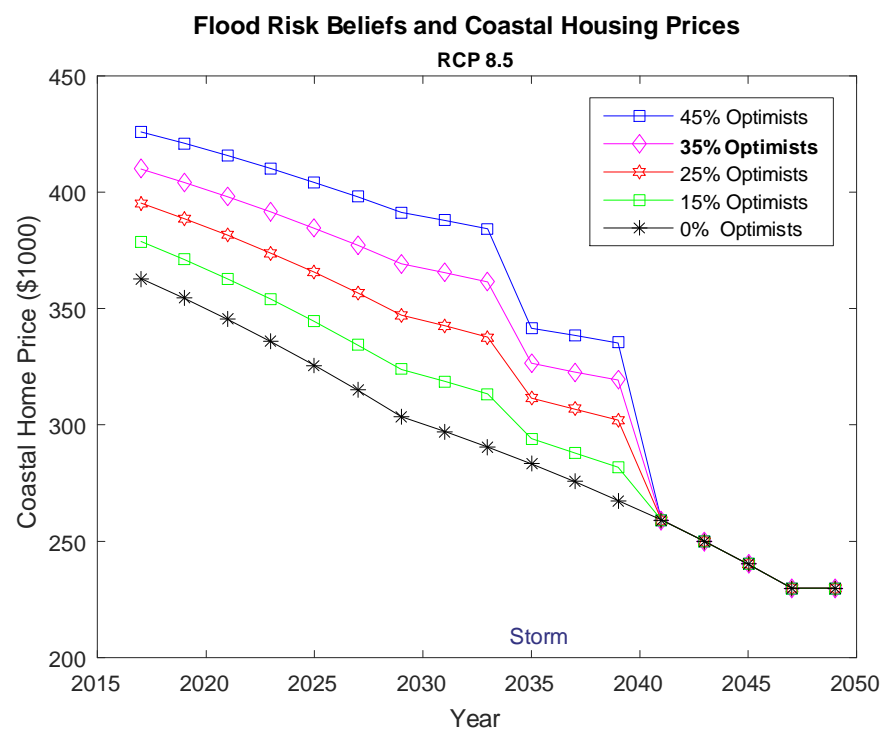

Figure 7: Flood Risk Beliefs and Housing Prices

The scenarios featured in Figure 7 assume that sea level rise matches its expected values. We next consider alternate realizations. Figure 8 showcases projected coastal housing prices and fundamental values in our benchmark setting $\left(\theta^{\circ}=35 \%\right)$ for SLR realizations ranging from their 5 th to 95 th percentile ${ }^{37}$ The range of projected medium-run outcomes is wide, ranging from coastal homes becoming worthless to gaining substantially in value if SLR turns out to be less severe than anticipated. Importantly for our purposes, however, we note two points. One, the initial overvaluation results are unchanged as depend only on expectations of future SLR (note that we consider uncertainty over SLR distributions in Section 5.3). Two, overvaluation persists across different future SLR realizations. By 2033, for example, while the 5 th percentile outcome yields an overvaluation of only about $1 \%$, in the 95th percentile of flood risk increases, the overvaluation reaches over 1,000\% as the fundamental

above and beyond the outside option of renting. For non-coastal homes, this value does not change. For coastal homes, it does due to changes in flood risk and marginal buyer amenity values.

37 We take the flood risk amplification factors for 2050 as the 5th and 95th percentiles estimated by Buchanan et al. (2017). For 2030, the 5th percentile SLR estimate in the underyling Kopp et al. (2014) framework was $8 \mathrm{~cm}$ above 2000 levels, which has already been reached by 2017. We consequently assume zero additional flood risk increase by 2030 above 2017 levels for the 5 th percentile. For the 95 th percentile Kopp et al. (2014) project 33cm of SLR by 2030 under RCP 8.5. Buchanan et al. (2017) estimate a flood risk amplification factor of 15 associated with $34 \mathrm{~cm}$ of SLR in another scenario. We thus adopt 15 as the relevant 2030 flood risk amplification factor for the 95th percentile. 
value collapses but prices are projected to remain high for a number more years.

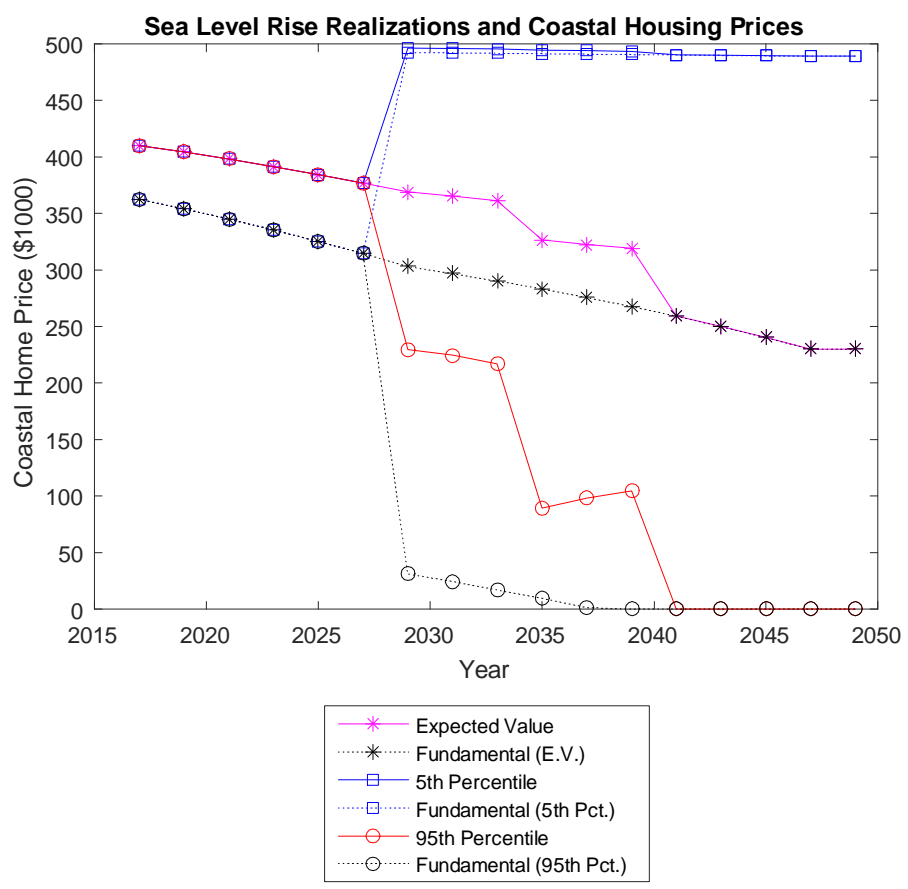

Figure 8: Sea Level Rise Realizations and Coastal Housing Prices

In sum, the results indicate that benchmark flood risk misperceptions may be contributing to an economically significant overvaluation of coastal homes relative to their fundamental value, preventing housing assets from fully reflecting climatic risks.

\subsection{Welfare}

This section describes both the efficiency costs and some distributional consequences of flood risk misperceptions and insurance reform. Within the context of our framework, the only efficiency cost associated with mispricing is the allocative inefficiency of realists with high amenity values being priced out of coastal markets. That is, a utilitarian social planner would allocate coastal homes to the optimists and realists with the $k_{1}$ highest valuations, equating the marginal buyers' valuations at the optimum $\left(\bar{\xi}^{o, *}=\bar{\xi}^{r, *}=\Xi\left(1-k_{1}\right)\right)$. In contrast, allocative inefficiency from belief heterogeneity occurs whenever the marginal realist's 
valuation exceeds that of the marginal optimist (i.e., $\bar{\xi}_{t}^{r}>\bar{\xi}^{r, *}$ and $\bar{\xi}_{t}^{o}<\bar{\xi}^{o, *}$ ). Let $q_{t}^{i}$ denote the quantity of coastal housing consumed by group $i$ in period $t$, which equals $q_{t}^{o}=\frac{\theta^{o}}{\Xi}\left(\Xi-\bar{\xi}_{t}^{o}\right)$ for optimists and $q_{t}^{r}=\frac{\left(1-\theta^{o}\right)}{\Xi}\left(\Xi-\bar{\xi}_{t}^{r}\right)$ for realists. The net loss in consumer surplus $C S_{t}$ from coastal housing in period $t$ due to belief heterogeneity is then given by:

$$
\Delta W_{t} \equiv C S_{t}^{*}-C S_{t}=\int_{q^{*, o}}^{q_{t}^{o}}\left[\Xi-\frac{\Xi}{\theta^{o}} q\right] d q-\int_{q_{t}^{r}}^{q^{*, r}}\left[\Xi-\frac{\Xi}{\left(1-\theta^{o}\right)} q\right] d q
$$

Brunnermeier, Simsek, and Xiong (2014) develop a belief-neutral efficiency welfare criterion for settings where beliefs are distorted and heterogeneous, but where the social planner does not know the objective belief. Intuitively, the criterion asks the planner to consider all convex combinations of reasonable beliefs. On the one hand, our setting differs from theirs in that we generally assume that flood risk is scientifically estimable rather than unknown, or that excessively low flood risk beliefs are not in the set of reasonable beliefs. Importantly, however, our welfare cost calculation (28) does not actually depend on whether the social planner adopts the realists' or optimists' beliefs. That is, even if a utilitarian social planner agreed with the optimists, he would perceive an allocative inefficiency cost from realists' excessively pessimistic beliefs keeping some with high coastal amenity valuations away from the water. The equilibrium allocation with heterogeneous beliefs is thus inefficient even in the belief-neutral welfare criterion sense of Brunnermeier, Simsek, and Xiong (2014).

Table 3 summarizes the allocative inefficiency costs on a per household basis, computed specifically as the present value of the flow costs (28) until policy reform ${ }^{38}$ The benchmark costs are estimated at $\$ 555$ per household $(\$ 2017)$ - a modest amount, although it should be noted that this is the average net cost across all households, not just those relocated due to flood risk optimism. For the whole of Bristol and Newport counties, the projected welfare costs thus amount to over $\$ 70$ million. Alternative assumptions for the maximum coastal amenity value $(\Xi)$ - set at either our hedonic regression estimate $(\$ 3.9 k / y r$, see Section 5.3$)$, or at the 75 th percentile of coastal residents in our survey $(\$ 8.5 k / y r)$ - only modestly affect

\footnotetext{
38 The Online Appendix presents a visualization of the allocative inefficiency over time.
} 
this estimate as higher losses for realists are partly offset by higher gains for optimists. In contrast, enacting flood insurance reform sooner than in the benchmark reduces the efficiency cost by more than half. Finally, Table 3 also shows that global climate policy can cut the allocative efficiency by almost $80 \%$.

\begin{tabular}{|l|l|}
\hline \multicolumn{2}{|l|}{ Table 3: Allocative Inefficiency Costs } \\
\hline \hline Scenario & Per Household Net Costs \\
\hline Benchmark $(\Xi=\$ 7.7 k)$ & $\$ 555$ \\
Lower Amenity Value $\Xi=\$ 3.9 k$ & $\$ 373$ \\
Higher Amenity Value $\Xi=\$ 8.5 k$ & $\$ 597$ \\
Early Insurance Reform $T=2035$ & $\$ 223$ \\
Global Climate Policy RCP 4.5 & $\$ 118$ \\
\hline
\end{tabular}

Underlying these aggregate effects are large distributional consequences. Table 4 illustrates the effects of immediate insurance reform for three key types of agents. First, "Realists in Waiting " are realists who currently live away from the coast but who would be living by the waterfront with efficient risk pricing. Second, "Hot Potato Sellers" are realists who currently live in coastal homes but will, with continued mispricing, sell their homes to an optimist before prices adjust (in line with our survey results). Third "Hot Potato Buyers" are optimists who currently live away from the coast but who would buy a coastal home in the future in the absence of insurance reform. We compare welfare for each agent in a variant of our benchmark scenario to one with immediate (year 2020) surprise insurance reform 39 The results show that the biggest winners are the "Hot Potato Buyers" who would go on to buy coastal property at inflated prices in the absence of policy reform. For example, a currently non-coastal optimist with a coastal amenity value of $\$ 376$ per month would gain over $\$ 47 \mathrm{k}$ in present value from avoided losses (net of coastal amenity benefits) as a result of the reform. Conversely, some of the biggest losers are the "Hot Potato Sellers" who would no

$39 \quad$ We specifically consider the present discounted value of realized (ex-post) utility in a scenario assuming zero flood events over the model time horizon (to ensure a clean comparison of the welfare effects of price and location adjustments alone) and that sea level rise takes its expected value. 
longer be able to sell their homes at above-fundamental value after the reform. For example, a currently coastal realist with a coastal amenity value of $\$ 563$ is projected to lose over $\$ 24 \mathrm{k}$ from immediate reform.40 Currently inland realists, in contrast, who are priced out of the market by coastal optimists, would gain substantially from insurance reform.

Table 4: Distributional Effects of Insurance Reform

\begin{tabular}{|c|c|c|c|c|c|}
\hline & & Location & & Coastal & Insurance \\
\hline Type & Initial & Interim & Post-Reform & Amenity ( $\$ /$ month) & Reform $\Delta W$ \\
\hline Realist in Waiting & Non-Coastal & Non-Coastal & Coastal & $\$ 549$ & $+\$ 34.2 \mathrm{k}$ \\
\hline Hot Potato Seller & Coastal & Non-Coastal & Coastal & $\$ 563$ & $-\$ 24.2 \mathrm{k}$ \\
\hline Hot Potato Buyer & Non-Coastal & Coastal & Non-Coastal & $\$ 376$ & $+47.1 \mathrm{k}$ \\
\hline
\end{tabular}

Displays change in present value of utility comparing a scenario with immediate (2020) insurance reform with delayed

(2041) reform. Considers realized utility assuming no storm events and sea level rise at expected values for each scenario.

Before proceeding, we address some potential caveats to our welfare calculations. First, our analysis assumes that inaccurate flood risk beliefs represent an informational distortion. Under certain behavioral models, however, agents might optimally choose to hold inaccurate beliefs. For example, Brunnermeier and Parker (2005) find that, if agents maximize the expected time-average of their felicity, they may optimally choose to hold excessively optimistic beliefs. Intuitively, agents trade off anticipatory utility from thinking positively about the future against the cost of the decision errors that result from holding inaccurate beliefs ${ }^{41}$ To the extent that inaccurate beliefs represent an optimal choice, our welfare cost estimates may be an overestimate. While preferences may certainly play a role in driving sorting into high-risk locations, we note several reasons why this is unlikely to be the only factor in our setting. First and foremost, the empirical evidence on how agents respond to

$40 \quad$ We note that current coastal home owners who are projected to stay in their homes regardless of the policy scenario are not counted as suffering the "loss" of a price correction due to insurance reform since this reflects a reduction in fundamental value due to sea level rise. That is, in the long run, price are assumed to reflect fundamental values in both scenarios.

41 Rational expectations would still be optimal beliefs in this setting if preferences are the canonical timeseparable specification without memory or anticipatory utility. 
flood risk information signals is at odds with the notion that their decisions were optimized whilst fully accounting for true risk. After flood events, housing prices in at-risk areas tend to fall by $5-20 \%$, even in areas that were not damaged but only received salience signals such as near-miss hurricanes (see, e.g., Hallstrom and Smith, 2005). Demand for flood insurance has similarly been found to spike upwards after flood events, including if those occur only elsewhere but in the same media market (Gallagher, 2014). A model of flood risk learning arguably fits these empirical facts better than a model where sorting into high risk areas is driven solely by perfectly informed preferences. As a further indicator for learning versus preference-based flood risk beliefs, we compare other beliefs and demographics across optimists and realists (see Online Appendix). Flood risk optimists do not appear to be optimistic about flood damages, and are actually significantly more pessimistic about government assistance in case of a flood event. We also compare demographics between optimists and realists as old agents and those without children and a bequest motive may face lower costs from adopting an excessively optimistic view of flood risks. Optimists are slightly older on average, but this difference is not driven by a disproportionate share of senior citizens, but rather by relatively more agents in their 50 s versus 40 s in the two groups. In addition, we find that household size is not significantly different across the two groups, and, by the point estimate, is slightly larger among optimists.

A second caveat to our welfare analysis is that coastal mispricing is likely to create welfare costs through channels which are not represented in our model. Examples include overinvestment in at-risk properties (Barrage and Furst, 2019), or, if optimists obtain loans using coastal properties as collateral, the devaluation of those properties due to flood events or policy changes could lead to defaults, further asset value losses, and adverse effects on credit markets (see, e.g., Geanakoplos, 2010), thereby exacerbating market incompleteness. When coastal properties constitute an important source of local tax revenues, both fluctuations and permanent reductions in their value could create additional efficiency costs depending on the fiscal policy response. As our model does not incorporate these effects, the efficiency 
cost estimates thus likely represent a lower bound.

\subsection{Robustness}

This section assesses the sensitivity of our main results in the benchmark setting. Results for other locations are discussed in Section 6. We first present quantitative robustness results, and then describe some qualitative model extensions below. Unless otherwise stated, we change one parameter at a time without adjusting other model elements.

Optimist Share: We begin with the estimated share of flood risk optimists. Uncertainty over this parameter arises both because of potential measurement error in our survey and the possibility of alternate definitions of optimists. Figure 9 displays the estimated initial coastal home price overvaluation as a function of the optimist share. While the overvaluation increases in the optimist share, the sensitivity is quantitatively modest once the share of optimists exceeds the share of coastal homes (14.51\%). For example, the benchmark analysis defines "optimists" as those under-estimating coastal flood risk by at least 50\% (relative to FEMA flood maps), yielding an estimated population share of $35 \%$ and an overvaluation of $13 \%$. Defining optimists more strictly as those under-estimating flood risk by at least $70 \%$ would imply a population share of $20 \%$, yielding an overvaluation estimate of $12 \%$. Defining optimists more loosely to imply a $70 \%$ population share yields an only modestly higher overvaluation of $16 \%$.

Coastal Amenity Values: Next, our benchmark analysis uses stated preference methods to quantify coastal amenity values. Uncertainty over these values arises both due to measurement error and alternate methodologies to elicit these values. In particular, hedonic regression can provide revealed preference estimates, but typically cannot cleanly disentangle the different components entering the observed coastal home price premium, as shown in Section 2. For comparison, we nonetheless collect housing price and requisite covariate data to generate a hedonic coastal amenity premium estimate, which is around $+23 \%$ implying an average marginal amenity value of $\$ 3.9 \mathrm{k}$ per year (see Online Appendix for details). Figure 


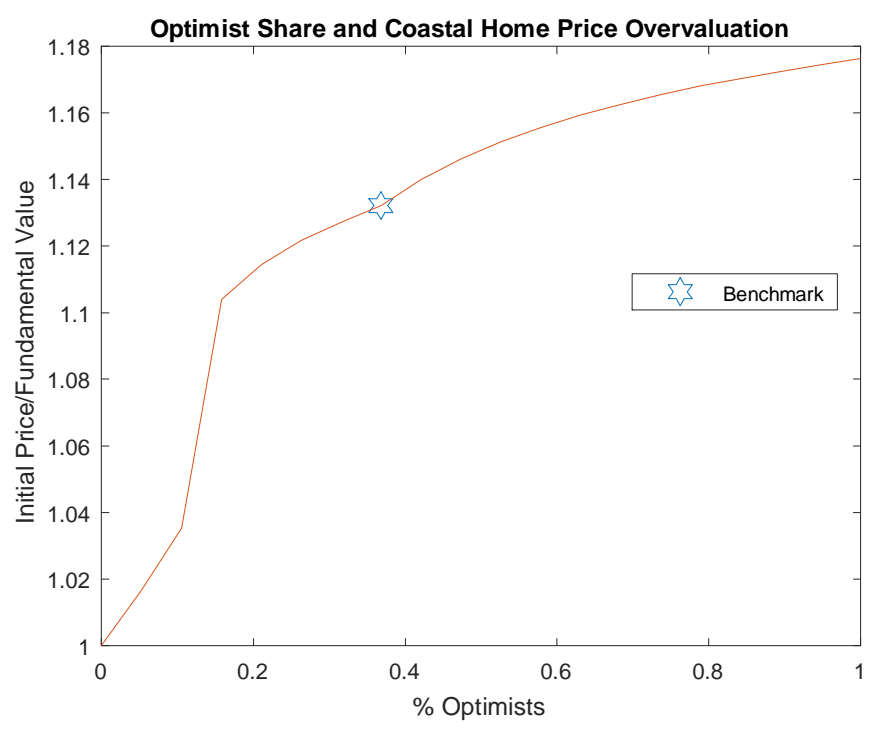

Figure 9: Optimist Share and Overvaluation

10 showcases results for a range of coastal amenity values including the hedonic estimate, although we again caution that this average marginal hedonic value is not directly comparable to the maximum coastal amenity we measure from the survey. In any event, however, the projected overvaluation does not appear very sensitive to this model input.

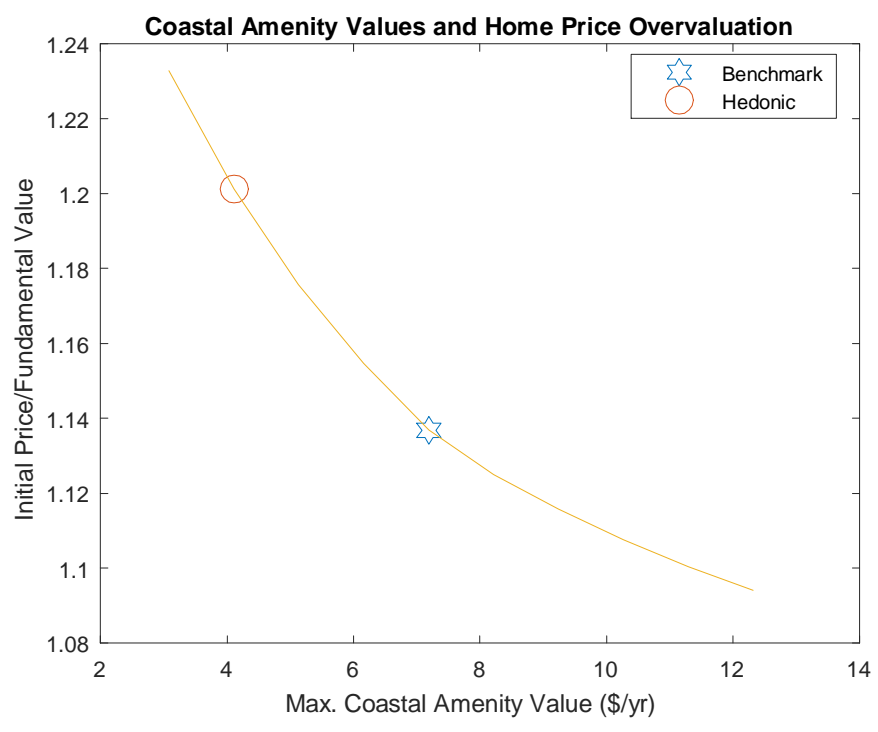

Figure 10: Max. Amenity Value and Overvaluation 
Sea Level Rise Uncertainty: The next source of uncertainty we confront is over sea level rise. While our analysis already accounts for uncertainty over SLR realizations, it assumes that the relevant distribution is known. One potential concern is that long-run SLR is subject to deep uncertainty particularly over contributions from polar ice sheets, and may thus not be well captured by a single probability distribution (Jevrejeva et al., 2019; Kopp et al., 2017). Importantly, however, for our near- to medium-run focus, the representation of uncertainty through a probability distribution is arguably reasonable. For example, in exploring deep uncertainty over polar ice sheets, Kopp et al. (2017) find that introducing relevant representations of ice sheet dynamics has only limited effects on SLR projection ranges through mid-century. Consequently, in a recent review of uncertainty over sea level rise, Jevrejeva et al. (2019) explicitly note that practitioners such as coastal adaptation planners may want to be "employing probability distributions for the time period of good agreement (through about 2050)" but account for ambiguity over such distributions for longer-run considerations. In addition, even studies that do formally account for deep uncertainty find its effects to be quantitatively limited over our time horizon of interest. For example, Barnett, Brock, and Hansen (2020) consider deep uncertainty in a general climateeconomic model, and find that the ambiguity-adjusted probability densities used by the planner do not start to diverge notably from the baseline density until 50 or more years into the future, for both uncertainty over the climate sensitivity (i.e., the equilibrium amount of warming due to doubling of carbon dioxide concentrations) and a climate damage parameter in the benchmark model. Similarly, Lemoine and Traeger (2016) find altogether small effects of ambiguity over climate tipping points. While these considerations motivate our benchmark approach, here we nonetheless consider sensitivity to alternative SLR forecasts. Figure 11 displays the projected initial overvaluation for a range of expected flood risk amplification values based on the 5-95\% interval identified by Buchanan et al. (2017). The results suggest that initial overvaluation is convex and increasing in expected flood risk amplification. One notable implication of this finding is that our approach of running the model at the expected 
flood risk amplification factor may thus underestimate the expected overvaluation.

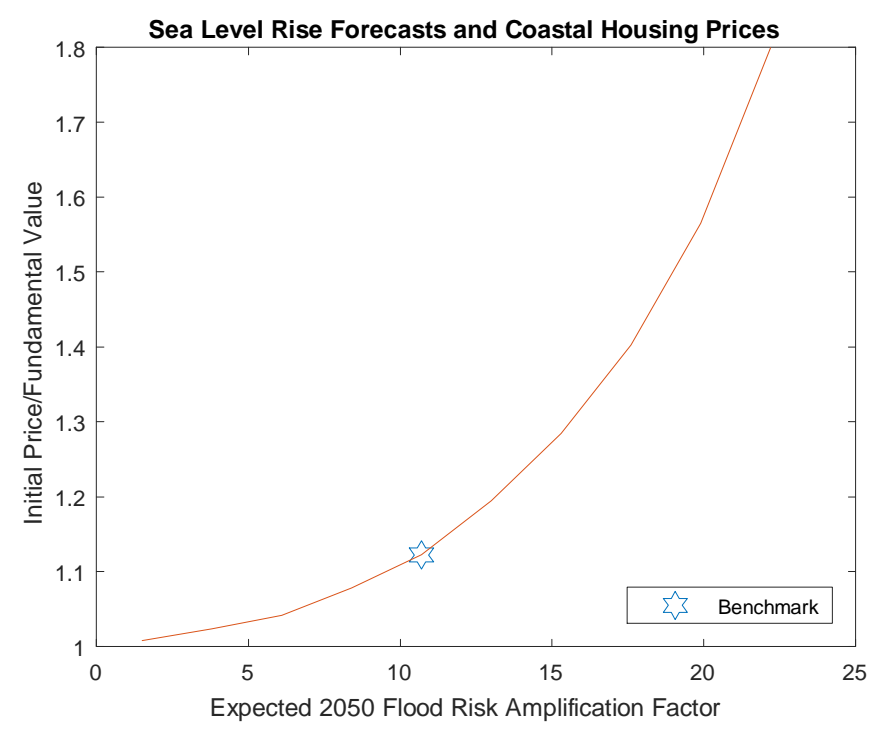

Figure 11: Sea Level Rise Forecast and Overvaluation

Flood Damages: Our final continuous sensitivity check varies the assumed level of flood damages in case of a flood event, as shown in Figure 12. Not surprisingly, mispricing is increasing in flood damages. The shape of the relationship again appears convex. The estimate also remains economically significant even for lower damage amounts.

Further Robustness: We next consider a number of discrete model changes. Results are presented in Table 5. The first is a behavioral modification that allows optimists to overreact to flood events or the lack thereof. This extension is motivated by empirical studies that have found home prices and flood insurance demand to revert to baseline within only 5-10 years after flood events (Bin and Landry, 2013; Gallagher, 2014), a pace not matched by a rational Bayesian framework. We thus introduce an overreaction parameter that increases (decreases) the agents' posterior in (19) by $15 \%$ in case of a (no) flood event to better match empirical studies (see Online Appendix). While this overreaction increases the volatility of future coastal housing prices compared to rational Bayesian updating, it does not affect the 


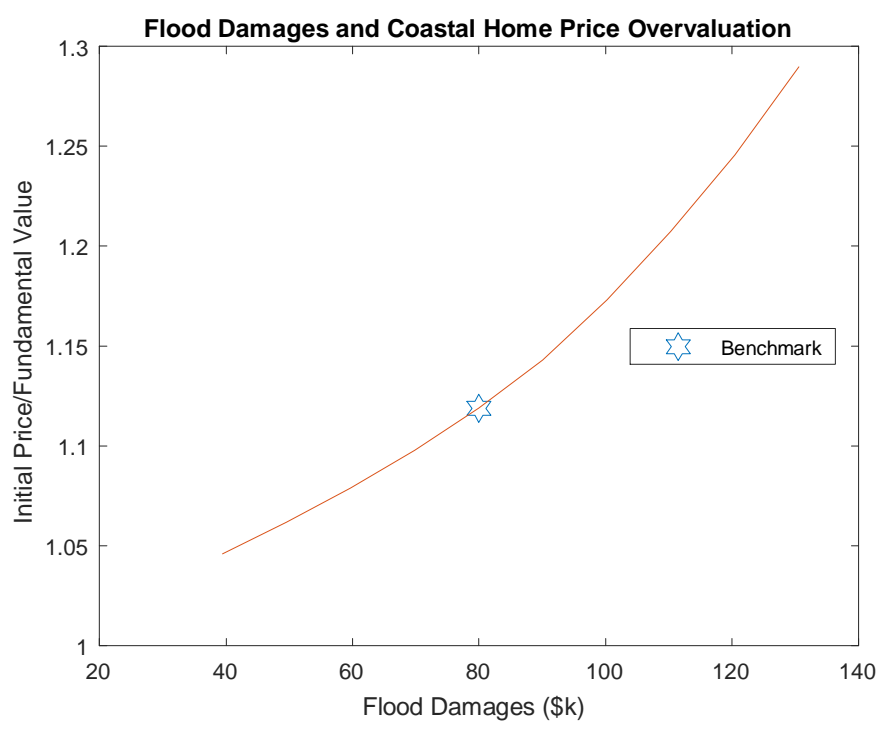

Figure 12: Flood Damages and Overvaluation

estimated overvaluation or overall price decline levels, as shown in Table 5. Next we consider alternative assumptions about optimists' expectations of long-run flood policy (insurance rates). In the benchmark, optimists assume flood policy will reflect the population-weighted average of beliefs $\left(\omega^{o}=\theta^{o}\right.$ in $(27)$ ). Table 5 shows results for two polar alternative cases, namely that long run rates will reflect only optimists' $\left(\omega^{o}=1\right)$ or only realists' $\left(\omega^{o}=0\right)$ views. The results indicate long-run flood insurance policy changes can significantly affect coastal housing prices in the present. Expectations of long-run availability of cheap insurance leads to an estimated overvaluation of $33 \%$. In contrast, if optimists expect to be forced to pay official risk rates eventually, overvaluation is significantly mitigated (2.5\%). The latter assumption is arguably not in line with empirical evidence on limited flood risk capitalization and the responses of housing prices to flood events and flood insurance requirements (e.g,. Gibson and Mullins, 2017), however.

Next we consider a global climate policy scenario consistent with the RCP 4.5 warming scenario (van Vuuren et al., 2011). This emissions scenario is projected to reduce the 2050 flood risk amplification factor in our benchmark area from 11.5 to 7.4 (Buchanan et al., 2017). Our interpolation moreover suggests that flood risk increases by 2030 would be reduced from 


\begin{tabular}{|l|l|l|}
\hline \multicolumn{3}{|l|}{ Table 5: Further Sensitivity Analysis } \\
\hline \hline Scenario & Overvaluation & $\operatorname{Var}(\% \Delta P)$ \\
\hline Benchmark & $13 \%$ & 22 \\
Bayesian updating overreaction $(15 \%)$ & $13 \%$ & 29 \\
Long-run policy optimism $\omega^{o}=1$ & $33 \%$ & 103 \\
Long-run policy realism $\omega^{o}=0$ & $2.5 \%$ & 0.4 \\
Global climate policy RCP $4.5^{\dagger}$ & $6.3 \%$ & 8.4 \\
Earlier policy reform $T=2035$ & $13 \%$ & 26 \\
Flood events: none & $13 \%$ & 38 \\
Flood events: double $(2033$ and 2037$)$ & $13 \%$ & 12 \\
Optimists' prior $q_{T_{1}}^{o}=0.2$ & $12 \%$ & 16 \\
Optimists' prior $q_{T_{1}}^{o}=0.3$ & $10 \%$ & 12 \\
\hline \hline${ }^{\dagger}$ Re-scales own-home utility value $e^{h}$ to hold initial coastal home price constant at $\$ 410 \mathrm{k}$. \\
Var $(\% \Delta P)$ refers to variance of year-to-year growth rates in coastal housing prices 2017-2050. \\
\hline
\end{tabular}

a factor of 4.79 to a factor of 1.44. As shown in Table 5, with this level of climate mitigation, the projected overvaluation falls to $6.3 \%$. Another alternate policy scenario we consider is one with earlier flood insurance reform, which yields similar results on overvaluation, but significantly lower welfare costs (see Table 4), albeit at a cost of higher price volatility. The next two rows consider alternative flood realization scenarios. These do not affect the coastal home price overvaluation, as both the initial price and fundamental value depend only on expectations over flood events. The volatility of prices does, however, depend on storm realizations, as they determine accumulated learning by the time policy reform is enacted. The last two rows of Table 5 consider different values for the prior optimists are assumed to place on the probability that sea level rise forecasts are correct. Doubling or even tripling our benchmark value of $10 \%$ yields only slightly smaller estimated values for the initial overvaluation of coastal homes.

Ex-Post Rationalization: In the Online Appendix we consider an illustrative extension of the model to account for the possibility that coastal residents change their flood risk beliefs differentially after moving to the coast in order to rationalize their sorting choice ex-post. We 
argue that ex-post rationalization should not fundamentally alter the main results as long as there are optimistic agents among the potential marginal buyers of coastal homes, as is consistent with the survey results. That is, while ex-post rationalization may create a class of 'entrenched' coastal residents (who are less likely to become marginal sellers), mispricing of coastal homes that are being sold (e.g., by informed agents) will continue as long as there are optimists among the marginal buyers. The survey results suggest this to be the case: $30 \%$ of (currently) non-coastal residents in our sample are optimistic about coastal flood risks, and recent movers (who relocated from another town to their survey area within the past 3 years) show a similar spread in the flood belief distribution to the full sample.

Transaction Costs: The Online Appendix also presents a version of the model with transaction costs in home buying. We show that, while transaction costs may affect price levels and transition dynamics in intuitive ways, importantly for our purposes, they do not affect the overvaluation arising from flood risk misperceptions.

Model Misspecification: Finally, we note that the robustness analysis presented here is all generated from within our model. In reality, our analysis is of course further subject to potential model misspecification. Important advancements in the literature have recently developed frameworks that can account for this concern in basic climate-economic models (Rudik, 2020), including alongside ambiguity and general uncertainty (e.g., Barnett, Brock, and Hansen, 2020; see also Brock and Hansen, 2018, and further references cited therein). Importantly for our purposes, however, several studies have found that deep uncertainty and model misspecification have limited quantitative effects especially over our time horizon of interest. For example, Rudik (2020) finds that insurance against model misspecification increases the optimal carbon price by only 1-2\%. Given these results and the high level of complexity that the integration of a robust control approach into our heterogeneous beliefs housing market model would require ${ }^{42}$ we leave this source of uncertainty for future study.

42 To our knowledge, robust control models with heterogeneous belief agents also remain rare especially of the form relevant in our setting. Frick (2019) considers a robust monetary policy authority which faces uncertainty over the economy's share of rational versus non-rational agents. However, this framework features only first-order belief heterogeneity as even rational agents do not account for non-rational 


\section{Extended Calibration}

This section expands the scope of our analysis by applying our framework to coastal cities beyond Rhode Island. We first demonstrate that our survey results - which were designed to measure precisely the role that flood risk optimism plays in sorting into high risk housing at the household level - can be mapped into county-level estimates of general climate change worry by the Yale Program on Climate Change Communications (YPCCC, Howe et al., 2015). Based on the estimated correspondence in Rhode Island, we then leverage the Yale estimates to extend the scope of our analysis. That is, while the Yale data cannot be used as a substitute to demonstrate the results of this study ${ }_{43}^{3}$ we use them as a complement to extend the analysis. Our survey covered three counties in Rhode Island (Bristol, Kent, and Newport). Instead of pooling the results, we now generate county-level estimates of the percentage of flood risk optimists using the same definition as before, namely the fraction that underestimates coastal flood risk by at least 50\%.44 We then compare our countylevel optimist shares against three potentially relevant measures from the Yale survey:45 the estimated percentages who "think global warming will harm people in the US not at all/only a little" (Figure 13), "are not very/not at all worried about global warming" (Figure 14),

households' belief process. Anderson et al. (2009) investigate the effects of uncertainty on excess asset returns in a model where agents solve a robust control problem. While professional forecasters' heterogeneous beliefs are used to measure uncertainty, the agents solving the problem are not themselves heterogeneous. Another example, Hansen and Sargent (2012) show that a Ramsey planner may have (endogenously) disparate beliefs from agents under different types of ambiguity.

43 First, the smallest geographic unit in the Yale data is the county or city. Consequently, one cannot compare risk perceptions inside and outside high risk flood zones, or among coastal vs. non-coastal households. Second, the Yale study does not elicit flood risk beliefs, but rather general levels of climate change concern or belief. Third, we require information on counterfactual beliefs of households about flood risk at homes they did not purchase, no such data is available in the Yale study or any other surveys products we are aware of. Finally, our analysis requires a joint assessment of households' amenity valuations of coastal living and their risk beliefs, as well as information on potentially confounding beliefs such as about flood damages and government assistance in case of a flood. Again, no such information is available in the Yale survey or comparable surveys we are aware of.

44 We correct for our survey's oversampling of coastal homes using county-specific weights for the shares of coastal homes, namely $20.94 \%$ in Newport, $13.4 \%$ in Bristol, and $9.16 \%$ in Kent county.

45 We collect Yale survey estimates for the year 2018 from the URL (accessed June 2020): https://climatecommunication.yale.edu/visualizations-data/ycom-us-2018 
and "think global warming will harm them personally not at all/only a little" (Figure 15), respectively. Though our number of observations is limited, we find a very strong association between our survey-based optimist measures and these general belief measures.

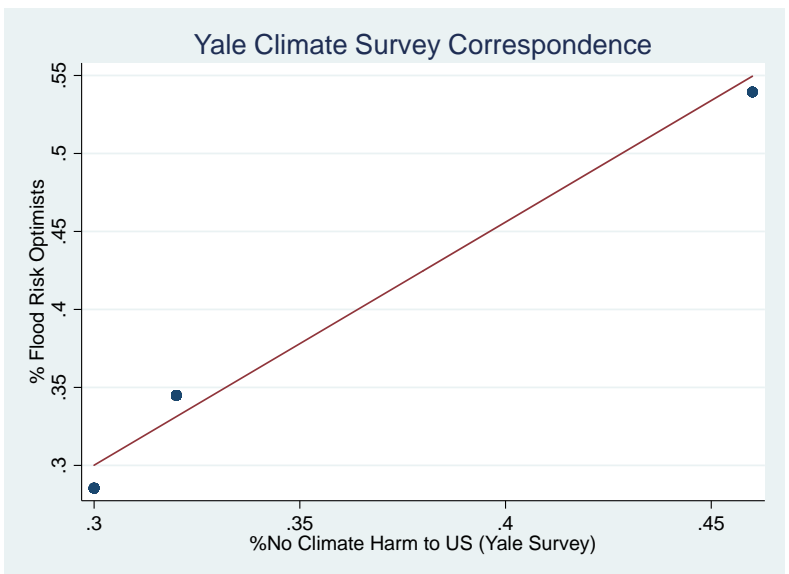

Figure 13: Yale Survey Correspondents: No U.S. Harm

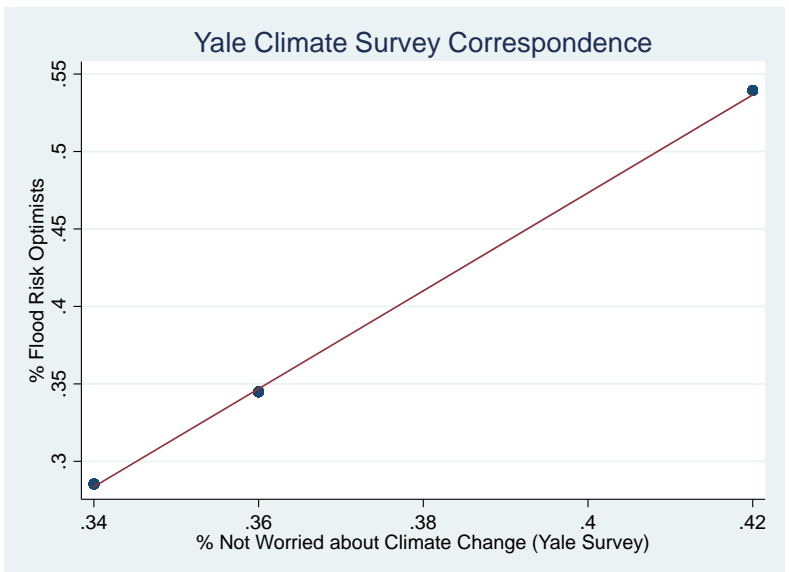

Figure 14: Yale Survey Correspondence: Not Worried

Next, we regress our county-level flood risk optimist shares on the Yale estimates of percent not worried about global warming. The results (see Online Appendix Table A2 for details) imply a predicted flood risk optimist share $\widehat{\theta}^{\circ}=-.8+3.2(\%$ not worried about global warming). We use this result along with YPCCC estimates for other counties to calibrate the share of flood risk optimists in areas beyond our survey area. 


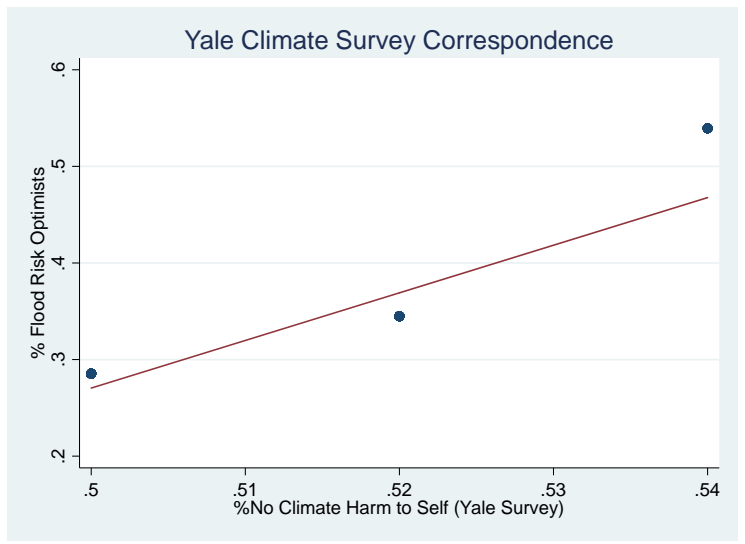

Figure 15: Yale Survey Correspondence: No Harm to Self

The remainder of the calibration proceeds as follows. We calculate the share of coastal homes $k_{1}$ using the same criterion (within 400 feet of the waterfront) and NOAA Continually Updated Shoreline Product coastline data. Flood risk amplification under sea level rise for each location is quantified based Buchanan et al. (2017) and Kopp et al. (2017) as described in Section $4.1{ }^{46}$ In order to quantify the coastal amenity value distribution, we first infer the approximate marginal coastal amenity value by applying our empirical hedonic estimate $(23 \%)$ to each location's median home price, obtained from Zillow ${ }^{47}$ We then assume the maximum of the distribution $\Xi$ based on the maximum-marginal ratio as in our benchmark calibration (2.6). Finally, to quantify expected flood damages $\delta$, we adopt the benchmark value for damages relative to home price (20\%) and compute values based on local median coastal home prices. All other parameters remain at benchmark values.

Table 6 presents the key model inputs and main results for an illustrative set of locations from across the United States ${ }^{48}$ Compared to our benchmark, the results imply significantly larger overvaluation potential in other locations. First, consider Boston, Massachusetts. While there are projected to be fewer flood risk optimists $(16 \%)$ than in our Rhode Island

$46 \quad$ Initial flood risk is set to the FEMA benchmark level of $1 \%$ per year in each location.

47 We obtain the median single family home sales price for each city and compute the 2017 average.

48 We select locations based on the criteria that they (i) have all calibration inputs available, including detailed future flood risk amplification predictions in Buchanan et al. (2017) (ruling out, e.g., Miami, FL), (ii) have a strong correlation between coastal and flood zone status (ruling out, e.g., Malibu, CA), (iii) do not have large-scale flood protective infrastructure (ruling out, e.g., New Orleans, LA), and (iv) represent a range of climate belief and flood risk amplification scenarios. 
area $(35 \%)$, the share of coastal housing $(2.3 \%)$ is also smaller compared to our benchmark (14.5\%), allowing optimists to potentially be relatively mode dominant in the coastal market. Importantly, Boston also faces significantly higher expected flood risk amplification factors (over 50 in 2050) compared to our benchmark (11.5). Consequently, the projected initial overvaluation is considerably higher at over $80 \%$. Next, in Wilmington, North Carolina, the model projects an even larger overvaluation of over four-fold. This is due to the combination of a high share of flood risk optimists (48\%) and extremely high climate vulnerability. In contrast, in Tampa, Florida, the model projects a very modest overvaluation (4\%), driven mainly by the very modest projected flood risk increases, especially in the medium run. Two other example cities - Charleston, South Carolina, and Corpus Christi, Texas - both show considerably higher projected overvaluation than our benchmark. In sum, these extended results thus suggest that (i) Rhode Island may be a conservative benchmark given the relatively modest flood risk increase projections, ${ }^{49}$ and that (ii) flood risk optimism may thus play an even more important role and contribute to larger overvaluations in other coastal housing markets across the country.

49 Indeed, Buchanan et al. (2017) estimate a median expected 100-year flood risk amplification factor of around 40 (by 2050) across tidal gauge locations across the contingous United States. 


\begin{tabular}{|c|c|c|c|c|c|c|c|c|c|c|}
\hline \multirow[b]{3}{*}{ Area } & \multicolumn{9}{|c|}{ Inputs } & \multirow{3}{*}{$\begin{array}{l}\text { Results } \\
\text { Overva- } \\
\text { luation }\end{array}$} \\
\hline & \multirow{2}{*}{$\begin{array}{r}\text { Coastal } \\
\text { homes } \\
k_{1}(\%) \\
\end{array}$} & \multirow{2}{*}{$\begin{array}{c}\text { Optimists } \\
\theta^{o}(\%)\end{array}$} & \multirow{2}{*}{$\begin{array}{c}\text { Max. } \\
\text { Amenity } \\
\Xi(\$ \mathrm{k} / \mathrm{yr})\end{array}$} & \multicolumn{2}{|c|}{$\begin{array}{l}\text { E[Flood } \\
\text { Risk AF }]\end{array}$} & \multirow[b]{2}{*}{$e^{h}$} & \multirow{2}{*}{$\begin{array}{c}\text { Dam. } \\
\delta \\
(\$ \mathrm{k})\end{array}$} & \multirow{2}{*}{\multicolumn{2}{|c|}{$\begin{array}{c}P_{0}^{N C} \mid P_{0} \\
(\$ \mathrm{k})\end{array}$}} & \\
\hline & & & & 2030 & 2050 & & & & & \\
\hline $\begin{array}{l}\text { Benchmark, } \\
\text { RI }\end{array}$ & 0.145 & 0.35 & 7.7 & 4.79 & 11.5 & 20.1 & 82 & 316 & 410 & $13 \%$ \\
\hline $\begin{array}{l}\text { Boston, } \\
\text { MA }\end{array}$ & 0.023 & 0.16 & 13.2 & 4.01 & 50.7 & 57.8 & 133 & 540 & 664 & $81 \%$ \\
\hline $\begin{array}{l}\text { Wilmington, } \\
\mathrm{NC}^{\dagger}\end{array}$ & 0.066 & 0.48 & 5.1 & 3.67 & 96.9 & 33.4 & 51 & 208 & 256 & $420 \%$ \\
\hline $\begin{array}{l}\text { Corpus } \\
\text { Christi, } \mathrm{TX}^{\dagger \dagger}\end{array}$ & 0.046 & 0.38 & 3.7 & 2.34 & 58.6 & 29.0 & 37 & 152 & 187 & $93 \%$ \\
\hline $\begin{array}{l}\text { Tampa, } \\
\text { FL }^{b}\end{array}$ & 0.109 & 0.44 & 4.6 & 1.07 & 4.4 & 32.0 & 47 & 190 & 234 & $4 \%$ \\
\hline $\begin{array}{l}\text { Charleston, } \\
\text { SC }\end{array}$ & 0.035 & 0.48 & 8.7 & 2.02 & 40.3 & 39.8 & 79 & 291 & 358 & $58 \%$ \\
\hline $\begin{array}{l}\text { Table displays } \\
{ }^{\dagger} \text { Optimist share } \\
\text { risk and sea leve }\end{array}$ & $\begin{array}{l}\text { del inputs } \\
\text { ased on Ne } \\
\text { ise based c }\end{array}$ & $\begin{array}{l}\text { nd results for } \\
\text { Hanover cou }\end{array}$ & $\begin{array}{l}\text { ifferent citie } \\
\text { ty Yale surv } \\
\text { † }^{\dagger} \text { Rockpo }\end{array}$ & $\begin{array}{l}\text { in a bu } \\
\text { y result. } \\
\text { TX an }\end{array}$ & $\begin{array}{l}\text { iness as } ~ \\
\text { and our } \\
\text { St. Pe }\end{array}$ & $\begin{array}{l}\text { sual w: } \\
\text { survey }\end{array}$ & $\begin{array}{l}\text { ming }(\mathrm{R} \\
\text { orrespon } \\
\text { FL. }\end{array}$ & $\begin{array}{l}\text { P } 8.5) \\
\text { ence. } F\end{array}$ & & \\
\hline
\end{tabular}

\section{Conclusion}

To what extent do asset prices reflect climatic risks? This issue is of growing interest due not only to its policy importance (Anderson et al., 2019), but also as it speaks to the fundamental question of the empirical determinants of asset prices. Flooding has long been one of the costliest natural disasters in the United States (NOAA, 2017b), and risks are set to increase as sea levels rise over the coming decades. At the same time, however, a rich empirical literature has documented that capitalization of these risks into housing prices is often weak and variable across housing markets and segments (e.g., Daniel et al., 2009; Bernstein et al., 2019; Murfin and Spiegel, 2019; Baldauf et al., 2020).

This paper has explored the role of flood risk belief heterogeneity and specifically of flood risk misperceptions in accounting for these present and potential future pricing dynamics in coastal U.S. housing markets. We provide both theoretical and novel empirical evidence 
through the combination of a dynamic housing market model allowing for heterogeneity in home types, consumer preferences, and flood risk beliefs, and a field survey providing direct evidence of belief distributions among waterfront and inland residents, as well as information on critical potential confounders.

The main results are threefold. First, we find that allowing for flood risk optimism enables our model to reconcile the mixed empirical evidence on flood risk penalties as driven by sorting and different equilibria across markets that may vary in the distribution of beliefs and housing market characteristics. Second, the survey results provide direct evidence that coastal flood zone residents have both significantly lower flood risk perceptions and higher waterfront amenity valuations than their inland counterparts. Close to $40 \%$ of flood zone residents indicate that they are "not at all" worried about flooding over the next decade. This lower degree of flood worry does not appear to be driven by different beliefs about flood damages, insurance payouts, or post disaster public aid.

Third, calibrating the model to these survey results and probabilistic flood risk projections under sea level rise, we estimate that coastal housing prices exceed fundamentals by $13 \%$ in our benchmark setting in Rhode Island. Extending our results to other cities reveals the potential for significantly larger overvaluations, especially in locations that face higher sea level rise vulnerability and more climate change skepticism. The overvaluation results are robust to a range of robustness checks, but sensitive to households' long-run flood policy beliefs, highlighting the potential power of policy expectations to mitigate - or exacerbate current inefficiencies. Future work could thus potentially elicit policy beliefs and explicitly model uncertainty about policy reform. The results also indicate the potential of flood insurance reform to have large distributional effects across agents with different beliefs: Optimists who currently live inland but would soon purchase an overvalued coastal home may gain substantially from immediate policy reform, whereas current coastal residents who would have been able to sell to said optimists stand to lose from a price correction. While our model can only capture aggregate welfare effects in the form of allocative inefficiency, de- 
valuations in at-risk markets may also be a significant policy concern due to their potential effects on mortgage and credit markets. A formalizations and quantification of these impact mechanism would be another highly interesting topic for future work.

While our analysis focuses on a select set of locations, coastal housing markets and flood risks are of national importance. By some estimates, the current asset value of U.S. real estate within $1 / 8^{\text {th }}$ of a mile of the coastline exceeds $\$ 1.4$ trillion (McNeill et al., 2014). Many areas face significant risks from climate change. Neumann et al. (2000) estimate that three feet of sea level rise - a plausible scenario by the end of the century (Melillo et al., 2014) - would result in substantial inundations plus a 7,000 square mile (38\%) increase in U.S. flood zones. At the same time, many households remain skeptical, with $60 \%$ of respondents in a recent national survey indicating that they do not believe rising sea levels to be a "very likely' consequence of climate change (Pew, 2016). The results of this paper highlight the potential of these beliefs to inhibit the efficient pricing of climate risks into housing assets, and the importance of accurate flood risk information and policy in ensuring the efficiency and stability of coastal housing markets moving forward.

\section{References}

[1] Abreu, Dilip, and Markus K. Brunnermeier. "Bubbles and crashes." Econometrica 71, no. 1 (2003): 173-204.

[2] Alberini, Anna. "Optimal designs for discrete choice contingent valuation surveys: Single-bound, double-bound, and bivariate models." Journal of Environmental Economics and Management 28, no. 3 (1995): 287-306.

[3] Anderson, Evan W., Eric Ghysels, and Jennifer L. Juergens. "The impact of risk and uncertainty on expected returns." Journal of Financial Economics 94, no. 2 (2009): 233-263.

[4] Anderson, Sarah E., Terry L. Anderson, Alice C. Hill, Matthew E. Kahn, Howard Kunreuther, Gary D. Libecap, Hari Mantripragada, Pierre Mérel, Andrew J. Plantinga, and V. Kerry Smith. "The critical role of markets in climate change adaptation." Climate Change Economics 10, no. 01 (2019): 1950003. 
[5] Arrow, Kenneth, Robert Solow, Paul R. Portney, Edward E. Leamer, Roy Radner, and Howard Schuman. "Report of the NOAA panel on contingent valuation." Federal Register 58, no. 10 (1993): 4601-4614.

[6] Atreya, Ajita, and Jeffrey Czajkowski. "Graduated flood risks and property prices in Galveston County." Real Estate Economics 47, no. 3 (2019): 807-844.

[7] Atreya, Ajita, Susana Ferreira, and Warren Kriesel. "Forgetting the flood? An analysis of the flood risk discount over time." Land Economics 89, no. 4 (2013): 577-596.

[8] Bakkensen, Laura A., and Lala Ma. "Sorting over flood risk and implications for policy reform." Journal of Environmental Economics and Management 104 (2020): 102362.

[9] Baldauf, Markus, Lorenzo Garlappi, and Constantine Yannelis. "Does climate change affect real estate prices? Only if you believe in it." The Review of Financial Studies 33 , no. 3 (2020): 1256-1295.

[10] Barnett, Michael, William Brock, and Lars Peter Hansen. "Pricing uncertainty induced by climate change." The Review of Financial Studies 33, no. 3 (2020): 1024-1066.

[11] Barrage, Lint, and Jacob Furst. "Housing investment, sea level rise, and climate change beliefs." Economics Letters 177 (2019): 105-108.

[12] Bayer, Patrick, Robert McMillan, Alvin Murphy, and Christopher Timmins. "A dynamic model of demand for houses and neighborhoods." Econometrica 84, no. 3 (2016): 893-942.

[13] Beltrán, Allan, David Maddison, and Robert JR Elliott. "Is flood risk capitalised into property values?." Ecological Economics 146 (2018): 668-685.

[14] Bernstein, Asaf, Matthew T. Gustafson, and Ryan Lewis. "Disaster on the horizon: The price effect of sea level rise." Journal of Financial Economics 134, no. 2 (2019): 253-272.

[15] Bin, Okmyung, Thomas W. Crawford, Jamie B. Kruse, and Craig E. Landry. "Viewscapes and flood hazard: Coastal housing market response to amenities and risk." Land Economics 84, no. 3 (2008): 434-448.

[16] Bin, Okmyung, and Jamie Brown Kruse. "Real estate market response to coastal flood hazards." Natural Hazards Review 7, no. 4 (2006): 137-144.

[17] Bin, Okmyung, and Craig E. Landry. "Changes in implicit flood risk premiums: Empirical evidence from the housing market." Journal of Environmental Economics and Management 65, no. 3 (2013): 361-376.

[18] Brock, William A., and Lars Peter Hansen. "Wrestling with uncertainty in climate economic models." University of Chicago, Becker Friedman Institute for Economics Working Paper 2019-71 (2018). 
[19] Brunnermeier, Markus K., and Jonathan A. Parker. "Optimal expectations." American Economic Review 95, no. 4 (2005): 1092-1118.

[20] Brunnermeier, Markus K., Alp Simsek, and Wei Xiong. "A welfare criterion for models with distorted beliefs." The Quarterly Journal of Economics 129, no. 4 (2014): 17531797.

[21] Buchanan, Maya K., Michael Oppenheimer, and Robert E. Kopp. "Amplification of flood frequencies with local sea level rise and emerging flood regimes." Environmental Research Letters 12, no. 6 (2017): 064009.

[22] Bunten, Devin, and Matthew E. Kahn. "Optimal real estate capital durability and localized climate change disaster risk." Journal of Housing Economics 36 (2017): 1-7.

[23] Burnside, Craig, Martin Eichenbaum, and Sergio Rebelo. "Understanding booms and busts in housing markets." Journal of Political Economy 124, no. 4 (2016): 1088-1147.

[24] Cameron, Trudy Ann, and Michelle D. James. "Efficient estimation methods for" closed-ended" contingent valuation surveys." The Review of Economics and Statistics (1987): 269-276.

[25] Campbell, John Y. "Household finance." The Journal of Finance 61, no. 4 (2006): 1553-1604.

[26] Carson, Richard T., and Robert Cameron Mitchell. "Sequencing and nesting in contingent valuation surveys." Journal of Environmental Economics and Management 28, no. 2 (1995): 155-173.

[27] CBO. "Understanding FEMA's rate-setting methods for the National Flood Insurance Program." (2014). Available online at: https : : //www.cbo.gov/sites/default/files/presentation/49441 femaratemethodsnfip.pdf.

[28] Daniel, Vanessa E., Raymond JGM Florax, and Piet Rietveld. "Flooding risk and housing values: An economic assessment of environmental hazard." Ecological Economics 69 , no. 2 (2009): 355-365.

[29] Davis, Morris A., and Stijn Van Nieuwerburgh. "Housing, finance, and the macroeconomy." Handbook of Regional and Urban Economics, vol. 5, pp. 753-811. Elsevier, 2015 .

[30] DellaVigna, Stefano, John A. List, and Ulrike Malmendier. "Testing for altruism and social pressure in charitable giving." The Quarterly Journal of Economics 127, no. 1 (2012): $1-56$.

[31] Desmet, Klaus, Robert E. Kopp, Scott A. Kulp, Dávid Krisztián Nagy, Michael Oppenheimer, Esteban Rossi-Hansberg, and Benjamin H. Strauss. "Evaluating the economic cost of coastal flooding." American Economic Journal: Macroeconomics, (2020): Forthcoming. 
[32] Diamond, Peter A., and Jerry A. Hausman. "Contingent valuation: is some number better than no number?." Journal of Economic Perspectives 8, no. 4 (1994): 45-64.

[33] Dieckmann, Stephan. "Rare event risk and heterogeneous beliefs: The case of incomplete markets." Journal of Financial and Quantitative Analysis 46, no. 02 (2011): 459-488.

[34] EPA. "Multi-model framework for quantitative sectoral impacts analysis: A technical report for the Fourth National Climate Assessment." U.S. Environmental Protection Agency, EPA (2017): 430-R-17-001.

[35] Favara, Giovanni, and Zheng Song. "House price dynamics with dispersed information." Journal of Economic Theory 149 (2014): 350-382.

[36] Favilukis, Jack, and Stijn Van Nieuwerburgh. "Out-of-town home buyers and city welfare." Working Paper. (2018).

[37] FEMA. "Public survey findings on flood risk." (2013). Available online at https : //www.fema.gov/public - survey - findings - flood - risk.

[38] FEMA. "National Flood Insurance Program and the consolidated appropriations act of 2014." (2014). Available online at https : //www.fema.gov/sites/default/files/2020 - 07/flood-insurance-consolidatedappropriations - act - 2014.pdf.

[39] FEMA. "Policy \& claim statistics for flood insurance." (2017). Available online at https : //www.fema.gov/policy - claim - statistics - flood - insurance.

[40] Frick, David. "Robust optimal monetary policy under heterogeneous beliefs." Working Paper (2019).

[41] Garbarino, Nicola, and Benjamin Guin. "High water, no marks? Biased lending after extreme weather." Bank of England Staff Working Paper (2020): No. 856.

[42] Gallagher, Justin. "Learning about an infrequent event: evidence from flood insurance take-up in the United States." American Economic Journal: Applied Economics (2014): 206-233.

[43] GAO. "Progress on many high-risk areas, while substantial efforts needed on others," (2017). GAO-17-317. Available online at: https : //www.gao.gov/products/GAO $17-317$.

[44] GAO. "The nation's fiscal health: Actions is needed to address the federal government's fiscal future. (2018a). Available online at: https : //www.gao.gov/assets/700/693001.pdf.

[45] Geanakoplos, John. "The leverage cycle." NBER Macroeconomics Annual 24, no. 1 (2010): 1-66. 
[46] Gibson, Matthew, and Jamie T. Mullins. "Climate risk and beliefs in new york floodplains." Journal of the Association of Environmental and Resource Economists 7, no. 6 (2020): 1069-1111.

[47] Giglio, Stefano, Matteo Maggiori, Johannes Stroebel, and Andreas Weber. "Climate change and long-run discount rates: Evidence from real estate." Working Paper (2018).

[48] Glaeser, Edward L., Joseph Gyourko, and Raven E. Saks. "Urban growth and housing supply." Journal of Economic Geography 6, no. 1 (2005): 71-89.

[49] Glaeser, Edward L., Joseph Gyourko, Eduardo Morales, and Charles G. Nathanson. "Housing dynamics: An urban approach." Journal of Urban Economics 81 (2014): $45-56$.

[50] Glaeser, Edward L., and Charles G. Nathanson. "Housing bubbles." National Bureau of Economic Research Working Paper (2014): No. w20426.

[51] Glaeser, Edward L., and Charles G. Nathanson. "An extrapolative model of house price dynamics." Journal of Financial Economics 126, no. 1 (2017): 147-170.

[52] Green, Richard K., Stephen Malpezzi, and Stephen K. Mayo. "Metropolitan-specific estimates of the price elasticity of supply of housing, and their sources." American Economic Review 95, no. 2 (2005): 334-339.

[53] Hallstrom, Daniel G., and V. Kerry Smith. "Market responses to hurricanes." Journal of Environmental Economics and Management 50, no. 3 (2005): 541-561.

[54] Hanemann, W. Michael. "Valuing the environment through contingent valuation." Journal of Economic Perspectives 8, no. 4 (1994): 19-43.

[55] Hanemann, Michael, John Loomis, and Barbara Kanninen. "Statistical efficiency of double-bounded dichotomous choice contingent valuation." American Journal of Agricultural Economics 73, no. 4 (1991): 1255-1263.

[56] Hansen, Lars Peter, and Thomas J. Sargent. "Three types of ambiguity." Journal of Monetary Economics 59, no. 5 (2012): 422-445.

[57] Harrison, J. Michael, and David M. Kreps. "Speculative investor behavior in a stock market with heterogeneous expectations." The Quarterly Journal of Economics 92, no. 2 (1978): 323-336.

[58] Harrison, David, Greg T. Smersh, and Arthur Schwartz. "Environmental determinants of housing prices: the impact of flood zone status." Journal of Real Estate Research 21, no. 1-2 (2001): 3-20.

[59] Head, Allen, Huw Lloyd-Ellis, and Hongfei Sun. "Search, liquidity, and the dynamics of house prices and construction." American Economic Review 104, no. 4 (2014): $1172-$ 1210. 
[60] Hino, Miyuki, and Marshall Burke. "Does information about climate risk affect property values?". No. w26807. National Bureau of Economic Research, (2020).

[61] Howe, Peter D., Matto Mildenberger, Jennifer R. Marlon, and Anthony Leiserowitz. "Geographic variation in opinions on climate change at state and local scales in the USA." Nature Climate Change 5, no. 6 (2015): 596-603.

[62] Jevrejeva, S., T. Frederikse, R. E. Kopp, Gonéri Le Cozannet, L. P. Jackson, and R. S. W. van de Wal. "Probabilistic sea level projections at the coast by 2100." Surveys in geophysics 40, no. 6 (2019): 1673-1696.

[63] Kahn, Matthew E., and Daxuan Zhao. "The impact of climate change skepticism on adaptation in a market economy." Research in Economics 72, no. 2 (2018): 251-262.

[64] Kanninen, Barbara J. "Optimal experimental design for double-bounded dichotomous choice contingent valuation." Land Economics (1993): 138-146.

[65] Kellens, Wim, Teun Terpstra, and Philippe De Maeyer. "Perception and communication of flood risks: a systematic review of empirical research." Risk Analysis: An International Journal 33, no. 1 (2013): 24-49.

[66] Kellens, Wim, Ruud Zaalberg, and Philippe De Maeyer. "The informed society: An analysis of the public's information-seeking behavior regarding coastal flood risks." Risk Analysis: An International Journal 32, no. 8 (2012): 1369-1381.

[67] Kling, Catherine L., Daniel J. Phaneuf, and Jinhua Zhao. "From Exxon to BP: Has some number become better than no number?." Journal of Economic Perspectives 26, no. 4 (2012): 3-26.

[68] Kopp, Robert E., Robert M. DeConto, Daniel A. Bader, Carling C. Hay, Radley M. Horton, Scott Kulp, Michael Oppenheimer, David Pollard, and Benjamin H. Strauss. "Evolving understanding of Antarctic ice-sheet physics and ambiguity in probabilistic sea-level projections." Earth's Future 5, no. 12 (2017): 1217-1233.

[69] Kopp, Robert E., Radley M. Horton, Christopher M. Little, Jerry X. Mitrovica, Michael Oppenheimer, D. J. Rasmussen, Benjamin H. Strauss, and Claudia Tebaldi. "Probabilistic 21st and 22nd century sea-level projections at a global network of tidegauge sites." Earth's Future 2, no. 8 (2014): 383-406.

[70] Kousky, Carolyn. "Learning from extreme events: Risk perceptions after the flood." Land Economics 86, no. 3 (2010): 395-422.

[71] Kousky, Carolyn. "Facts about FEMA household disaster aid: examining the 2008 floods and tornadoes in Missouri." Weather, Climate, and Society 5, no. 4 (2013): 332-344.

[72] Kousky, Carolyn, Howard Kunreuther, Brett Lingle, and Leonard Shabman. "The emerging private residential flood insurance market in the United States." Wharton Risk Management and Decision Processes Center Working Paper. (2018). 
[73] Kousky, Carolyn, and Erwann Michel-Kerjan. "Examining flood insurance claims in the United States: Six key findings." Journal of Risk and Insurance 84, no. 3 (2017): 819-850.

[74] Kuchler, Theresa, and Basit Zafar. "Personal experiences and expectations about aggregate outcomes." The Journal of Finance 74, no. 5 (2019): 2491-2542.

[75] Kuminoff, Nicolai V., V. Kerry Smith, and Christopher Timmins. "The new economics of equilibrium sorting and policy evaluation using housing markets." Journal of Economic Literature 51, no. 4 (2013): 1007-1062.

[76] Lemoine, Derek, and Christian P. Traeger. "Ambiguous tipping points." Journal of Economic Behavior \& Organization 132 (2016): 5-18.

[77] Lindell, Michael K., and Seong Nam Hwang. "Households' perceived personal risk and responses in a multihazard environment." Risk Analysis: An International Journal 28, no. 2 (2008): 539-556.

[78] Malmendier, Ulrike, and Stefan Nagel. "Depression babies: Do macroeconomic experiences affect risk taking?." The Quarterly Journal of Economics 126, no. 1 (2011): $373-416$.

[79] Manski, Charles F. "Measuring expectations." Econometrica 72, no. 5 (2004): 13291376.

[80] McNeill, Ryan, Deborah J. Nelson, and Duff Wilson. "Water's Edge: The crisis of rising sea levels." Reuters (2014). Available online at https://www.reuters.com/investigates/special-report/waters-edge-the-crisis-of-risingsea-levels/

[81] Melillo, Jerry M., Terese Richmond, and Gary W. Yohe, Eds. "Climate change impacts in the United States: The Third National Climate Assessment." U.S. Global Change Research Program (2014): 841 pp.

[82] Mitchell, Robert Cameron, and Richard T. Carson. Using surveys to value public goods: the contingent valuation method. Rff Press, (2013).

[83] Moore, D. "NFIP vs. private flood insurance." (2017). Available online at http : //www.davemooreinsurance.com/news - and - resources/nfip - vs - private flood-insurance/.

[84] Murfin, Justin, and Matthew Spiegel. "Is the risk of sea level rise capitalized in residential real estate?." The Review of Financial Studies 33, no. 3 (2020): 1217-1255.

[85] Neumann, J. E. "Sea-level rise \& global climate change: A review of impacts to US coasts (Vol. 4)." Pew Center on Global Climate Change. (2000).

[86] NOAA "Global and regional sea level rise scenarios for the United States." NOAA Technical Report (2017a). NOS CO-OPS 083. 
[87] NOAA National Centers for Environmental Information. "U.S. billiondollar weather and climate disasters." (2017b). Available online at https : //www.ncdc.noaa.gov/billions/.

[88] Ortega, Francesc, and Süleyman Taspınar. "Rising sea levels and sinking property values: Hurricane Sandy and New York's housing market." Journal of Urban Economics 106 (2018): 81-100.

[89] Ouazad, Amine, and Matthew E. Kahn. "Mortgage finance in the face of rising climate risk." National Bureau of Economic Research Working Paper (2019): No. w26322.

[90] Pagneux, Emmanuel, Guðrún Gísladóttir, and Salvör Jónsdóttir. "Public perception of flood hazard and flood risk in Iceland: a case study in a watershed prone to ice-jam floods." Natural Hazards 58, no. 1 (2011): 269-287.

[91] Pew Reserach. "The politics of climate." (2016). Available online at http : //www.pewinternet.org/2016/10/04/public - views - on - climate - change - andclimate - scientists/.

[92] Piazzesi, Monika, and Martin Schneider. "Momentum traders in the housing market: Survey evidence and a search model." American Economic Review 99, no. 2 (2009): 406-11.

[93] Rhode Island Coastal Resources Management Council. "Protecting Rhode Island's shorelines from flooding and erosion." (2013) Available online at http://www.beachsamp.org/wp-content/uploads/2013/04/sea-wall-fact-sheet-sept27.pdf

[94] Rhode Island Coastal Resources Management Council. "Coastal Management Program." (2020) Available online at www.crmc.ri.gov/regulations/RICRMP.pdf

[95] Rudik, Ivan. "Optimal climate policy when damages are unknown." American Economic Journal: Economic Policy 12, no. 2 (2020): 340-73.

[96] Saiz, Albert. "The geographic determinants of housing supply." The Quarterly Journal of Economics 125, no. 3 (2010): 1253-1296.

[97] SAMP. "Derived inundation surfaces - Scaled SLR." (2017). Available online at http: //www.beachsamp.org/stormtools/.

[98] Schade, Christian, Howard Kunreuther, and Philipp Koellinger. "Protecting against low-probability disasters: The role of worry." Journal of Behavioral Decision Making 25, no. 5 (2012): 534-543.

[99] Scheinkman, Jose A., and Wei Xiong. "Overconfidence and speculative bubbles." Journal of Political Economy 111, no. 6 (2003): 1183-1220.

[100] Severen, Christopher, Christopher Costello, and Olivier Deschenes. "A forward-looking Ricardian approach: Do land markets capitalize climate change forecasts?." Journal of Environmental Economics and Management 89 (2018): 235-254. 
[101] Simsek, Alp. "Belief disagreements and collateral constraints." Econometrica 81, no. 1 (2013): 1-53.

[102] Van Vuuren, Detlef P., Jae Edmonds, Mikiko Kainuma, Keywan Riahi, Allison Thomson, Kathy Hibbard, George C. Hurtt et al. "The representative concentration pathways: an overview." Climatic change 109, no. 1 (2011): 5-31.

[103] Wagner, Katherine. "Adaptation and adverse selection in markets for natural disaster insurance." Working Paper (2019). Available at SSRN 3467329.

[104] Xiong, Weil. "Bubbles, crises, and heterogeneous beliefs." in Handbook on Systemic Risk, edited by Jean-Pierre Fouque and Joseph A. Langsam, Cambridge University Press (2013): 663-713. 


\title{
Flood Risk Belief Heterogeneity and Coastal Home Price Dynamics: Going Under Water? Online Appendix
}

\author{
Laura Bakkensen $\quad$ Lint Barrage* \\ U. Arizona UCSB \& NBER
}

January 2021

\section{Contents}

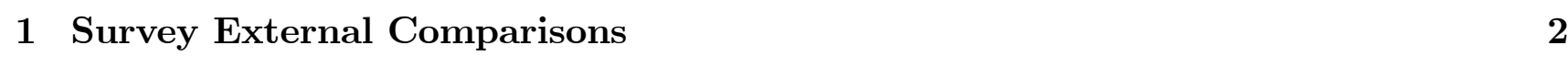

1.1 Home Market Values vs. Zillow . . . . . . . . . . . . . . . . . . . . . . . . 2

1.2 Home Purchase Year . . . . . . . . . . . . . . . . . . . . . 2

1.3 Respondent Demographics . . . . . . . . . . . . . . . . . . . . . 3

1.4 Flood Survey - Yale Data Mapping . . . . . . . . . . . . . . . . . . . . . . . 4

2 Further Survey Results $\quad 5$

2.1 Sea Wall Expectations . . . . . . . . . . . . . . . . . . . 5

2.2 Flood Risk Mitigation $\ldots \ldots \ldots$. . . . . . . . . . . . . . 6

2.3 Secondary Homeownership . . . . . . . . . . . . . . . . . . . . 7

2.4 Perceived vs. Inundation Model Flood Risk . . . . . . . . . . . . . . . . . . 8

2.5 Optimist vs. Realist Demographics ． . . . . . . . . . . . . . . . . . . . 10

2.6 Flood Experience and Beliefs $\ldots \ldots \ldots$. . . . . . . . . . . . . . 12

2.7 Double-Bounded Dichotomous Choice Estimation ． . . . . . . . . . . . . . . . . . 13

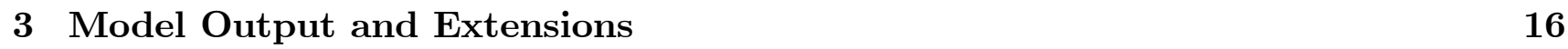

3.1 Transaction Costs . . . . . . . . . . . . . . . . . . . . . . . . . 16

3.2 Allocative Inefficiency $\ldots \ldots \ldots$. . . . . . . . . . . . . . . . . 18

3.3 Overreaction to Flood Events . . . . . . . . . . . . . . . . . . . . . . . . . . . . . 19

*Emails: laurabakkensen@arizona.edu and lint_barrage@ucsb.edu. 
3.4 Ex-Post Rationalization vs. Ex-Ante Belief Heterogeneity . . . . . . . . . . . . . . 21

\begin{tabular}{|rr}
\hline 4 Hedonic Estimation & 23
\end{tabular}

\section{$1 \quad$ Survey External Comparisons}

\subsection{Home Market Values vs. Zillow}

As a first external quality check on our survey responses, we examine survey question (12.3) that asks respondents: "How much do you think your home would sell for on today's market?" We compare respondents' answers with Zillow home value "Zestimates" from the month of the survey. Figure A1 presents a scatterplot comparing stated home value beliefs against Zillow Zestimates, as well as the 45 degree line. While a number of homeowners seem to place a higher value on their homes than Zillow, there is generally good agreement between the two figures, with a correlation of 0.89 .

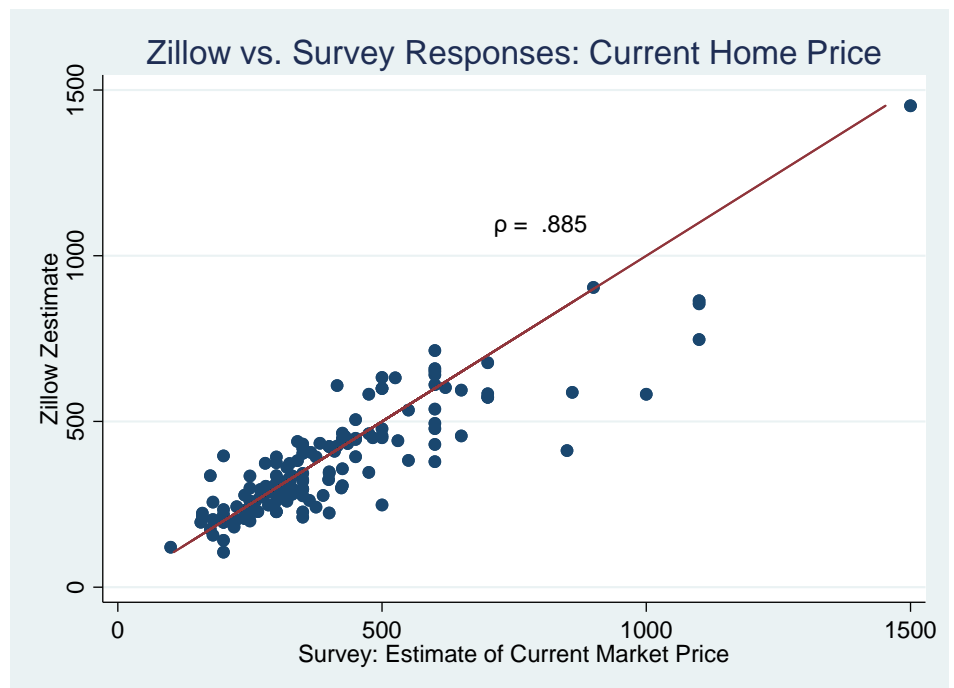

Figure A1

\subsection{Home Purchase Year}

Another survey question that can be externally verified is home purchase year. To this end we work to infer purchase dates from publicly available tax assessor records. One complication is that these records include non-arms length sale deeds which are often listed or made at a price of $\$ 0$, such as quit claim deeds that transfer property into a trust or transfer interest among 
family members (e.g., after the passing of one of the owners). While some towns provide the history of ownership names associated with all past deeds and thus enable us to differentiate deeds within families and identify the genuine purchase date of a home, they mostly do not. We thus chiefly restrict this comparison to homes where the most recent deed on record is clearly as sale to new owners at a positive price $L^{1}$ Figure A2 displays the relationship between survey stated and tax assessor-inferred home purchase dates, along with the 45 degree line. With one exception, respondents generally answer this question accurately. The correlation between stated and official purchase year excluding the outlier is 0.996 . The one outlier appears to most likely have been a misunderstanding as the respondent's other answers appear sensible. Importantly, we note that this home is located inside the high risk flood zone and that the respondent stated high flood risk worry (8/10) and a high perceived flood risk probability. Consequently, excluding this observation from our final sample on account of data quality concerns would only strengthen our finding that flood zone inhabitants exhibit lower flood risk worry.

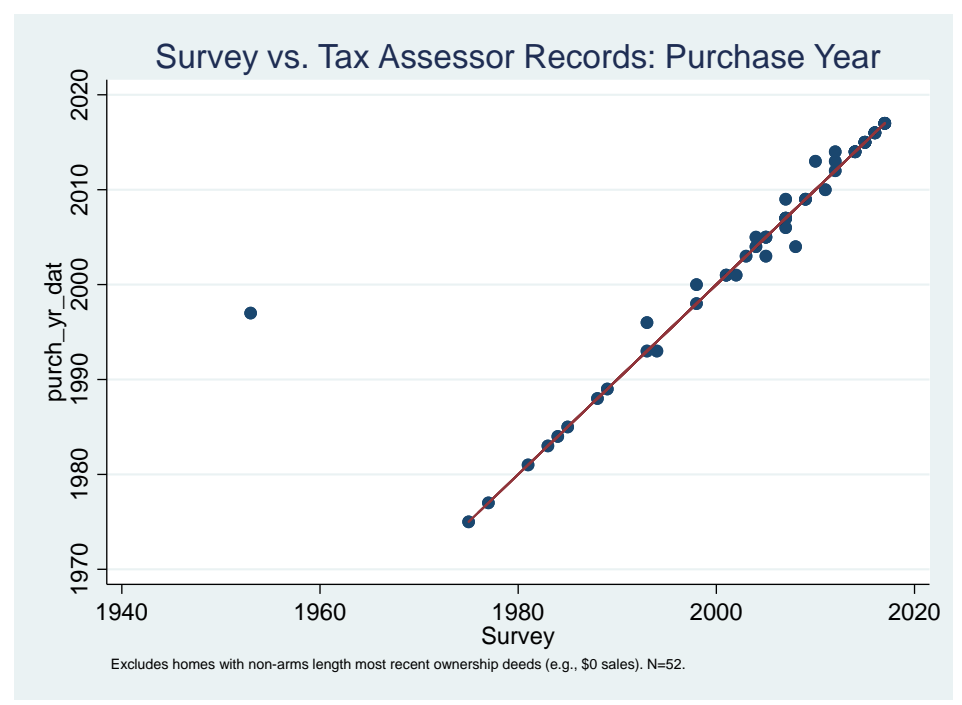

Figure A2

\subsection{Respondent Demographics}

Table A1 compares key demographic variables in our sample of survey respondents (re-weighted to account for oversampling of coastal homes) against averages of the relevant population values across Bristol, Kent, and Newport Counties in Rhode Island. Data were obtained from the American Community Survey (2015-19, U.S. Census) and from the Consumer Financial Protection

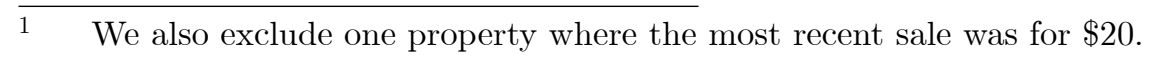


Bureau via the Home Mortgage Disclosure Act (2001-17). Our respondents compare reasonably well to population measures, but skew somewhat older and more educated. One notable difference is that our survey focused on single-family homes, whereas population data include multi-family units as well, suggesting that some differences should be expected. Importantly for our purposes, however, we fail to detect a significant association between these demographic measures and sorting into flood zones.

Table A1: Respondent Demographics

\begin{tabular}{|l|l|l|}
\hline \hline \multicolumn{1}{l}{ Variable } & \multicolumn{1}{l}{ Survey } & \multicolumn{1}{l}{ Cross-County Average } \\
\hline Household Income (Avg.) & $\$ 113 \mathrm{k}$ & $\$ 107 \mathrm{k}$ \\
Age (Median) & 51 & 45 \\
Non-White (\%) & $13.8 \%$ & $8.2 \%$ \\
Hispanic (\%) & $2.8 \%$ & $4.6 \%$ \\
Education: College+ & $66 \%$ & $54 \%$ \\
Number of bedrooms (Avg.) & 2.8 & 2.6 \\
Household Size (Avg.) & 2.98 & 2.32 \\
Non-primary residence (\%) & 11.45 & 11.88 \\
\hline
\end{tabular}

\subsection{Flood Survey - Yale Data Mapping}

Table A2 presents the results from a regression of our county-level optimist share measures in Rhode Island on the county-level estimated population share that "are not very/not at all worried about global warming" from the Yale Program on Climate Change Communications (YPCCC, Howe et al., 2015). 
Table A2: Survey Extrapolation

$\%$ Not worried $3.191^{* *}$

Constant $-0.801^{* *}$

Observations

3

Adj. $R^{2}$

0.999

Reports results of linear regression of our survey-based

estimate of the shares of flood risk optimists in each of Kent,

Newport, and Bristol Counties, on the Yale survey-based

estimate of the fraction not worried about global warming.

Standard errors in parentheses. $\left(* * * \mathrm{p}<0.01,{ }^{*} \mathrm{p}<0.05, * \mathrm{p}<0.1\right)$.

\section{Further Survey Results}

\subsection{Sea Wall Expectations}

One may be concerned that low flood risk worry among flood zone residents is driven by a belief in future public protective infrastructure investments. Our survey followed up the question eliciting future flood risk change expectations with the question "Why do you think flood risk will change this way?" Only four respondents mention sea walls or construction as a reason why they expect flood risk to decrease in the future. Our results are not driven by these four respondents; we can easily exclude them and find the same main results, such as that average flood risk worry is significantly lower among flood zone residents, as shown in Table A3 below. One possible caveat is that we did not ask the follow-up question of households who stated that they believe flood risk will remain unchanged in the future. As an additional robustness check, we thus also exclude all respondents who expect future flood risk to remain unchanged from the sample, and again find the same main result of differential flood risk worry across the flood zone, further adding evidence that this result is not driven by heterogeneous future mitigation beliefs. 
Table A3: Sea Wall Expectations and Heterogeneous Flood Worry

\begin{tabular}{|c|c|c|c|c|}
\hline Sample & Variable & $\begin{array}{l}\text { Non-Flood } \\
\text { Zone }\end{array}$ & $\begin{array}{l}\text { Flood } \\
\text { Zone }\end{array}$ & $\begin{array}{l}\text { Difference } \\
(\mathrm{SE})\end{array}$ \\
\hline Full $(\mathrm{n}=185)$ & Flood Worry Index (1-10) & 5.62 & 3.61 & $\begin{array}{l}2.00^{* * *} \\
(0.46)\end{array}$ \\
\hline $\begin{array}{l}\text { Exclude respondents expecting } \\
\text { sea walls to be built }(n=181)\end{array}$ & Flood Worry Index (1-10) & 5.64 & 3.63 & $\begin{array}{l}2.01^{* * *} \\
(0.47)\end{array}$ \\
\hline $\begin{array}{l}\text { Exclude respondents expecting } \\
\text { future flood risk to remain unchanged } \\
\text { and those expecting sea walls }(n=142)\end{array}$ & Flood Worry Index (1-10) & 5.73 & 3.97 & $\begin{array}{l}1.76^{* * *} \\
(0.54)\end{array}$ \\
\hline
\end{tabular}

$* *(* * *) \sim$ significant difference for two-sided t-test at $5 \%(1 \%)$ level.

\section{$2.2 \quad$ Flood Risk Mitigation}

Table A4 reports results from the survey's question about private flood risk mitigation ("Have you taken any precautionary steps to reduce your risk of flooding? [E.g.: install water pump, elevate water heater, etc.] If yes, what steps have you taken?"). This question was only included in the second survey wave and only asked of coastal residents, limiting the sample size. The results, shown in Table A4, are nonetheless reassuring. First, "optimists" list the same number of mitigation measures on average (1.18) as "realists" (1.20). Second and similarly, respondents indicating the lowest level of worry about flooding (1 or 2 out of 10) actually list slightly fewer mitigation measures (1.04) on average compared to other coastal residents (1.35). Of course a simple count of mitigation measures ignores the fact that some efforts (e.g., sea wall) provide much greater protection than others (e.g., sand bags). Third, we thus compare flood worry levels between those who report having a sea wall, stilts, and/or have undertaken general elevation. ${ }^{2}$ Here we find that respondents listing these significant protection efforts appear, if anything, more worried on average (although not significantly so), consistent with the notion that worry drives risk reducing behaviors. In sum, we thus fail to detect evidence that low levels of worry and flood risk optimism are driven by higher levels of private mitigation.

2 Homes that have been elevated sufficiently so as to reduce their annual flood risk below $1 \%$ per year can be individually removed from FEMA's high risk flood zone map and designation through a so-called "Letter of Map Revision." Our analysis would then not count those homes as being in the high risk flood zone. 
Table A4: Flood Risk Mitigation Measures

\begin{tabular}{llllll}
\hline \hline & & & & & \\
\hline \hline Count & 1.19 & Std. Dev. & Min & Max & N. \\
& & 1.14 & 0 & 4 & 47 \\
Mean & Optimists & Realists & Diff. & & \\
Count: & 1.18 & 1.20 & 0.02 & & \\
& & & $(0.35)$ & \\
& Not Worried & Worried & Diff. & \\
Mean & $($ Worry $\leq 2)$ & $($ Worry $>2)$ & & & \\
Count: & 1.04 & 1.35 & 0.31 & & \\
& & & $(0.33)$ & \\
Mean & Wall or Elevate & No Wall & & \\
Worry: & 4 & 3.33 & -0.67 & \\
& & & $(0.93)$ & \\
\hline
\end{tabular}

\subsection{Secondary Homeownership}

We construct a measure of second homeownership based on property tax records. In particular, property information generally includes the name and mailing address of the owners, which may differ from the property's physical address if it is a secondary home. Based on this measure we find that only around $15 \%$ of homes in our sample are secondary. Adjusting for coastal oversampling, this implies a population estimate of $11.45 \%$ secondary homes. We note that this figure matches external data very well. For example, Home Mortgage Disclosure Act loan origination data for the purchase of homes in the three counties in our study area (Bristol, Kent, Newport) for 2007-2017 indicate that $11.88 \%$ are non-owner-occupied primary residences ${ }^{3}$

In order to gauge the potential influence of those observations, we re-compute the relevant survey results excluding all observations from secondary homes. Reassuringly, we find virtually identical results. Figure A3 presents the analog of Figure 1 in the paper with second homes excluded. The mean worry levels are correspondingly unchanged: Inside the flood zone, 5.62 with and 5.60 without secondary homes; outside the flood zone, 3.65 with and 3.70 without secondary homes, respectively $\bigsqcup^{4}$ These results strongly indicate that secondary homeownership is not driving the results.

3 The data were obtained from URL [www.consumerfinance.gov/] (accessed June 2020).

4 The means are similar even among the second home owners: mean flood concern is 5.8 outside and 3.34 inside the flood zone, respectively. 


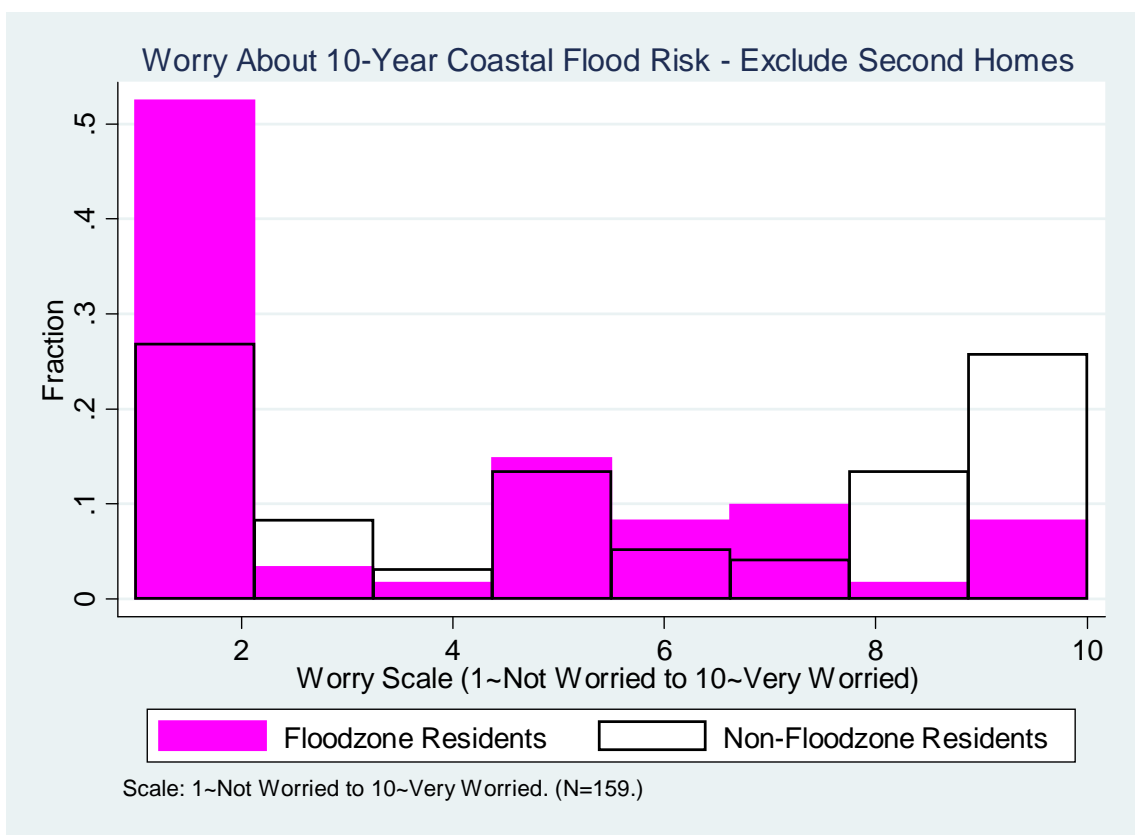

Figure A3

\subsection{Perceived vs. Inundation Model Flood Risk}

First, Table A5 presents results from a linear regression of coastal survey respondents' perceived 10-year flood risk on inundation model-based estimates of 10-year flood risk to their homes. Since the survey elicits flood risk perceptions in ranges (e.g,. 0.2-0.5\%), Column 1 uses the midpoint as perceived flood measure (e.g., 0.35\%), Column 2 uses the low point (e.g., $0.2 \%$ ), and Column 3 uses the high point (e.g., $0.5 \%$ ). All specifications indicate that perceived flood risk is a highly significant predictor of actual flood risk. 


\begin{tabular}{lccc}
\hline Table A5: Actual vs. Perceived Coastal Flood Risk \\
\hline \hline
\end{tabular}

Second, Table A6 compares the means of perceived versus inundation model-based flood risk estimates. Regardless of the measure used, we see that perceived flood risk is significantly lower than inundation models suggest.

\begin{tabular}{llll}
\multicolumn{2}{l}{ Table A6: Mean Actual vs. Perceived Coastal Flood Risk } \\
\hline \hline
\end{tabular}

Table reports results from two-sided t-test of mean difference between coastal residents' perceived and inundation-model based flood risk estimates.

Rows differ by whether they use the mid-point, minimum ("low"), or maximum ("high") of respondents' subjective risk ranges. $\mathrm{N}=93$. 


\subsection{Optimist vs. Realist Demographics}

This section provides a further information on optimists versus realists from our survey as per the benchmark definition. This comparison is motivated in part by concerns that optimists may rationally be choosing to hold inaccurate beliefs as may occur under behavioral models such as Brunnermeier and Parker (2005). Older agents and those without children and a bequest motive may face lower costs from adopting an excessively optimistic view of flood risks. First, Table A7 compares the groups' means across (i) flood damage expectations, and (ii) demographics. Importantly, we fail to detect evidence that flood risk optimists are also more optimistic about flood damages or insurance reimbursements. To the contrary, optimists hold significantly lower expectations of government assistance in case of a flood event. If flood risk optimists were rationally choosing to be optimistic, this choice should presumably carry over. Demographically, the groups appear similar as well, except that optimists are slightly older on average than realists. In order to delve further into this difference, Figure A4 below presents the distribution of ages across optimists and realists. The distribution of optimists is generally shifted to the right, but, importantly, the main difference between the groups is a higher share of agents in their early 50s versus early 40s, and not by a disproportionate share of senior citizens. We also fail to detect evidence that optimists have smaller households which could have signaled fewer children and lack of a bequest motive. 
Table A7: Demographics of Optimists vs. Realists

\begin{tabular}{|c|c|c|c|}
\hline \multicolumn{4}{|c|}{ Mean Differences } \\
\hline Variable: & Optimists & Realists & Difference (SE) \\
\hline $\begin{array}{l}\text { Flood Damage Expectations } \\
\text { (percent of home value) }\end{array}$ & 0.36 & 0.39 & $\begin{array}{l}0.03 \\
(0.06)\end{array}$ \\
\hline $\begin{array}{l}\text { Government Assistance Expectations } \\
\text { (percent of damages) }\end{array}$ & 6.98 & 16.92 & $\begin{array}{l}9.94^{* *} \\
(3.55)\end{array}$ \\
\hline $\begin{array}{l}\text { Insurance Expectations } \\
\text { (percent of damages) }\end{array}$ & 59.9 & 56.5 & $\begin{array}{l}-3.4 \\
(5.2)\end{array}$ \\
\hline
\end{tabular}

Demographics:

\begin{tabular}{|c|c|c|c|}
\hline Race (Mixed or Non-White) & 0.20 & 0.11 & $\begin{array}{c}-0.09 * \\
(0.05)\end{array}$ \\
\hline Household Size & 2.99 & 2.84 & $\begin{array}{l}-0.14 \\
(0.21)\end{array}$ \\
\hline Education & 7.04 & 6.93 & $\begin{array}{l}-0.12 \\
(0.31)\end{array}$ \\
\hline Male & 0.56 & 0.58 & $\begin{array}{l}0.02 \\
(0.07)\end{array}$ \\
\hline Age & 54.92 & 51.14 & $\begin{array}{l}-3.77^{*} \\
(2.22)\end{array}$ \\
\hline Income & 130.83 & 119.56 & $\begin{array}{r}-11.27 \\
(9.48)\end{array}$ \\
\hline Political Spectrum $(0=\mathrm{D}, 1=\mathrm{I}, 2=\mathrm{R})$ & 0.76 & 0.74 & $\begin{array}{l}-0.02 \\
(0.11)\end{array}$ \\
\hline
\end{tabular}

Home Characteristics:

\begin{tabular}{|l|l|l|l|}
\hline Year Built & 1955.9 & 1953.7 & $\begin{array}{l}-2.17 \\
(4.37)\end{array}$ \\
\hline Number of Rooms & 6.19 & 6.06 & $\begin{array}{l}-0.13 \\
(0.23)\end{array}$ \\
\hline Property Area (sqft) & 10,049 & 9,517 & $\begin{array}{l}-532.7 \\
(972.3)\end{array}$ \\
\hline
\end{tabular}

$* *(* * *) \sim$ significant difference for two-sided t-test at $5 \%(1 \%)$ level. 


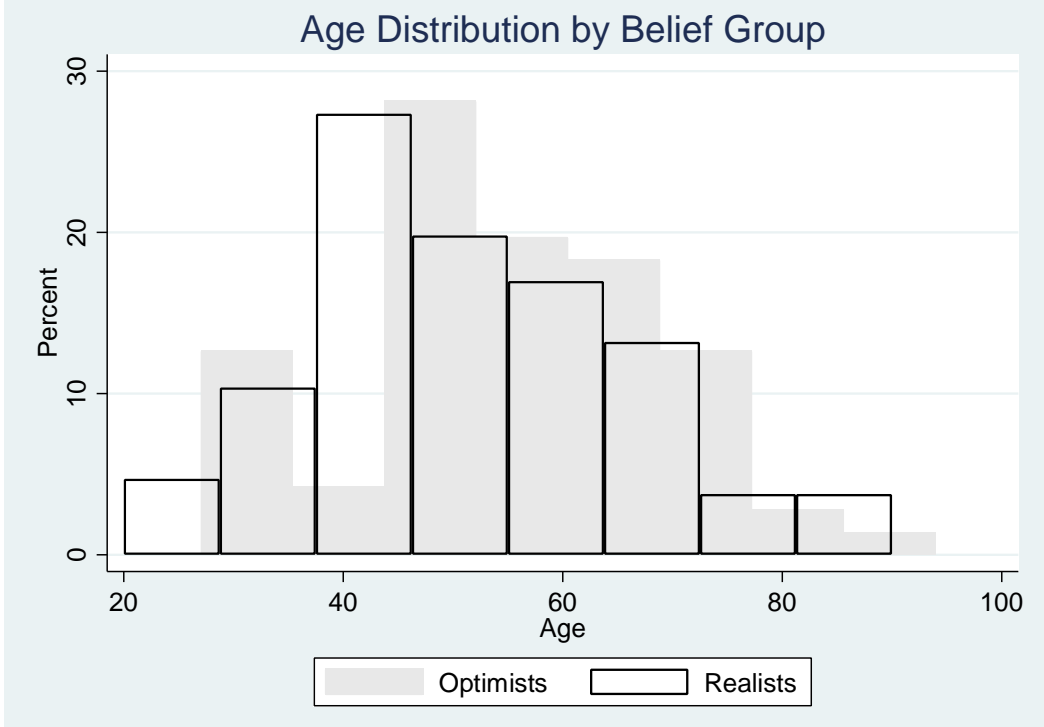

Figure A4

\subsection{Flood Experience and Beliefs}

Figure A5 showcases the distribution of flood risk worry across agents that have (solid purple) and have not (white) experienced a flood at their homes in the past.

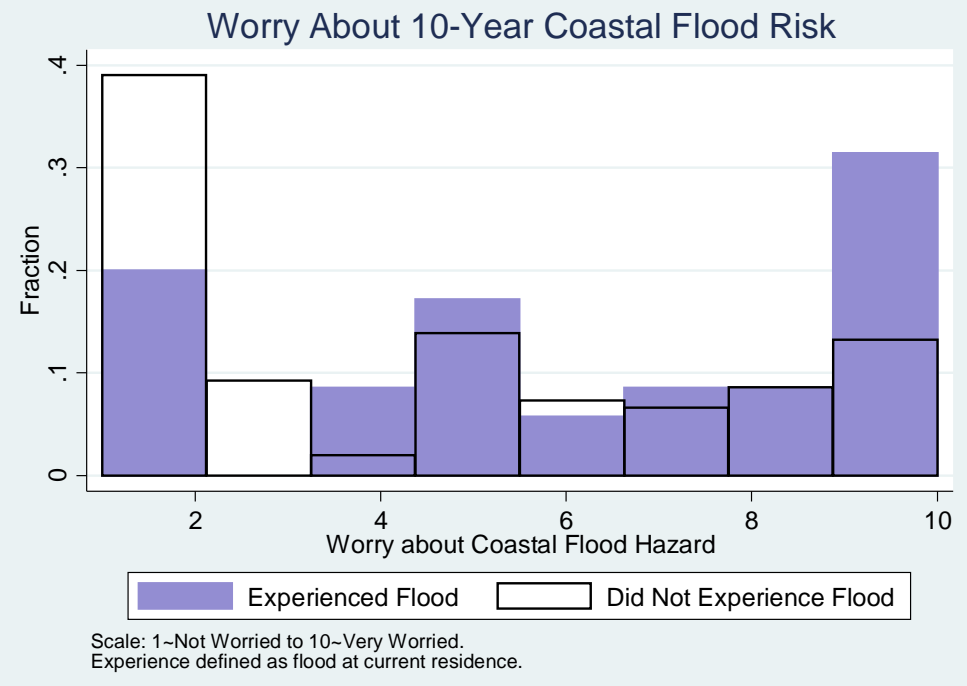

Figure A5 


\subsection{Double-Bounded Dichotomous Choice Estimation}

Motivation: Based on our theoretical model, the coastal amenity value is a key factor motivating individuals to select a coastal versus non-coastal home. Thus, we require an empirically-grounded estimate of coastal amenity value to calibrate our model. Environmental values, such as the coastal amenity values, can be estimated by various methods (see e.g., Haab and McConnell, 2002). One common approach is to use a revealed preference hedonic model to estimate such a value, yet strong correlation between coastal amenities and flood risk has been a long-standing challenge for the hedonic literature (Bin et al., 2008). In addition, our model results highlight that the hedonic approach confounds amenity values, sorting, and future coastal home price expectations, and provide information only on the marginal buyers. For the purposes of our model, we need an unbiased estimate of the coastal amenity value for individuals living on the coast and those who chose to not live on the coast. Thus, while we do estimate the coastal amenity value using a hedonic approach for robustness, we turn to stated preference contingent valuation methods to estimate this important model parameter.

Contingent valuation (CV) has been used for decades to estimate the value of key environmental goods and bads. As a signal of the technique's prominence and important, the National Oceanic and Atmospheric Administration organized Blue Ribbon Panel composed of top econo-

mists including Kenneth Arrow and Robert Solow to generate guidance and best practices for implementation and interpretation of the technique (Arrow et al., 1993). While the technique does have criticisms, especially with respect to estimates of non- or passive-use values such as existence value (Diamond and Hausman, 1994), the technique has been well documented as robust to estimate use values, especially when best practices are followed to minimize potential biases (e.g., respondent fatigue, hypothetical bias) (Kling at al., 2012). The original CV technique focused on a single dichotomous choice (yes/no) question that asks individuals about their willingness to pay (accept) for an increase in an environmental good (bad) at a randomly assigned bid price. Later work found that a double-bounded dichotomous choice, asking a first yes/no question, and then following up with a second yes/no question with bid dependent on the first answer, significantly increased the statistical efficiency of the technique (Hanemann et al., 1991).

Estimation: As motivated in the main text and guided by best practices recommendations in Contingent Valuation survey design and implementation (Arrow et al., 1993; Mitchell and Carson, 2013) we utilize double-bounded dichotomous choice (DBDC) estimation in order to estimate a plausibly unbiased value of the coastal amenity for both coastal and non-coastal residents. The DBDC question was asked early in the survey to avoid bias due to priming with flood risk information. We utilize two versions of our contingent valuation survey questions, one for current coastal residents and one for current non-coastal residents, to elicit a coastal amenity value for all survey respondents. For non-coastal residents, the following survey question 3.1 
asks them about their preferences to move to an identical home within 400 feet of the coast (information inside brackets is for survey interviewers):

"Imagine that you had the option to instantly move to another house in [current town] that was within 400 feet of the waterfront, but that was otherwise identical to your home: Same house, same school district, same environmental risks, etc. everything the same except being within 400 feet of the waterfront. Would you be willing to move to such a house if you had to pay $\$[$ Bid 1$] /$ month extra in housing costs? Would you be willing to pay: $\$[\operatorname{Bid} 2$ depending on yes or no to previous question]/month extra in housing costs?

[Note: If in question, clarify that this is holding flood risk constant.]"

For coastal residents, we asked the same question except for their preferences (i.e., if you could save $\$[$ BID 1$] /$ month in housing costs) for moving from their current coastal home to an identical home but 400 feet farther inland. After the first randomly assigned bid, $B_{i}$, if the respondent replied "yes", then a second question with a second bid $\left(B_{i}^{u}\right)$ that is higher than the first $\left(B_{i}^{u}>B_{i}\right)$ is then asked. If the respondent replied "no", then a second question with a second bid $\left(B_{i}^{d}\right)$ that is lower than the first bid $\left(B_{i}>B_{i}^{d}\right)$ is asked. Guided by the literature on efficient starting bid design (Kanninen, 1993; Alberini, 1995), the three starting bids of $\$ 150$, $\$ 250$, and $\$ 350$ were chosen based on a hedonic estimation of the annualized waterfront living premium using U.S. Census American Housing Survey data for 2013 performed by the authors.

Based on respondents' answers and DBDC theory (Hanemann et al. 1991), respondents can fall into one of four categories: those who answered yes to the first and second questions ("yy"), those who answered no to both questions ("nn"), those who answered yes to the first and no to the second ("yn") and those who answered no to the first but yes to the second ("ny"). The likelihoods of these outcomes are $\pi^{y y}, \pi^{n n}, \pi^{y n}$, and $\pi^{n y}$ respectively. Assuming that individuals are utility maximizing, Hanemann et al. (1991) show that the probabilities can be written as: $\pi^{y y}\left(B_{i}, B_{i}^{u}\right)=1-G\left(B_{i}^{u} ; \theta\right), \pi^{n n}\left(B_{i}, B_{i}^{d}\right)=G\left(B_{i}^{d} ; \theta\right), \pi^{y n}\left(B_{i}, B_{i}^{u}\right)=G\left(B_{i}^{u} ; \theta\right)-G\left(B_{i} ; \theta\right)$, $\pi^{n y}\left(B_{i}, B_{i}^{d}\right)=G\left(B_{i} ; \theta\right)-G\left(B_{i}^{d} ; \theta\right)$, where $G(B ; \theta)$ is the normal cumulative density function of the individual's true maximum willingness to pay and $\theta$ are coefficient parameters. From this, the log-likelihood function has the form: $\ln L^{D}(\theta)=\sum_{i=1}^{N}\left\{d_{i}^{y y} \ln \pi^{y y}\left(B_{i}, B_{i}^{u}\right)+d_{i}^{n n} \ln \pi^{n n}\left(B_{i}, B_{i}^{d}\right)+\right.$ $\left.d_{i}^{y n} \ln \pi^{y n}\left(B_{i}, B_{i}^{u}\right)+d_{i}^{n y} \ln \pi^{n y}\left(B_{i}, B_{i}^{d}\right)\right\}$, where Hanemann et al. (1991) define $d_{i}^{y y}, d_{i}^{n n}, d_{i}^{y n}$, and $d_{i}^{n y}$ as indicator variables equal to 1 if the respondents are of that response category and 0 otherwise.

The model is then estimated using maximum likelihood. In addition to the first and second bids, we include the following control variables in the willingness to pay model: the natural log of the estimated home market value, an indicator variable for a respondent being a coastal resident, 
income, age, number in household, education, race, property size, and number of rooms in the house. Table A8 presents the results of our estimation of coastal amenity values based on the double-bounded dichotomous choice mechanism implemented using the Stata doubleb routine by Lopez-Feldman (2010).

\begin{tabular}{|c|c|c|}
\hline \multicolumn{3}{|c|}{ Table A8: Coastal Amenity Willingness-to-Pay } \\
\hline \multicolumn{3}{|c|}{ DBDC Estimation on WTP for Coastal Amenity } \\
\hline & Beta & Sigma \\
\hline ln(Est. Home Market Value) & $\begin{array}{c}410.3^{* * *} \\
(150.5)\end{array}$ & \\
\hline Coastal & $\begin{array}{c}339.5^{* * *} \\
(96.34)\end{array}$ & \\
\hline Income & $\begin{array}{c}-0.000322 \\
(0.766)\end{array}$ & \\
\hline Age & $\begin{array}{l}-3.412 \\
(2.812)\end{array}$ & \\
\hline Number in Household & $\begin{array}{l}-27.72 \\
(29.79)\end{array}$ & \\
\hline Education Index (1-9) & $\begin{array}{c}20.90 \\
(19.89)\end{array}$ & \\
\hline Caucasian & $\begin{array}{l}207.4^{*} \\
(125.7)\end{array}$ & \\
\hline Property Square Footage & $\begin{array}{c}-0.0149 * * \\
(0.00726)\end{array}$ & \\
\hline House \# Rooms & $\begin{array}{c}24.50 \\
(30.95)\end{array}$ & \\
\hline Constant & $\begin{array}{c}-2,358^{* * *} \\
(857.9)\end{array}$ & $\begin{array}{c}277.4^{* * *} \\
(59.82)\end{array}$ \\
\hline Observations & 126 & 126 \\
\hline $\begin{array}{l}\text { Reports results of double-bou } \\
\text { estimation of WTP (non-coas } \\
\text { for living within } 400 \text { feet of th } \\
\text { from } \$ 150, \$ 250 \text {, and } \$ 350 \text {. F } \\
\text { Standard errors in parenthese }\end{array}$ & $\begin{array}{l}\text { ded dichot } \\
\text { al) or willir } \\
\text { e waterfron } \\
\text { llow-up bid } \\
\quad(* * * \mathrm{p}<0\end{array}$ & $\begin{array}{l}\text { oice } \\
\text { accept (coastal) } \\
\text { g bids randomized } \\
\text { tract } \$ 75 \text {. } \\
<0.05, * \mathrm{p}<0.1) .\end{array}$ \\
\hline
\end{tabular}




\section{$3 \quad$ Model Output and Extensions}

\subsection{Transaction Costs}

This section illustrates the potential effects of adding transaction costs in home purchasing to our framework. We show that, while transaction costs may affect price levels and transition dynamics in intuitive ways, importantly for our purposes, they do not affect the overvaluation arising from flood risk misperceptions. In order to generate clear analytic insights, we consider a simplified 3-period version of the model. Period 0 is the present, with initial flood risk level $\pi^{L}$. Period 1 is the medium-term future, where sea level rise will take place and flood risk increases to level $\pi^{H}$. We abstract from ex-ante uncertainty about sea level rise. Realists immediately adjust their beliefs, whereas optimists' are skeptical, so that $\pi_{1}^{o}<\pi_{1}^{r}=\pi^{H}$. Finally, Period 2 is the policy reform period where flood insurance at official rates $\pi_{2}^{*}$ becomes mandatory, and effective beliefs thus converge. Thereafter, the market is in a steady-state.

We take both initial price levels in coastal $P_{0}$ and non-coastal homes $P_{0}^{N C}$, and the initial distribution of agents across home types as given. Our illustration focuses on the empirically relevant case where both optimists and realists are initially in the coastal housing market. We are interested in the model's prediction for prices in Period 1, after flood risk increases and as beliefs diverge.

Consider first an initially non-coastal optimist homeowner. The benchmark model predicts that some measure of these agents would move into coastal housing in Period 1 and purchase homes from initially coastal realists. Assume now that buying a home involves transaction cost c. An initially non-coastal optimist would nonetheless want to move to the coast in Period 1 if:

$$
-c-P_{1}+\beta\left(\varepsilon^{h}+\xi^{i}-\pi_{1}^{o} \delta+E_{1}^{o}\left[P_{2}\right]\right) \geq-P_{1}^{N C}+\beta\left(\varepsilon^{h}+E_{1}^{o}\left[P_{2}^{N C}\right]\right.
$$

Condition (11) can be used to infer the threshold coastal amenity value for optimists who do move to the coast in Period $1: e^{h} \equiv \varepsilon^{h}-\left(\varepsilon^{r}-w\right)$

$$
\overline{\xi_{1}^{o}}=\left[c+\left(P_{1}-P_{1}^{N C}\right)+\beta \pi_{1}^{o} \delta+\beta\left(E_{1}^{o}\left[P_{2}^{N C}\right]-E_{1}^{o}\left[P_{2}\right]\right)\right] \frac{1}{\beta}
$$

We see that, ceteris paribus, higher transaction costs $c$ increase the equilibrium marginal buyer's amenity value. This is because higher transaction costs imply that only optimists with sufficiently high coastal amenity values will find it worthwhile to move to the coast. We next consider initially coastal realists who would potentially be interested in selling their homes in Period 1 and moving inland. Using analogous logic to the above, it is easy to show that the equilibrium 
coastal marginal realist in Period 1 will have threshold amenity value defined by:

$$
\beta \overline{\xi_{1}^{r}}=\left[-c+\left(P_{1}-P_{1}^{N C}\right)+\pi_{1}^{r} \delta+\beta\left(E_{1}^{r}\left[P_{2}^{N C}\right)-E_{1}^{r}\left[P_{2}\right]\right)\right] \frac{1}{\beta}
$$

Here we see that the marginal coastal realist's threshold is decreasing in $c$, ceteris paribus. Intuitively, higher transaction costs deter more realists from selling their coastal homes, thus depressing the marginal remaining agent's amenity value.

We next consider the coastal housing price in Period 1 by solving analytically for $P_{1}$. We first note that, analogous to the benchmark model at time $T-1$, agents' Period 1 expectations of coastal home prices after policy reform are given by:

$$
\begin{aligned}
& E_{1}^{r}\left[P_{2}\right]=-c+\frac{\beta\left(e^{h}+\Xi\left(1-k_{1}\right)\right)}{(1-\beta)}+\frac{\beta E_{1}^{r}\left[\pi_{2}^{*}\right] \delta}{(1-\beta)} \\
& E_{1}^{o}\left[P_{2}\right]=-c+\frac{\beta\left(e^{h}+\Xi\left(1-k_{1}\right)\right)}{(1-\beta)}+\frac{\beta E_{1}^{o}\left[\pi_{2}^{*}\right] \delta}{(1-\beta)}
\end{aligned}
$$

In the benchmark model, we further assumed that realists correctly anticipate actuarially fair policy reform $E_{1}^{r}\left[\pi_{2}^{*}\right]=\pi^{H}$, whereas, for optimists $E_{1}^{o}\left[\pi_{2}^{*}\right] \leq \pi^{H}$. The precise values and assumptions are not important for demonstrating the effects of transaction costs, however. Next, note that the non-coastal housing price is constant and pinned down by the rental market. That is, for agents who are initially renters to be indifferent between renting and buying a non-coastal home, it must be the case that:

$$
\beta\left(\varepsilon^{r}-w\right)=-c-P_{t}^{N C}+\beta\left(\varepsilon^{h}+E_{t}\left[P_{t+1}^{N C}\right]\right)
$$

Once again defining $e^{h} \equiv \varepsilon^{h}-\left(\varepsilon^{r}-w\right)$, we thus obtain the dynamic non-coastal home pricing condition $P_{t}^{N C}=-c+\beta\left(e^{h}+E_{t}\left[P_{t+1}^{N C}\right]\right)$ implying the steady-state value:

$$
P^{N C}=\frac{-c+\beta e^{h}}{1-\beta}
$$

The last condition we need to solve for prices is the housing market clearing condition for coastal homes:

$$
\frac{\theta^{o}}{\Xi}\left(\Xi-\bar{\xi}_{t}^{o}\right)+\frac{\left(1-\theta^{o}\right)}{\Xi}\left(\Xi-\bar{\xi}_{t}^{r}\right)=k_{1}
$$

Finally, combining (2)-(6) we can solve for coastal housing prices in terms of model primitives:

$P_{1}=\beta\left(\Xi\left(1-k_{1}\right)+e^{h}-\left[\left(1-\theta^{o}\right) \pi_{1}^{r}+\theta^{o} \pi_{1}^{o}\right] \delta-\beta\left[\left(1-\theta^{o}\right) E_{1}^{r}\left[\pi_{2}^{*}\right]+\theta^{o} E_{1}^{o}\left[\pi_{2}^{*}\right]\right] \delta-c+\frac{\beta\left(e^{h}+\Xi\left(1-k_{1}\right)\right)}{(1-\beta)}\right)$ 
Coastal housing prices are consequently a function of coastal and general housing amenity values, population-weighted average expectations of current and future flood risks, transaction costs, and long-run future home values. Importantly for our purposes, (7) demonstrates that coastal home prices will exceed fundamentals if the population share of optimists $\theta^{\circ}$ exceeds zero and if optimists under-estimate current and/or future flood risk. More formally, we can compare (7) to the fundamental coastal home value $P_{1}^{*}$ :

$$
P_{1}^{*}=\beta\left(\Xi\left(1-k_{1}\right)+e^{h}-\pi_{1}^{r} \delta-\beta E_{1}^{r}\left[\pi_{2}^{*}\right] \delta-c+\frac{\beta\left(e^{h}+\Xi\left(1-k_{1}\right)\right)}{(1-\beta)}\right)
$$

Finally, subtracting (8) from (7) showcases that the overvaluation due to flood risk misperceptions does not depend on transaction $\operatorname{costs} c$ :

$$
P_{1}-P_{1}^{*}=\theta^{o}\left[\left(\pi_{1}^{o}-\pi_{1}^{r}\right)+\beta\left(E_{1}^{o}\left[\pi_{2}^{*}\right]-E_{1}^{r}\left[\pi_{2}^{*}\right]\right)\right] \delta
$$

Equation (9) demonstrates that the overvaluation of coastal homes depends only on the population prevalence of optimists and the severity of their flood risk misperceptions.

\subsection{Allocative Inefficiency}

Figure A6 visualizes the allocative inefficiency that arises due to flood risk optimism in our benchmark setting. It specifically illustrates the evolution of the marginal coastal optimist's and

realist's respective amenity values $\left(\bar{\xi}_{t}^{o}\right.$ and $\left.\bar{\xi}_{t}^{r}\right)$ over time (right axis), as realists increasingly move out of coastal property markets (left axis). 


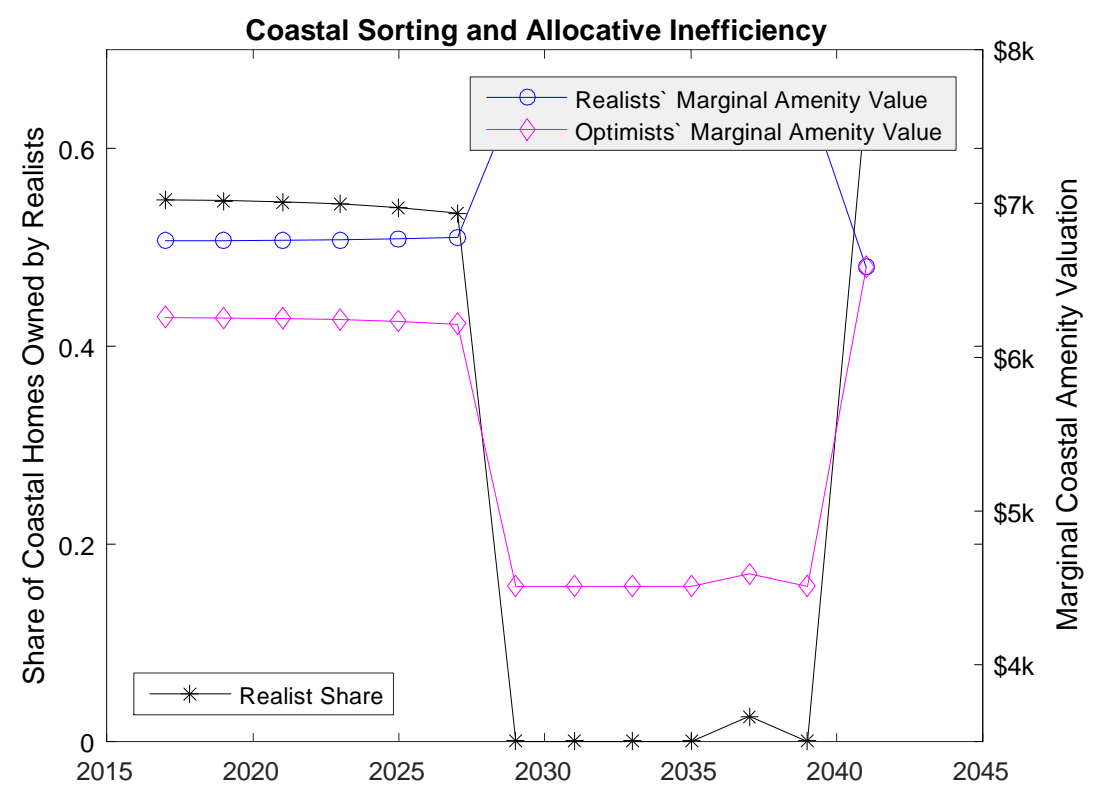

Figure A6

In line with the survey results indicating that misallocation is currently limited (paper Figure 5), the model projections imply that misallocation is initially low, that is, that marginal amenity values of optimists and realists differ only modestly at present. As the flood risk increases and beliefs diverge more, however, realists are projected to move out of coastal markets. This prediction is in line both with our survey finding that coastal residents who are more concerned about flooding are also significantly more likely to intend to sell their homes within the next five years, and with empirical evidence that transaction volumes of vulnerable homes increased after the release of worsening sea level rise projections (Bernstein et al., 2019). In our model, the departing realists are replaced by optimists with lower amenity values (pink line with diamonds). After the storm event assumed to occur in 2037 lowers coastal home prices and thus allows some realists - those with the very highest amenity values - to move back in. Only once the policy reform at time $T$ enforces the internalization of real risk rates do prices adjust so that all realists with appropriate amenity valuations return to coastal housing markets, restoring allocative efficiency.

\subsection{Overreaction to Flood Events}

While the benchmark model assumes rational Bayesian updating, the sensitivity analysis also considers a behavioral extension to agents overreacting to flood events or the lack thereof. We 
specifically incorporate an overreaction parameter $\gamma$ into agents' updating rules as follows (illustrated here for $\left.T_{1} \leq t<T\right)$ :

$$
\begin{aligned}
& \left.\widetilde{q}_{t+1}^{o}\right|_{\text {Flood }=1}=\operatorname{Pr}\left(\left.\pi^{H}\right|_{\text {Flood }=1}\right)=\frac{\left(\pi_{1} \cdot q_{t}^{o}\right) \cdot(1+\gamma)}{\pi_{1} q_{t}^{o}+\left(1-q_{t}^{o}\right) \pi^{L}} \\
& \left.\widetilde{q}_{t+1}^{o}\right|_{\text {Flood }=0}=\operatorname{Pr}\left(\left.\pi^{H}\right|_{\text {Flood }=0}\right)=\frac{\left(\left(1-\pi_{1}\right) \cdot q_{t}^{o}\right) \cdot(1-\gamma)}{\left(1-\pi_{1}\right) q_{t}^{o}+\left(1-q_{t}^{o}\right)\left(1-\pi^{L}\right)}
\end{aligned}
$$

Several empirical studies have found that home prices and flood insurance demand to revert to baseline within only 5-10 years after flood events (Bin and Landry, 2013; Gallagher, 2014). Setting $\gamma=.15$ allows our model to match this pace, as shown in Figure A7 below. The figure specifically showcases the evolution of optimists' beliefs in a hypothetical scenario without flood insurance policy reform and with only one flood event in period 2035 . With a $15 \%$ overreaction, the optimist's beliefs converge back to their pre-flood levels within ten years.

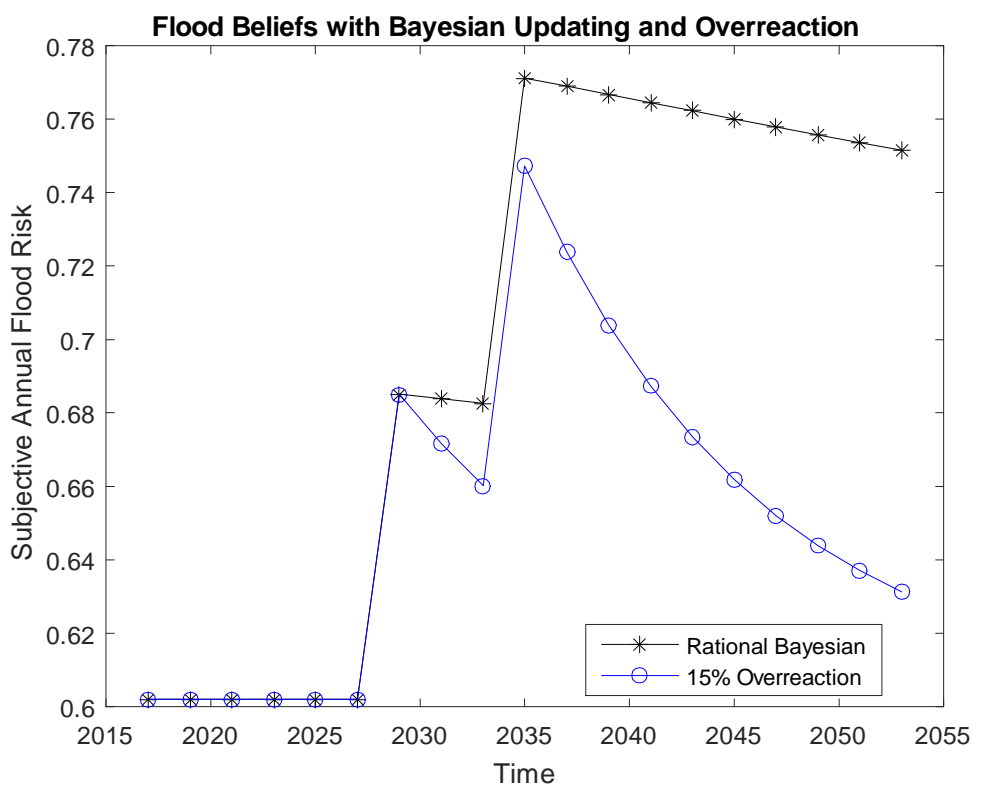

Figure A7

$5 \quad$ Gallagher (2014) formally compares the rational Bayesian model to a modification with a discounting parameter that weights older flood events less in agents' updating rules. Our model is not strictly comparable both as he focuses on a Beta-Bernoulli model and because we focus on learning in the context of changing flood risk and sea level rise. We therefore consider 10 as an analogous modified updating rule to match the empirical evidence. 


\subsection{Ex-Post Rationalization vs. Ex-Ante Belief Heterogeneity}

The main analysis assumes that households' flood risk perceptions evolve principally based on the realization of flood events, or the lack thereof. One potential concern with interpreting observed flood risk belief heterogeneity in this way is that coastal residents could also be changing their beliefs differentially after moving to the coast in order to rationalize their sorting choice ex-post. This section presents an illustrative extension of the model to showcase the potential effects of ex-post rationalization. For ease of illustration, assume that the world starts in a neutral state where nobody has yet purchased or rented a home, and all optimists $o$ initially have common flood risk belief $\pi_{0}^{o}$. The initial sorting in period 0 is thus the same as in the benchmark model.

We focus on the most interesting and empirically relevant case where both optimists and realists are initially in the coastal home market. In period 0, the market-clearing coastal home price $P_{0}$ equates both the marginal optimist's and realist's willingness to pay:

$$
P_{0}^{*}=\beta\left(e^{h}+\overline{\xi_{0}^{r}}-\pi^{r} \delta+E_{0}^{r}\left[P_{1}\right]\right)=\beta\left(e^{h}+\overline{\xi_{0}^{o}}-\pi_{0}^{o} \delta+E_{0}^{o}\left[P_{1}\right]\right)
$$

If no storm occurs in period 0, both coastal and non-coastal Bayesian learners update their flood risk beliefs downward. Importantly, however, coastal residents may further change their beliefs differentially in response to having moved to the coast (ex-post rationalization). Specifically, let $\pi_{1}^{o, C_{0,1}}$ denote the period 1 flood risk belief of optimists that lived on the coast from period 0 to $1\left(C_{0,1}\right)$, and $\pi_{1}^{o, N C_{0,1}}$ analogously for optimists who did not live on the coast $\left(N C_{0,1}\right)$. Beliefs evolve according to:

$$
\pi^{r}>\underbrace{\pi_{0}^{o}>\pi_{1}^{o, N C_{0,1}}}_{\begin{array}{c}
\text { Bayesian } \\
\text { Updating }
\end{array}} \underbrace{>\pi_{1}^{o, C_{0}, 1}}_{\text {Rationalization }}
$$

Beliefs (12) imply the following changes. First, the coastal home price valuation of optimists already living on the coast has increased more than other agents', indicating that they will retain the highest willingness to pay and remain in their coastal homes. Consequently, measure $\frac{\theta^{\circ}}{\Xi}\left(\Xi-\bar{\xi}_{0}^{o}\right)$ of coastal homes remains occupied by their initial optimist residents. Second, the period 0 marginal optimist's contemporaneous coastal home price valuation has increased, i.e.: $\left[\overline{\xi_{0}^{o}}-\pi_{1}^{o, N C_{0,1}} \delta\right]>\left[\overline{\xi_{0}^{o}}-\pi_{0}^{o} \delta\right]$. In contrast, the marginal realist's contemporaneous valuation remains unchanged $\left(\overline{\xi_{0}^{r}}-\pi^{r} \delta\right)$. While a full characterization of the period 1 equilibrium would require us to take a stance on the full evolution of all agent's future price expectations $E_{1}^{r}\left[P_{2}^{m_{2}}\right], E_{1}^{o, N C_{0,1}}\left[P_{2}^{m_{2}}\right]$, $E_{1}^{o, C_{0,1}}\left[P_{2}^{m_{2}}\right], E_{2}^{o, N C_{0,2}},\left[P_{3}^{m 3}\right], E_{2}^{o, N C_{0,1} ; C_{1,2}}\left[P_{3}^{m_{3}}\right], \ldots$ including the extent to which each type of agent is aware of ex-post rationalization effects, how it colors their beliefs about others' beliefs, etc., a plausible scenario - in line with the structure of the baseline model - is that optimists' future price expectations at time 1 increase at least weakly more than realists' future price expectations 
in response to their updated beliefs $(12): E_{1}^{o, C_{0,1}}\left[P_{2}^{m_{2}}\right] \geq E_{1}^{o, N C_{0,1}}\left[P_{2}^{m_{2}}\right] \geq E_{1}^{r}\left[P_{2}^{m_{2}}\right] \geq E_{0}^{r}\left[P_{1}^{m_{1}}\right]$. In that case, we would expect the period 1 equilibrium to unfold as follows: some measure of noncoastal optimists' valuations now exceed those of coastal resident realists, leading the former to buy coastal homes from the latter. Importantly, the marginal buyers are now the previously noncoastal optimists, whereas the marginal sellers are the realists ${ }^{6}$ The equilibrium coastal home price in period 1 is thus determined by the interaction between these groups. More formally:

$$
\begin{aligned}
P_{1}^{*} & =\underbrace{\beta\left(e^{h}+\overline{\xi_{1}^{r}}-\pi^{r} \delta+E_{1}^{r}\left[P_{2}\right]\right)}_{\text {Newly marginal coastal realists }}=\underbrace{\beta\left(e^{h}+\overline{\xi_{1}^{o}}-\pi_{1}^{o, N C_{0,1}} \delta+E_{1}^{o, N C_{0,1}}\left[P_{2}\right]\right)}_{\text {Marginal new coastal Bayesians }} \\
& <\underbrace{\beta\left(e^{h}+\overline{\xi_{0}^{o}}-\pi_{1}^{o, C_{0,1}} \delta+E_{1}^{o, C_{0,1}}\left[P_{2}\right]\right)}_{\text {Long-term coastal Bayesians }}
\end{aligned}
$$

With ex-post rationalization (or differential updating), the model thus predicts that long term coastal residents' valuations of their homes will exceed the market price of coastal homes being sold. However, as long as there are marginal buyers of coastal homes that hold inaccurate flood risk beliefs $\pi_{1}^{o, N C_{0,1}}$, the potential for mispricing remains robust.

Empirically, the key implication of $(13)$ is that optimistic beliefs should be calibrated based on a sample representing marginal buyers, which may not correspond to the full sample. That is, if (long-term) coastal residents are more optimistic about flood risks than the marginal Bayesians whose beliefs pin down prices, we might be concerned that combining survey responses from all residents leads to an overestimate of optimism compared to the relevant population. As noted in the main text, our survey results suggest that $30 \%$ of currently non-coastal residents are optimistic about coastal flood risks. We also find that new movers - defined as agents who moved from another town to their survey area within the past 3 years - exhibit a similar distribution including flood risk optimism, as shown in Figure A8. While the moving history questions were added to the survey late, thus limiting the sample size underlying Figure A 8 to $n=26$, the concept of out-of-town movers as having a 'fresh' distribution of flood risk beliefs is common in the literature (see, e.g., discussions in Gallagher, 2014).

$6 \quad$ In the aftermath of a storm, coastal optimists could become marginal sellers as well, depending on how they update their beliefs. 


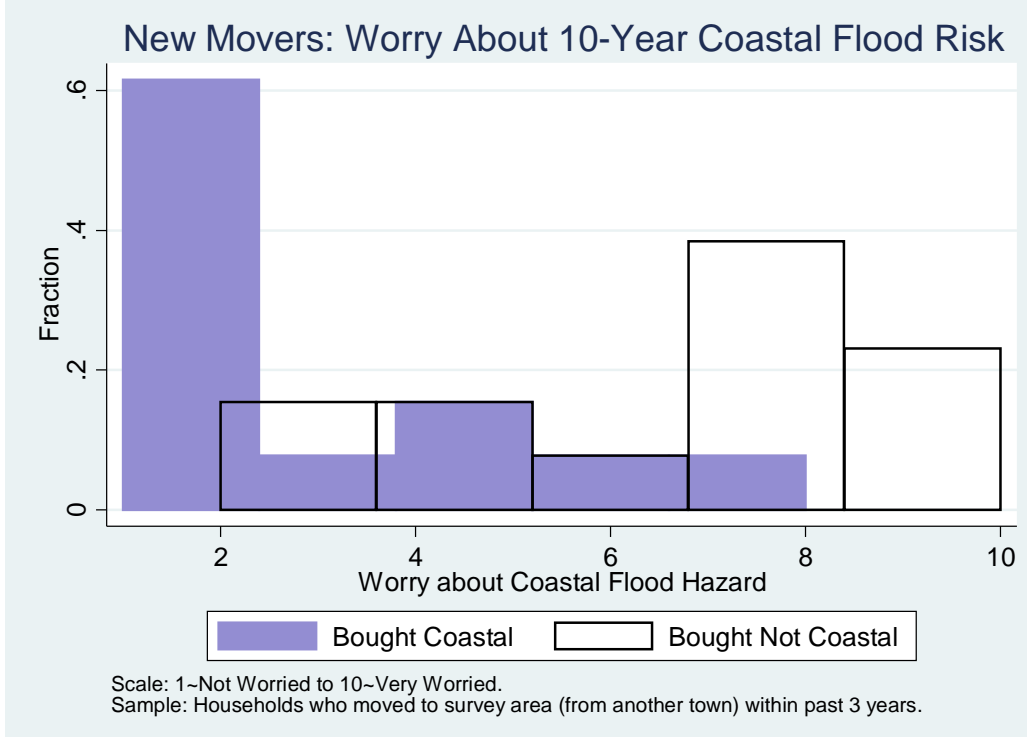

Figure A8

In sum, the potential marginal buyers for coastal properties thus appear likely to underestimate flood risks in our sample and empirical setting, regardless of whether beliefs of established coastal residents are additionally affected by ex-post rationalization.

\section{Hedonic Estimation}

This section describes our hedonic estimation of coastal amenity premiums and flood risk capitalization in our empirical setting. We scrape property data for the Rhode Island Bristol County towns of Barrington, Warren, and Bristol from Tax Assessor's records, including transactions histories and property characteristics from 2017. In addition, to allay concerns that potential homebuyers view Bristol County as a housing market, and therefore our control group of nonflood zone homes could be impacted through spillovers in housing market interactions, we also collect data for all of North Smithfield, Rhode Island, given that it has similar sociodemographic characteristics and proximity to Providence as Bristol Country. Our results are robust to excluding these data. Next, we locate buildings within a property using a GIS layer of all structures in Rhode Island originally compiled by the Rhode Island E-911 Uniform Emergency Telephone System and redistributed by the Rhode Island Geographic Information System (RIGIS, 2017). This layer geolocates all known structures in Rhode Island to the latitude and longitude of the center of the building. We obtain official flood map information from FEMA's Map Services Center and older flood maps from RIGIS. Finally, to map shorelines, we obtain the Rhode Island 
Continually Updated Shoreline Product from RIGIS (RIGIS, 2016). We add a 400 foot buffer to the shoreline in order to select coastal properties. In addition, we obtain the spatial extent of Superstorm Sandy surge inundation from STORMTOOLS (SAMP, 2017). We match individual property structures to their flood zone, coastal/non-coastal designation, and Sandy inundation status. We then match properties with Tax Assessor data including building structure information and the history of property transactions including sales price (which we inflation-adjust to 2015 SUSD using the BLS Consumer Price Index) and deed type. In order to control for potentially confounding flood policy events, we also categorize property sales as before or after: the Biggert-Waters Act Flood Insurance Reform Act passage (July 6, 2012), the Homeowner Flood Insurance Affordability Act (HFIAA) passage (March 21, 2014) and introduction (October 29, 2013).

We trim our transactions data to exclude the bottom and top $1 \%$ of annualized price changes between sales, and, for the recent analysis (2010-2016), observations for which the sales price is more than $50 \%$ below the 2017 tax assessor value, in order to remove non-arm's length deals. We also trim non-standard properties in terms of bedrooms (those with more than 10 bedrooms) and bathrooms so as to exclude apartment buildings, nursing homes, etc. We also drop observations where multiple deeds are recorded with different sales prices on the same date. Finally, we also consider a restriction to "Warranty" deed types, omitting deeds such as Quit Claims more likely to be associated with non-market sales.

We conduct two estimation exercises. The first focuses on recent post-crisis years (2010-2017) since several important variables are only available for the past decade or 2017 (e.g., property characteristics, tax assessor values, active flood maps, etc.). The second focuses on a longer time horizon (1970-2017) but has to use a fixed effects specification and is subject to more measurement error, as described below.

First, we estimate the following specification for 2010-2017:

$$
\ln P_{i t}=\beta_{0}+\gamma_{i} X_{i}+\delta c_{i}+\beta_{1} f_{i}+\beta_{2} B W_{i t}+\beta_{3} f_{i} * B W_{i t}+\alpha_{c}+\theta_{t} d_{Y t}+\varepsilon_{i t}
$$

As shown in Table A9, we regress the log of house sales price (2015 \$USD) on a vector of home characteristics $\left(X_{i}\right)$, an indicator for a coastal home (within 400 feet of the coastline; $c_{i}$ ), an indicator for being in a flood zone $\left(f_{i}\right)$, an indicator for a house sold after the passage of the Biggert-Waters Act (and before its partial repeal in 2014; $B W_{i t}$ ), the interaction between the flood zone and Biggert-Waters status $\left(f_{i} * B W_{i t}\right)$, as well as Census tract fixed effects $\left(\alpha_{c}\right)$ and year fixed effects $\left(d_{Y t}\right)$. Column (1) presents results including property sales between 2010 and 2017 that were not directly impacted by Sandy and whose flood designation did not change over the time period. Column (2) excludes the inland area of North Smithfield from the sample. 
Column (3) considers warranty deeds only. Finally, Column (5) restricts the sample to the time before the HFIAA was introduced. The results indicate a significant coastal housing premium of around $23 \%$. Given the median coastal home price in the data $(\$ 424 \mathrm{k})$, at a real interest rate of $4 \%$, this estimate corresponds to an annual coastal value of $\$ 3.9 \mathrm{k}$.

\section{Table A9: Hedonic Home Price Estimation}

\begin{tabular}{|c|c|c|c|c|}
\hline \multicolumn{5}{|c|}{ Dependent Variable: Log(Real Sales Price) $(\$ 2015)$} \\
\hline \multirow{3}{*}{ Land Area (Acres) } & (1) & $(2)$ & $(3)$ & (4) \\
\hline & $0.135^{* * *}$ & $0.224^{* * *}$ & $0.152^{* * *}$ & $0.0951^{* * *}$ \\
\hline & $(0.0425)$ & $(0.0598)$ & $(0.0340)$ & $(0.0313)$ \\
\hline \multirow[t]{2}{*}{ Age } & $-0.00407^{* * *}$ & $-0.00399^{* * *}$ & $-0.00323^{* * *}$ & $-0.00433^{* * *}$ \\
\hline & $(0.000786)$ & $(0.000879)$ & $(0.000647)$ & $(0.000907)$ \\
\hline \multirow[t]{2}{*}{$\mathrm{Age}^{2}$} & $1.48 \mathrm{e}-05^{* * *}$ & $1.63 \mathrm{e}-05^{* * *}$ & $1.21 \mathrm{e}-05^{* * *}$ & $1.55 \mathrm{e}-05^{* * *}$ \\
\hline & $(3.74 \mathrm{e}-06)$ & $(4.99 \mathrm{e}-06)$ & $(4.07 \mathrm{e}-06)$ & $(4.64 \mathrm{e}-06)$ \\
\hline \multirow[t]{2}{*}{ \#Bathrooms } & $0.219^{* * *}$ & $0.220^{* * *}$ & $0.235^{* * *}$ & $0.217^{* * *}$ \\
\hline & $(0.0234)$ & $(0.0244)$ & $(0.0195)$ & $(0.0275)$ \\
\hline \multirow[t]{2}{*}{ \#Bedrooms } & -0.000934 & $3.30 \mathrm{e}-05$ & 0.0129 & 0.00379 \\
\hline & $(0.0198)$ & $(0.0247)$ & $(0.0195)$ & $(0.0251)$ \\
\hline \multirow[t]{2}{*}{ Coastal (w/in 400 feet) } & $0.242^{* * *}$ & $0.229^{* * *}$ & $0.183^{* * *}$ & $0.264^{* * *}$ \\
\hline & $(0.0648)$ & $(0.0614)$ & $(0.0523)$ & $(0.0660)$ \\
\hline \multirow[t]{2}{*}{ FEMA Flood zone } & -0.0459 & -0.0403 & -0.0146 & -0.0583 \\
\hline & $(0.0719)$ & $(0.0746)$ & $(0.0756)$ & $(0.0898)$ \\
\hline \multirow[t]{2}{*}{ During Biggert-Waters Act } & 0.0777 & $0.0988^{*}$ & 0.0639 & $0.0671^{* *}$ \\
\hline & $(0.0487)$ & $(0.0530)$ & $(0.0472)$ & $(0.0309)$ \\
\hline \multirow[t]{2}{*}{ Flood zone*Biggert-Waters } & 0.00215 & -0.00535 & -0.0429 & -0.0287 \\
\hline & $(0.0707)$ & $(0.0726)$ & $(0.0622)$ & $(0.0611)$ \\
\hline \multirow[t]{2}{*}{ Constant } & $12.33^{* * *}$ & $12.34^{* * *}$ & $12.26^{* * *}$ & $12.24^{* * *}$ \\
\hline & $(0.119)$ & $(0.116)$ & $(0.0963)$ & $(0.118)$ \\
\hline Observations & 2,979 & 2,502 & 2,280 & 1,266 \\
\hline R-squared & 0.596 & 0.614 & 0.634 & 0.604 \\
\hline Adj.R-sq. & 0.592 & 0.610 & 0.629 & 0.596 \\
\hline
\end{tabular}

Reports results of OLS regression of $\log$ (Real Sales Price) on indicated variables plus Census tract- and year

fixed effects. Col. (2) excludes North Smithfield. Col. (3) restricts sample to "Warranty" claims. Col. (4)

excludes homes after HFIAA introduction.. Standard errors clustered at the census tract level and in parentheses.

The second use of the hedonic analysis is to provide direct empirical evidence on the capitalization of flood risks in our empirical setting, specifically over a longer time horizon (1970-2017). 
The homogeneous rational beliefs model would predict that the announcement of climate change should have lead to an immediate (absolute value) increase in the flood risk penalty, followed by a continual increase as sea level rise draws nearer. Bernstein, Gustafson, and Lewis (2019) fail to detect such a decline for owner-occupied housing in a nation-wide analysis for 2007-2016. While our data cover only our empirical setting (Bristol County, Rhode Island), they include a longer time horizon (1970-2017) featuring many historic climate news milestones. We analyze these data with a fixed effects specification (since we do not observe property characteristics in a panel) to utilize only price variation within properties over time to identify the treatment effects of interest.7 We also restrict the specification to "Warranty" deeds since we do not observe historical tax assessor valuations, and thus cannot control for non-arm's length sales based on a price-to-assessor-value criterion as above.

The second specification thus includes property fixed effects $\alpha_{i}$, year dummies $d_{Y t}$, and flood zone dummies $f_{i}$ interacted with five-year time period dummies $\delta_{i, \tau}$ :

$$
\ln P_{i t}=\beta_{0}+\alpha_{i}+\theta_{t} d_{Y t}+\sum_{\tau=1970-74}^{2010-14}+\beta_{3} f_{i} * \delta_{i, \tau}+\varepsilon_{i t}
$$

Figure A9 visualizes the estimated hedonic flood zone premium over time. Once again, we fail to detect the pattern predicted by the homogeneous rational beliefs model in our setting, which would indicate that the flood risk premium should become more negative over time as flood risk is increasing.

$\overline{7} \quad$ A remaining identification concern would be if flood zone properties are differentially likely to receive renovations than non-flood zone properties, which could bias our estimated flood zone coefficient trend downward (to be more negative over time). Since our central finding is the absence of such a downward trend, however, this potential source of bias is not a concern for spuriously driving our result. It should be noted that McCoy and Zhao (2018) find a positive effect of Hurricane Sandy on investment rates at damaged buildings inside but not outside the flood zone in New York City. Column (2) thus excludes all properties damaged by Hurricane Sandy to avoid this potential confounder in damage repairs. We also note that other time periods with large statewide flood events (e.g., 1980-85) we find differentially more negative flood risk premia, suggesting that differentially positive investment in flood zones is unlikely to be a significant confounder in our setting. 


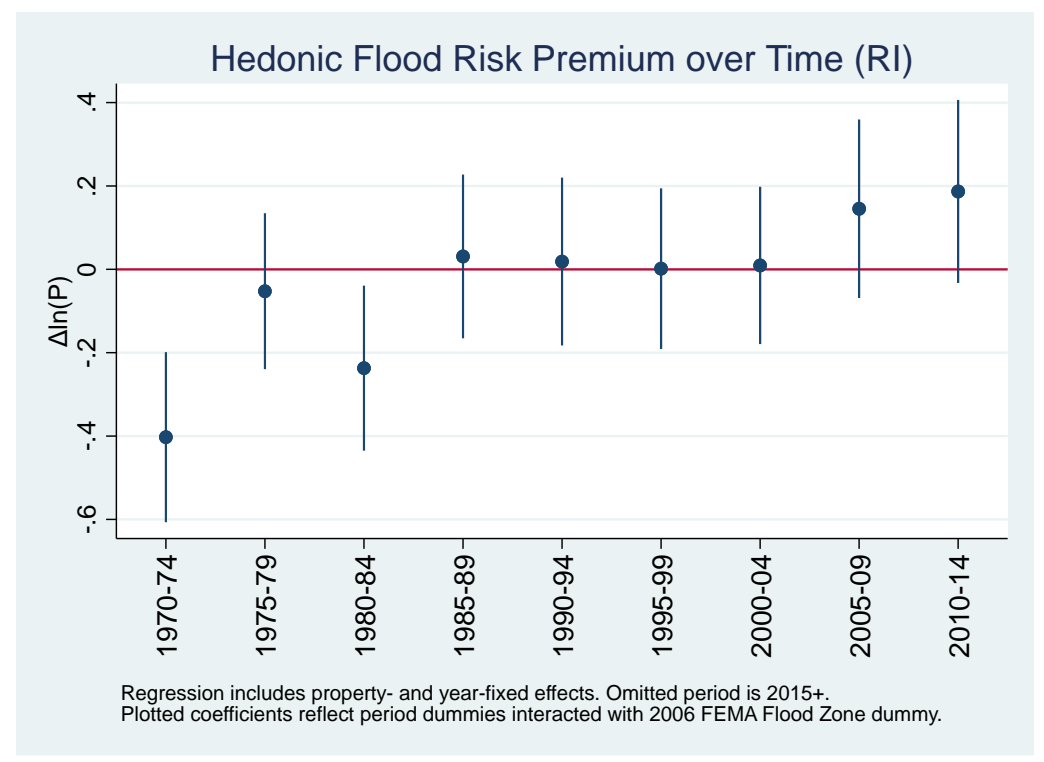

Figure A9

Finally, Table A10 shows the estimation results in full detail. Column (1) is the benchmark; Column (2) clusters standard errors at the property level; Column (3) excludes properties affected by Hurricane Sandy, and Column (4) clusters standard errors at the Census tract level to allow for arbitrary correlations of shocks within Census tracts. 


\section{Table A10: Historical Hedonic Home Price Estimation}

\begin{tabular}{|c|c|c|c|c|}
\hline \multicolumn{5}{|c|}{ Dependent Variable: Log(Real Sales Price) (\$2015) } \\
\hline \multirow{3}{*}{ Flood zone*1970-74 } & $(1)$ & $(2)$ & $(3)$ & $(4)$ \\
\hline & $-0.403^{* * *}$ & $-0.403^{*}$ & $-0.411^{* * *}$ & -0.411 \\
\hline & $(0.104)$ & $(0.218)$ & $(0.103)$ & $(0.379)$ \\
\hline \multirow[t]{2}{*}{ Flood zone*1975-79 } & -0.0525 & -0.0525 & -0.0610 & -0.0610 \\
\hline & $(0.0954)$ & $(0.129)$ & $(0.0945)$ & $(0.201)$ \\
\hline \multirow[t]{2}{*}{ Flood zone*1980-84 } & $-0.237 * *$ & -0.237 & $-0.245^{* *}$ & -0.245 \\
\hline & $(0.101)$ & $(0.168)$ & $(0.100)$ & $(0.141)$ \\
\hline \multirow[t]{2}{*}{ Flood zone*1985-89 } & 0.0310 & 0.0310 & 0.0228 & 0.0228 \\
\hline & $(0.100)$ & $(0.116)$ & $(0.0993)$ & $(0.0938)$ \\
\hline \multirow[t]{2}{*}{ Flood zone*1990-94 } & 0.0186 & 0.0186 & 0.0105 & 0.0105 \\
\hline & $(0.103)$ & $(0.139)$ & $(0.102)$ & $(0.126)$ \\
\hline \multirow[t]{2}{*}{ Flood zone*1995-99 } & 0.00166 & 0.00166 & -0.00546 & -0.00546 \\
\hline & $(0.0983)$ & $(0.0900)$ & $(0.0974)$ & $(0.0527)$ \\
\hline \multirow[t]{2}{*}{ Flood zone*2000-04 } & 0.00937 & 0.00937 & 0.00423 & 0.00423 \\
\hline & $(0.0962)$ & $(0.116)$ & $(0.0954)$ & $(0.109)$ \\
\hline \multirow[t]{2}{*}{ Flood zone*2005-09 } & 0.145 & 0.145 & 0.137 & 0.137 \\
\hline & $(0.109)$ & $(0.127)$ & $(0.108)$ & $(0.122)$ \\
\hline \multirow[t]{2}{*}{ Flood zone*2010-14 } & $0.187^{*}$ & 0.187 & 0.159 & 0.159 \\
\hline & $(0.112)$ & $(0.137)$ & $(0.111)$ & $(0.110)$ \\
\hline Observations & 7,032 & 7,032 & 6,720 & 6,718 \\
\hline R-squared & 0.862 & 0.862 & 0.862 & 0.861 \\
\hline Adj.R-sq. & 0.708 & 0.708 & 0.719 & 0.718 \\
\hline Property fixed effects? & $\checkmark$ & $\checkmark$ & $\checkmark$ & $\checkmark$ \\
\hline Year fixed effects? & $\checkmark$ & $\checkmark$ & $\checkmark$ & $\checkmark$ \\
\hline "Warranty" Deeds only & $\checkmark$ & $\checkmark$ & $\checkmark$ & $\checkmark$ \\
\hline S.E. Clustering & & Property & & Census tract \\
\hline \multicolumn{5}{|c|}{$\begin{array}{l}\text { Reports OLS regression of } \log (\text { Real Sales Price) on indicated variables } \\
\text { plus a constant for } 1970-2017 \text {. Omitted category is Flood zone*2015+. } \\
\text { Columns (3)-(4) omit buildings damaged by Hurricane Sandy. }\end{array}$} \\
\hline
\end{tabular}

\section{References}

[1] Alberini, Anna. "Optimal designs for discrete choice contingent valuation surveys: Singlebound, double-bound, and bivariate models." Journal of Environmental Economics and 
Management 28, no. 3 (1995): 287-306.

[2] Arrow, Kenneth, Robert Solow, Paul R. Portney, Edward E. Leamer, Roy Radner, and Howard Schuman. "Report of the NOAA panel on contingent valuation." Federal register 58, no. 10 (1993): 4601-4614.

[3] Bernstein, Asaf, Matthew T. Gustafson, and Ryan Lewis. "Disaster on the horizon: The price effect of sea level rise." Journal of Financial Economics 134, no. 2 (2019): 253-272.

[4] Bin, Okmyung, Thomas W. Crawford, Jamie B. Kruse, and Craig E. Landry. "Viewscapes and flood hazard: Coastal housing market response to amenities and risk." Land Economics 84, no. 3 (2008): 434-448.

[5] Bin, Okmyung, and Craig E. Landry. "Changes in implicit flood risk premiums: Empirical evidence from the housing market." Journal of Environmental Economics and Management 65, no. 3 (2013): 361-376.

[6] Brunnermeier, Markus K., and Jonathan A. Parker. "Optimal expectations." American Economic Review 95, no. 4 (2005): 1092-1118.

[7] Diamond, Peter A., and Jerry A. Hausman. "Contingent valuation: is some number better than no number?." Journal of Economic Perspectives 8, no. 4 (1994): 45-64.

[8] Gallagher, Justin. "Learning about an infrequent event: evidence from flood insurance takeup in the United States." American Economic Journal: Applied Economics (2014): 206-233.

[9] Haab, T.C. and McConnell, K.E., 2002. Valuing environmental and natural resources: the econometrics of non-market valuation. Edward Elgar Publishing.

[10] Hanemann, Michael, John Loomis, and Barbara Kanninen. "Statistical efficiency of doublebounded dichotomous choice contingent valuation." American Journal of Agricultural Economics 73, no. 4 (1991): 1255-1263.

[11] Howe, Peter D., Matto Mildenberger, Jennifer R. Marlon, and Anthony Leiserowitz. "Geographic variation in opinions on climate change at state and local scales in the USA." Nature Climate Change 5, no. 6 (2015): 596-603.

[12] Kanninen, Barbara J. "Optimal experimental design for double-bounded dichotomous choice contingent valuation." Land Economics (1993): 138-146. 
[13] Kling, Catherine L., Daniel J. Phaneuf, and Jinhua Zhao. "From Exxon to BP: Has some number become better than no number?." Journal of Economic Perspectives 26, no. 4 (2012): $3-26$.

[14] Lopez-Feldman, Alejandro. "DOUBLEB: Stata module to compute contingent valuation using double-bounded dichotomous choice," (2010). Statistical Software Components S457168, Boston College Department of Economics, revised 14 Oct 2013.

[15] McCoy, Shawn J., and Xiaoxi Zhao. "A city under water: A geospatial analysis of storm damage, changing risk perceptions, and investment in residential housing." Journal of the Association of Environmental and Resource Economists 5, no. 2 (2018): 301-330.

[16] Mitchell, Robert Cameron, and Richard T. Carson. Using surveys to value public goods: the contingent valuation method. Rff Press, (2013).

[17] RIGIS. "E-911 sites." (2017). Rhode Island Geographic Information System (RIGIS) Data Distribution System. Available online at: https ://www.rigis.org/datasets/e - 911 - sites.

[18] RIGIS. "Rhode Island Continually Updated Shoreline Product; RI_CUSP." (2016). Rhode Island Geographic Information System (RIGIS) Data Distribution System. Available online at: http : //www.rigis.org.

[19] SAMP. "Derived inundation surfaces - Scaled SLR." (2017). Available online at: http : //www.beachsamp.org/stormtools/. 